\title{
DE INFINITIVI FINALIS VEL CONSECUTIVI CONSTRUCTIONE APUD PRISCOS POETAS GRAECOS
}

\author{
DISSERTATIO INAUGURALIS \\ QUAM \\ ad Summos in Philosophia Honores \\ AB \\ Amplissimo Philosophordm Ordine \\ in Universitate Colombiae \\ RITE IMPETRANDOS
}

SCRIPSIT

CHARLES JONES OGDEN

111

NOVI EBORACI

MDCCCCIX 



\section{DE INFINITIVI FINALIS VEL CONSECUTIVI CONSTRUCTIONE APUD \\ PRISCOS POETAS GRAECOS}





\title{
DE INFINITIVI FINALIS VEL CONSECUTIVI CONSTRUCTIONE APUD PRISCOS POETAS GRAECOS
}

\author{
DISSERTATIO INAUGURALIS \\ QUAM \\ ad Stumos in Phrlosophia Honores \\ $A B$ \\ Amplissimo Philosophorum Ordine \\ in Universitate Columbiae \\ RITE IMPETRANDOS
}

SCRIPSIT

CHARLES JONES OGDEN

NOVI EBORACI

MDCCCCIX 
PRESS OF

THE NEW ERA PRINTING COMPANY LANCASTER, PA. 
This monograph has been approved by the Department of Greek in Columbia University as a contribution to knowledge worthy of publication.
E. D. PERRY
J. R. WHEELER
C. H. YOUNG 



\section{DE INFINITIVI FINALIS VEL CONSECU- TIVI CONSTRUCTIONE APUD PRISCOS POETAS GRÆCOS}

\section{PRAFATIO}

Vir doctus, ${ }^{1}$ cum de quæstionibus quibusdam grammaticæ Græcæ nuper disputaret, hæc dixit: 'The simple infinitive of so-called purpose, whatever it was with Homer, as in $\delta o{ }^{2}$ ă $\gamma \epsilon \iota$, is in classic prose not a purpose in the great majority of cases, but a permission, or commission, or something analogous. There

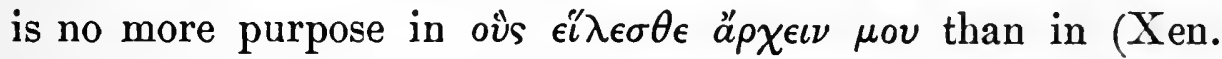

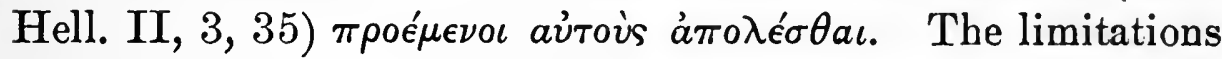
of this use of the infinitive I have never seen satisfactorily stated.'

Cum iam animadvertissem hanc infinitivi constructionem, quæ cum in aliis linguis recentioris ætatis est frequens, tum vero in Anglica frequentissima, rariorem esse in sermone Attico, non inutile fore putavi auctore Humphreysio quærere quomodo scriptores Græci antiquissimi eam usurpassent, ut eorum spectata consuetudine fundamenta essent ad ceteras litteras perscrutandas posita. Neque enim, quamquam multa de hac constructione apud singulos scriptores multi iam tractaverunt, quo sunt in numero Meyerus, ${ }^{2}$ La Rocheius, ${ }^{3}$ Meierheimius, ${ }^{4}$ Steinacherius, ${ }^{5}$

${ }^{1}$ Humphreys, M. W., The Problems of Greek, Congress of Arts and Science, St. Louis, 1904, Vol. III, pp. 171 sq.

${ }^{2}$ Meyer, L., Der Infinitiv der homerischen Spraclıe, Göttingen, 1856.

${ }^{3}$ La Roche, J., Der Infinitiv bei Homer, Homerische Untersuchungen, II, Leipzig, 1893, pp. 45-73.

${ }^{4}$ Meierheim, C., De infinitivo Homerico capita III, Specimen I, Gottingæ, 1875 .

${ }^{5}$ Steinacher, J., Die Syntax des Hesiodeischen Infinitivs, etc., Landskron, 1885. 
eorum quisquam quod sciam materiam satis uberem et collegit et idem ordine disposuit terminisque certis circumscripsit. Nam quæ exempla congesserunt Meyerus et La Rocheius pleraque sunt confusa neque ab aliis constructionibus bene distincta ; quæ autem Meierheimius luculenter tractavit ita ordinavit ut originem infinitivi potius exquireret quam usum definiret. Hac igitur dissertatione infinitivi qui finalis vél consecutivus appellatur constructionem tractabo qualis est primum in fontibus illis omnium litterarum Græcarum, Iliade et Odyssea, deinde in carminibus quæ ex iis conformationem verborum magna quidem ex parte hauserunt, Hesiodeis, Hymnis Homericis, fragmentis ceterorum epicorum priscorum. Quibus accedent elegiacorum fragmenta, quippe quæ redoleant sermonem epicum; neque ab his iambographi in editionibus nostris adiuncti separandi sunt.

Quæstio igitur in duas partes erit divisa, quarum una infinitivi constructio qualis est in Iliade Odysseaque ita tractabitur ut appareat quatenus sit usurpata in ea linguæ Græcæ forma qua nullam antiquiorem cognoscere nunc possumus ; altera vero, quæ multo minor et quasi in appendicis loco erit, consuetudo reliquorum scriptorum explicabitur et cum Homerica comparabitur. 


\section{PARS PRIOR: DE INFINITIVI CONSTRUCTIONE IN ILIADE ET ODYSSEA}

\section{Procemium}

Priusquam infinitivos finales vel consecutivos enumeremus, pauca de dispositione dicere necesse est. Primum enim fatendum est nos his vocibus 'finali' et 'consecutiva' abuti cum quæ de enuntiatis secundariis proprie dicantur, ea adhibeamus ad infinitivos definiendos, in quibus sæpe notiones et finis et consecutionis simul inhæreant adeo ut inter se distingui non possint. Quam ob rem si infinitivo vis modo finalis modo consecutiva videtur inesse, non idcirco licet nobis cum .Stahlio ${ }^{1}$ facientibus ea ratione partiri exempla. Nec multum prodest quærere quatenus vim principalem, quæ dativi casus propria videtur fuisse, ${ }^{2}$ infinitivus linguæ Homericæ servet; nam licet a dativo duxerit originem, constat tamen tum cum poesis epica floreret, dativos numeri singularis in litteras a desinentes iam obsolevisse eique casui detractam esse significationem fiualem; quare infinitivus iam videri dativo similis non poterat. Melius erit igitur, subtiliore quæstione omissa, exempla huius constructionis rationibus planis atque apertis disponere. Quarum forsitan ea optima videatur quam est secutus La Rocheius, ut exempla ad verba quibuscum infinitivi coniuncti essent ordinaret ; sed, cum sæpe verbum idem diversas adsciscat constructiones, minus perspicua sit divisio nec declaret quæ ratio sit infinitivi cum ceteris sententiæ partibus coniungendi. Aliam igitur, quæ est Meierheimii, insecutus sum, ut quæ vocabula enuntiati principalis sint artissime cum infinitivo coniuncta, ad ea potissimum in distribuendo spectem. Ille enim spectans ad

${ }^{1}$ Stahl, J. M., Kritisch-historische Syntax des griechischen Verbums, Heidelberg, 1907, pp. 606 sqq.

${ }^{2}$ Brugmann, Gr. Gramm., ed. 3, \& 570 . 
vocabulum quod est subiectum actionis per infinitivum significatæ sic distribuit exempla: ' $a$ ) in quibus subiectum infinitivi deesse et supplendum esse dicunt. b) Subiectum infinitivi dativus est. c) Accusativus cum infinitivo. d) Infinitivi et verbi finiti subiectum idem est." ${ }^{1}$

Sed ne hic ordo totus servetur varia monent. Primum enim aliud caput est faciendum, quo contineantur infinitivi quales

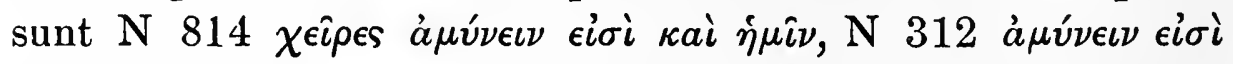
кai ä $\lambda \lambda o \iota$, qui, quamquam id quod fieri potest potius quam exitum vel consilium notant, ab hac constructione minime sunt abiudicandi. Cum autem eo maxime a ceteris infinitivis differant, quod illi cum enuntiatis sunt iuncti quæ motum vel actionem significant, hi cum iis quæ statum vel condicionem, genus hoc ad naturam enuntiati principalis constituere necesse est. Sed etiam in illo genere infinitivus non solum per vocabulum quod subiectum eius esse dicimus cum enuntiato principali potest esse coniunctus sed vero per obiectum suum, veluti

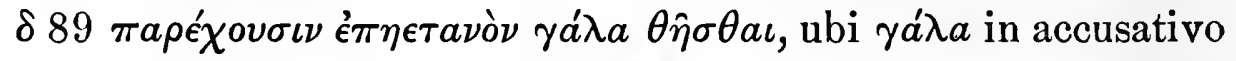
positum et ad verbum et ad infinitivum relatum est; ac multa alia exempla in quibus subiectum infinitivo deesse videtur facilius tractabuntur si obiecti rationem habebimus. Ergo exempla infinitivorum qui effectum actionis indicant sic in genera distribuemus :

In genere I, subiectum verbi principalis est subiectum infinitvi ;

" " II, obiectum verbi principalis est subiectum infinitivi ;

" " IIIa, obiectum verbi principalis est obiectum infinitivi ;

" " IIIb, alia ratio intercedit inter infinitivum et accusativum aut alium casum obliquum cum verbo principali coniunctum;

" " IV, infinitivus pendet ex enuntiato statum significante.

${ }^{1}$ Op. cit., pp. $28,35,43,59$. De hac re fusius disserit auctor pp. 24 sqq. 
Animadvertendum est nos has voces 'subiectum' et 'obiectum' usurpare potius ad naturam sententiæ quam ad conformationem verborum spectantes, ut subiectum verbi passivi fungi obiecti vice dicamus. Neque satis absolute dividi possunt exempla quin nonnulla in plura cadant genera; quæ, ne linguæ consuetudini ordinem arte grammatica confectum anteponamus, cum iis constructionibus proferemus quibus simillima erunt visa. Restant etiam quæ utrum ad constructionem finalem vel consecutivam an alio sint referenda ambigatur, velut infinitivi coniuncti cum verbis nitendi, properandi, vocandi. Quæ cum certa ratione definiri non possint, suo quodque loco breviter tractabuntur. Denique aliæ quædam constructiones infinitivis huiusmodi similem habentes significationem strictim sunt investigandæ; nam quantus sit usus constructionis cuiusque recte cognoscere nequeamus nisi ea exempla cum ceteris modis eandem rem dicendi comparemus. Sed cum in maxima linguæ Græcæ copia sæpe lateat causa cur alia alii præferatur constructio, non nisi frequentissimam quamque earum quæ possunt infinitivo comparari perstringam. 


\section{CAPUT I \\ SubIECTUM VERBI PRINCIPALIS EST SUBIECTUM INFINITIVI}

$\mathrm{Ab}$ exemplis ${ }^{1}$ ordiemur in quibus a verbo eundi pendet infinitivus, quod vim constructionis maxime declarent. Primum obtinet locum vox illa quæ constat e $\beta \hat{\eta}(\beta a ́ v, \beta \hat{\eta} \nu)$ verbo cum iévaı ( $\left.\iota^{\prime} \mu \epsilon \nu, \iota^{\prime} \mu \epsilon \nu a \iota\right)$ infinitivo coniuncto. Cuius exempla sunt in Iliade duo et triginta, in Odyssea unum et quadraginta : $\Delta 199$. 209. E 167. Z 296. @ 220. I 596. K 32. 73. 136. 179. 273. 297. 336. M 299. N 167. 208. 242. 789. 目 134.166. 188.

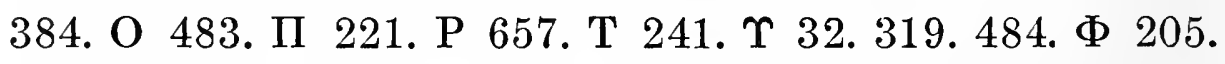
$\Omega$ 95. 347. a 441. $\beta$ 5. 10. 298. 394. $\delta$ 24. 310. 528. 679. 779. $\epsilon$ 475. $\zeta$ 15. 50. 130. $\theta$ 56. 109. 273. 277. 287. [303]. ${ }^{2}$ $\kappa$ 208. 407. $\mu$ 367. $\nu$ 160. $\xi$ 73. 532. o 109. $\pi$ 341.413. $\rho$ 365. 604. $\sigma$ 341. 428. $\tau$ 429. $v$ 146. $\phi$ 8. 58. $\chi 109.146 .179$. 400. His similia sunt: $\beta \hat{\eta}$ cum $\theta \epsilon \epsilon \epsilon \nu$ B 183. $\Lambda$ 617. 805. M

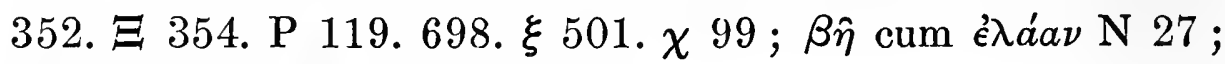

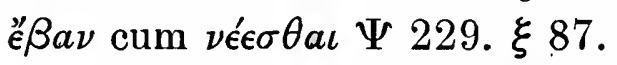

Hi loci, ab omnibus inter exempla infinitivi finalis relati, eo sunt singulares quod certis verbis vel, ut ita dicam, formulis concepti sunt. Namque tres primæ voces eam habent conformationem ut verbum in aoristo pasitum sequatur $\delta \dot{e}$ aut $\rho a$ particula, tum autem infinitivus temporis præsentis; atque omnes

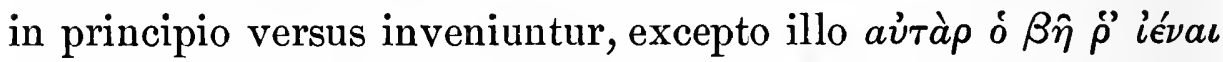
$\mathrm{K}$ 73. $\Upsilon$ 484. $\Phi 205$. Reliquæ vero vocis exempla, $є \beta a \nu$

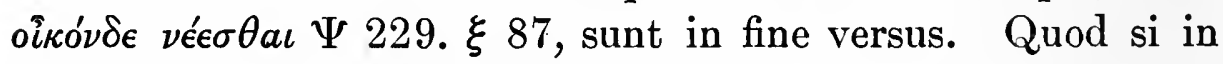
his solis vocibus infinitivus est cum $\beta a i v \omega$ verbo coniunctus,

${ }^{1}$ Ilias laudatur ex editione quam curaverunt Monro et Allen, Homeri Opera, I et II, Oxon., 1902; Odyssea ex editione Monrovii, Homeri Opera et Reliquiæ, Oxon., 1896.

${ }^{2} \mathrm{Om}$. codd. plerique. 
colligere licet hanc constructionem, tum cum oratio epica maxime vigeret, vi finali obscurata, a vetustate esse repetitam. ${ }^{1}$

Non ita sæpe infinitivus invenitur cum aliis verbis eundi coniunctus. Haec autem omnino sunt eius exempla : cum $\epsilon i \mu \iota$

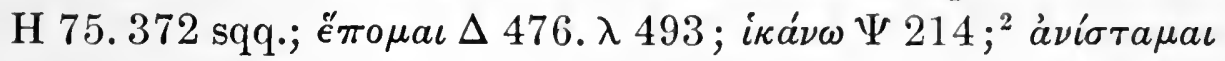

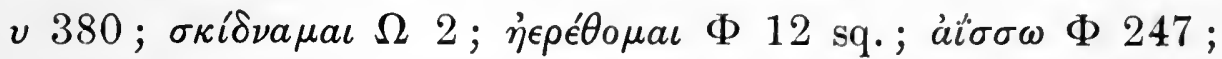

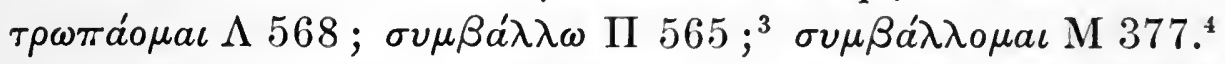

Alia vero liberiorem quandam constructionem habent: П 834

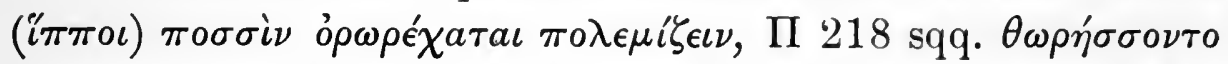

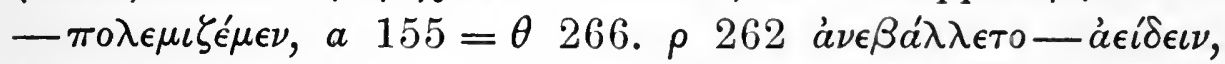

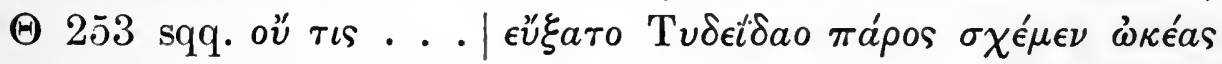

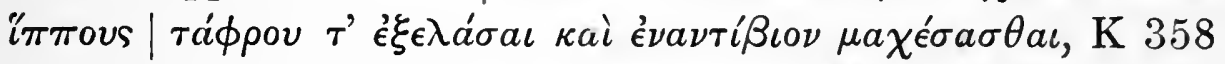

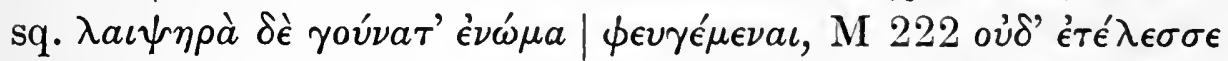

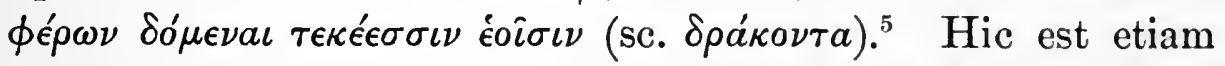
commemorandus, sententia potius quam forma spectata, locus

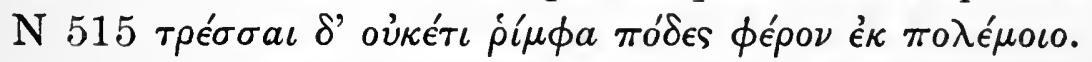

Iam ad exempla transeamus in quibus infinitivus non modo cum subiecto enuntiati principalis sed etiam cum parte aliqua prædicati est coniunctus. Quorum primum est $\mu a \dot{\sigma} \tau \iota \xi \epsilon \nu \delta^{\prime}$

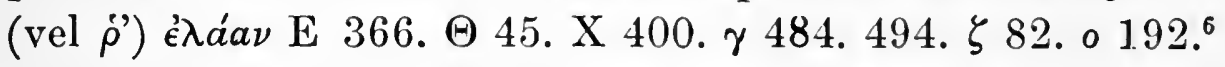

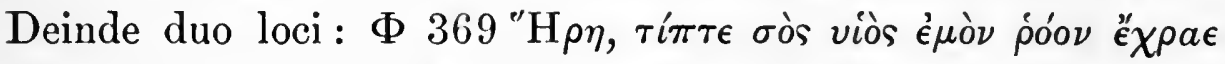

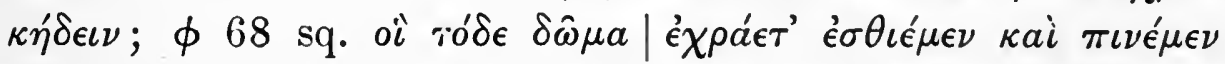

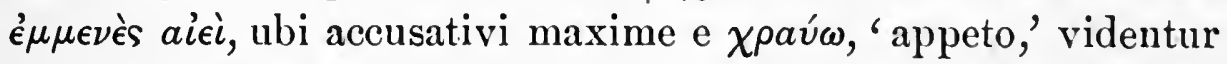
pendere. Genetivus autem est à $\dot{a}_{o} \kappa o \iota \nu o \hat{v}$ positus $\lambda 591 \tau \hat{\omega} \nu$

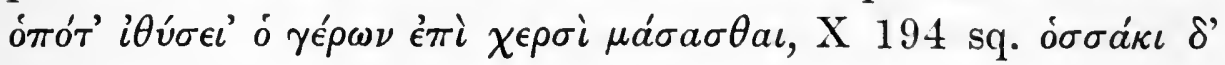

${ }^{1}$ Hre res digna est qua animadvertatur, quod, cum usum constructionis ratione temporum definimus, obsoleta sunt seiungenda.

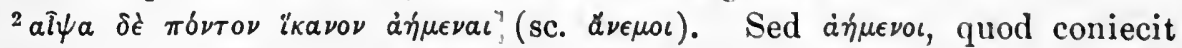
Meierheim, op. cit., p. 71, a multis est probatum, cf. Ameis-Hentze, Anh. ad loc., et Leaf ad loc.

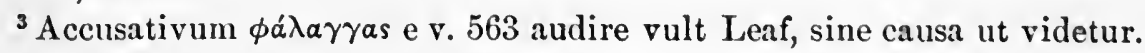

${ }^{4}$ Activam formam verbi scribit Leaf, codicem $\mathrm{T}$ (ownleianum) secutus.

${ }^{5}$ Infinitivus hic non e $\phi \epsilon \hat{\epsilon} \rho \nu$ participio sed ex $\dot{\epsilon} \tau \epsilon \lambda \epsilon \sigma \sigma \epsilon(\delta \delta \delta \nu)$ pendet. Vide Meierheim, op. eit., pp. 63 sq.

${ }^{6}$ Accusativus $\imath_{\pi}$ mous ( $\dot{\eta} \mu \dot{b} \nu 0 u s \zeta 82$ ) non modo cum verbo sed etiam cum infinitivo est audiendus. 


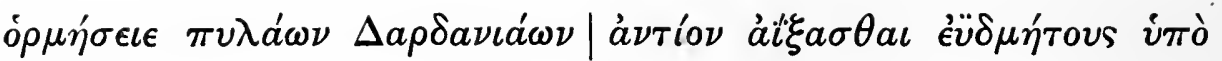
$\pi u ́ p$ yous. ${ }^{1}$

De his quidem verbis vocibusque, quæ propriam servant significationem, dubitatio nulla est orta quin finalem constructionem adsciscerent; nunc autem difficiliora sunt tractanda, quæ iam in carminibus Homericis ex significatione eundi in aliam cœpta erant transferri, qualia sunt verba ô $\rho \nu v \mu a \iota, o ́ p \mu a ́ o \mu a \iota$, ¿ $\epsilon \mu a \iota^{2}$ Meierheimius quidem ad naturam constructionis definiendam proposuit hanc regulam $:^{3}$ 'si verba eundi proprium sensum, ut corporis motus designetur, habent, inf. est finalis, si vero translatum sensum, inf. alteri rationi, directioni, indicandæ inservit (hoc autem loco, ut per se patet, inf. fin. non excluditur). Si hæc regula vera est, quæstionem multo faciliorem esse apparet, tum enim sufficit cognosse, utrum proprium an translatum sensum in singulis exemplis verba eundi habeant.' At illud ipsum minime facile est cognitu ; nam semper fere in huiusmodi verbis fieri potest ut, infinitivo adiuncto, vim translatam habeant; quam ob ren necessario dubium est utrum finalis sit infinitivus an artius cum verbo coniunctus ad explendam sententiam usurpetur. Quomodo enim vertendum est

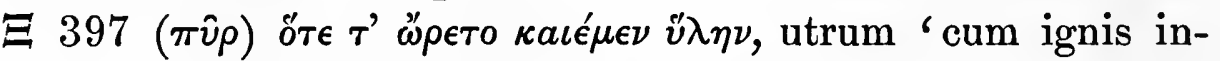
citavit sese ut silvam ureret,' an simpliciter 'cum ignis cœpit silvam urere'? Quæ cum alius aliter sit iudicaturus, non expedit plura moliri; sed ne tota quæstio in medio relinquatur, eorum locorum faciam mentionem in quibus paulo apertior est vis finalis. Verba autem sunt hæc: óp

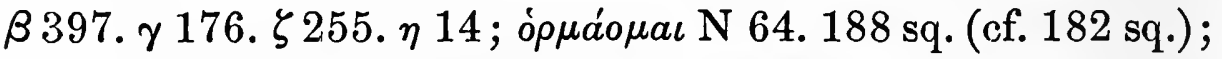

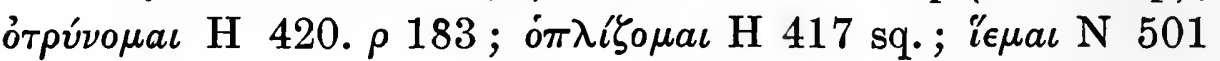

${ }^{1}$ Edd. plerique iungunt $\pi v \lambda a ́ \omega \nu$ cum solo infinitivo, sed poscit rhythmus ut e verbo pendeat. Vide Seymour, T. D., On the Homeric Cæsura, Harv. Stud., III, p. 110.

${ }^{2}$ De hoc verbo, quod in tempore presenti cum i $\eta \mu$, in futuro et aoristo cum $\epsilon^{i} \mu \iota$ sæpe est confusum, vide van Leeuwen, Enchiridium Dictionis Epicæ, \& 41. 44, \& 201 ; Meyer, L., Bezzenbergers Beiträge, I, pp. 301 sqq.

${ }^{3}$ Op. cit., pp. 66 sq. 


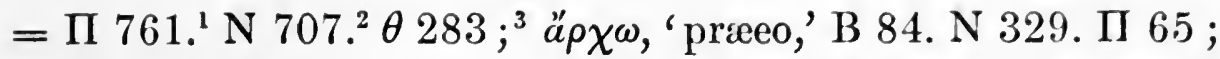

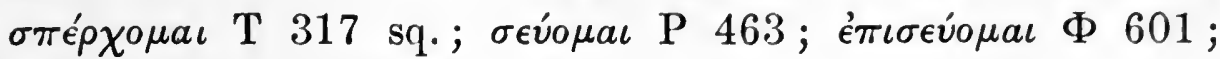
$i \theta \dot{v} \omega \mathrm{P} 353 ;{ }^{4} \dot{\epsilon} \pi \iota \theta \dot{v} \omega \Sigma 174$ sq.

His exemplis enumeratis, licet denique pauca proferre in quibus infinitivus, cum a verbis pendeat quæ motum animi, non corporis significant, tamen servat vim finalem vel consecutivam:

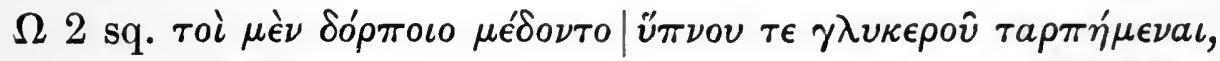

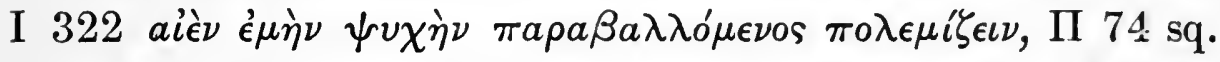

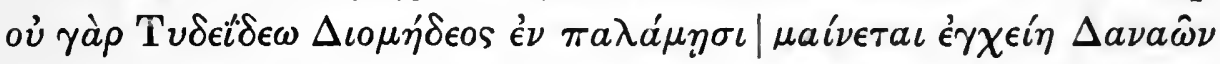

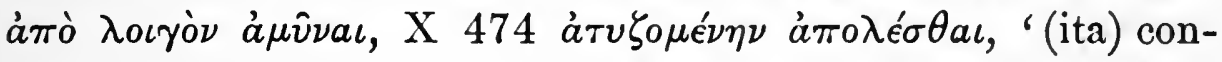

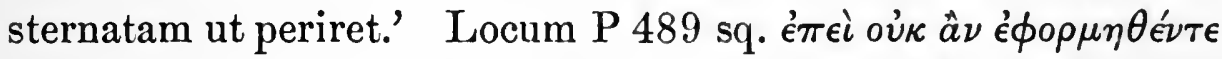

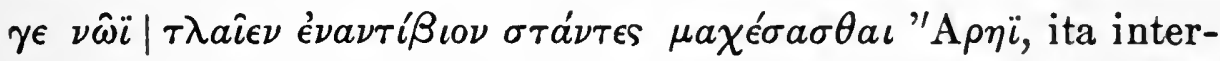
pretantur Ameis-Hentze ad loc., ut $\nu \hat{\omega} \hat{\imath}$ e $\tau \lambda a \hat{\imath} \epsilon \nu$ verbo pendeat atque infinitivus sit finalis. Sed cum ět $\lambda \eta \nu$ nusquam alibi accusativum adsciscat, malo Leafium sequi anacoluthon statuentem.

De aliis constructionibus. - Inter constructiones quæ infinitivi munere fungi videntur participium futuri præcipue commemorandum est, cuius apud Homerum infinitivo finali simillimus est usus ; nam, paucis locis exceptis, ${ }^{5}$ cum verbis motum significantibus coniungi solet ad finem notandum. Exempla autem, cum a Classenio sint enumerata, ${ }^{6}$ hic tantummodo per-

${ }^{1}$ Vide Leaf ad loc.

${ }^{2} \mathrm{Si}$ quidem scribimus e coniectura ran Herwerdeni, quam receperunt

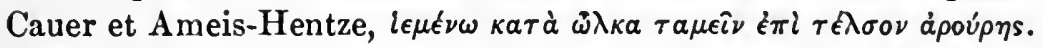

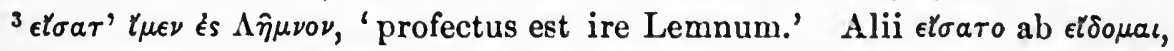
'videor,' esse volunt, sed hoc minus aptum. Vide Ahrensii sententiam laudatam ab Ameis-Hentze, Anh. ad loc.

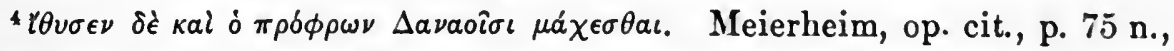
existinat infinitivum a $\pi \rho \delta \phi \rho \omega \nu$ adiectivo pendere. Sed cum exemplum certum huius constructionis non sit apud Homerum, prestat $\pi \rho \delta \phi \rho \omega \nu$ infinitivo adiungere, 'ut libens pugnaret.'

${ }^{5}$ Vide Monro, Hom. Gramm., ed. 2, §244; Classen, J., Beobachtungen über den Homerischen Sprachgebrauch, Frankfurt 1879, pp. 78 sqq.

${ }^{6} \mathrm{Hrec}$ autem in enumeratione Classenii, op. cit., p. 79, sunt corrigenda addendave. Pro $\Omega 248$ (l. 15) scribendum $\Omega 240$ et pro $\tau 509$ (1. 13) $\tau 504$. Loci $\Lambda$ 101. $\tau$ 48. $504 \mathrm{sub} \beta a l \nu \omega$, non $\epsilon \bar{\mu} \mu$ subiciendi sunt; $\chi 162$ sub $\beta a l \nu \omega$, non єै 
stringemus, ita ut ea in quibus participium est ad subiectum relatum cum infinitivo conferantur. Intellegendum est participia desiderativa, $\kappa \epsilon \in \omega \nu$ seu $\kappa \epsilon i ́ \omega \nu$ et $\partial \dot{\psi} \epsilon i ́ \omega \nu$ esse adnumerata.

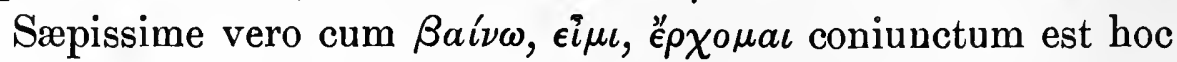
participium ; cuius exempla sunt cum $\beta \alpha i v \omega$ et compositis con-

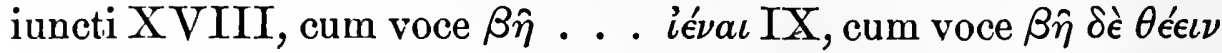
I, cum $\epsilon^{i} \mu \iota$ et compositis XXV, cum "̈ $\rho \chi o \mu a \iota$ et compositis XXVI. Participii cum aliis verbis coniuncti quæ nonnum-

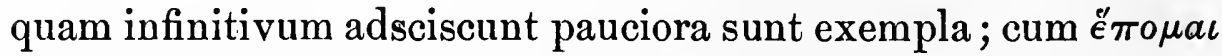
II, cum $\iota \kappa \nu \epsilon o \mu \alpha \iota$ I ( $\kappa 492$, sed cf. $\kappa 565$, qui versus p. 19 trac-

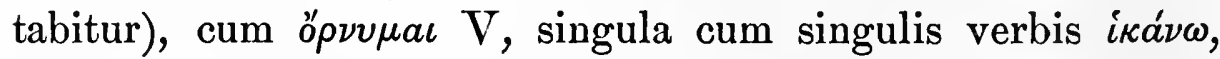

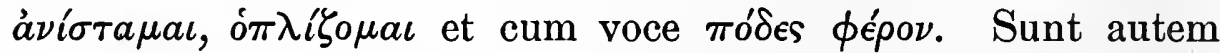
exempla XIX participii cum aliis verbis eundi coniuncti quæ infinitivum non adsciscunt; ac III ( $\zeta 58$ sq. $\rho 298$ sq. $\tau 506$ sq.) cum verbis transitivis coniuncti relatique ad subiectum. Denique in duobus tantum locis coniunctum est cum verbis

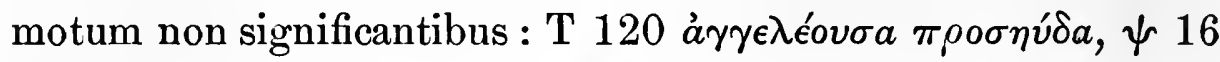

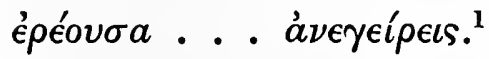

Apparet igitur tria verba eundi usitatissima participium futuri adeo adsciscere solere ut nullus fere sit infinitivi usus, voce $\beta \hat{\eta} \delta^{\prime}$ ' iéva similibusque exceptis ; cetera autem utramque constructionem pariter recipere. Sed his de rebus plura dicemus cum reliqua genera infinitivorum excusserimus.

Nunc autem aliud quærendum, liceatne enuntiata secundaria quæ finem significent cum infinitivis comparare, præsertim cum multa quidem ita sint conformata ut infinitivus pro iis reponi non possit. Ac primum infinitivus finalis cum particula negativa coniunctus in carminibus Homericis quidem non invenitur;

$\Phi 530$ participium præsentis nunc legitur. Addenda sunt hæc: loci iterati a $424(=\mathrm{A} 606) . \quad \delta 528(=\delta 24) . \quad \chi 434(=\sigma 186)$; $\dot{a} \nu \tau \iota b \omega \nu(-\omega \sigma \alpha$,

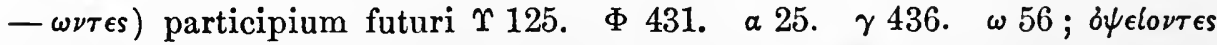

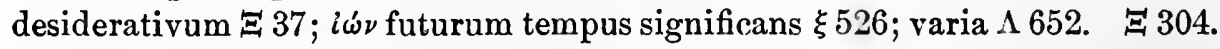
0179 (v. 1. $\pi 0 \lambda \epsilon \mu l \xi \omega \nu$ ). P 146. $\Psi$ 226. $\quad \theta 257 . \quad \xi 433 . \quad \psi 16$ (locus corruptus?)

${ }^{1}$ Locus vexatus, qui fortasse Axtii coniectura el’ovora sanandus est; vide Ameis-Hentze Anh., van Leeuwen et Mendes ad loc. 
cuius rei ea videtur esse causa quod etiam inerat in illo tanta vis substantiva ut actio significata nequiret per particulam, ut in verbo, negari. Quæ autem sunt apud posteriores scriptores,

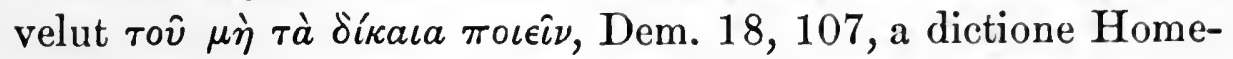
rica longe abhorrent. Deinde infinitivus qui, ut supra monuimus, terminum vel effectum actionis potius quam ipsum finem notat, eo minus est aptus ubi notio finis non ex tota sententia colligitur sed constructione verborum aperte declaranda est. Ergo si quid dicitur per ironiam, ut Z $143 \hat{a} \sigma \sigma o \nu ~ ¿ ' \theta$ ', ̈̋s $\kappa \epsilon \nu$

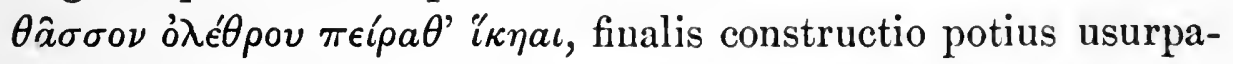
tur quam infinitivus. Qui contra si habet vim consecutivam,

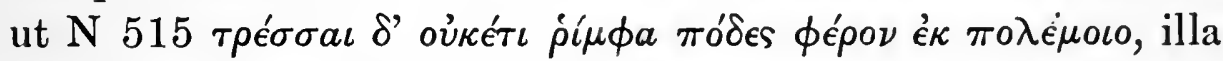
plane non potest reponi. Sed plura exempla proferamus non est necesse ; nam, ut ante dictum est, rationes inter usus variarum constructionum distinguendi, cum in re metrica rhetoricaque ac tota dictione sitæ sint, obscuriores solent esse quam ut subtiliter investigentur. Itaque in re dubia hoc tantum conabor, quæ enuntiata finalia propius ab infinitivis supra tractatis abesse videantur, ea comparandi causa hoc loco enumerare. Hæc autem subiectum idem habent atque enuntiata e quibus pendent et plerumque cum verbis eundi sunt coniuncta. Sed ad exempla pergamus, quæ sunt : cum $\beta a i \nu \omega$ verbo et compositis,

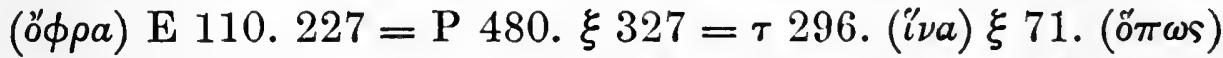

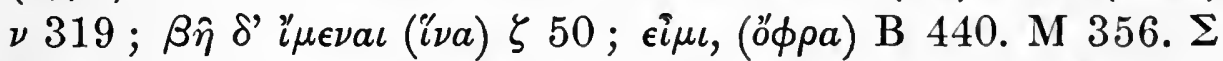

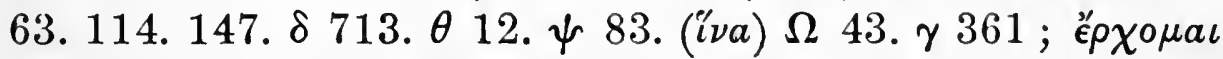

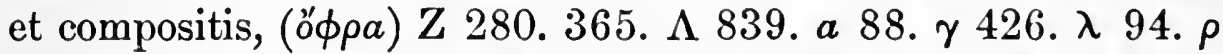

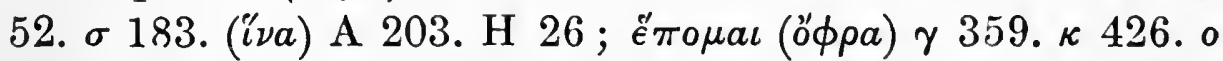

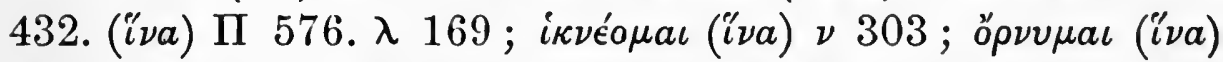

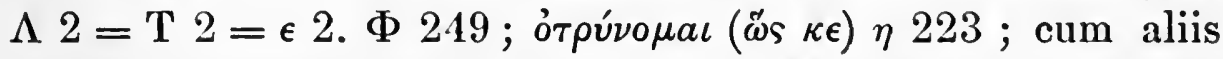
verbis vocibusque eundi, (öфpa) $\Gamma$ 163. M 281. P 685. $\mu 333$.

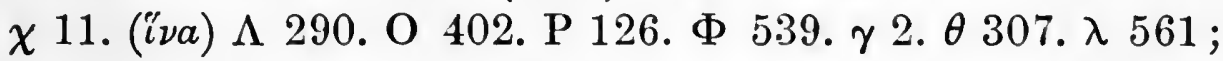

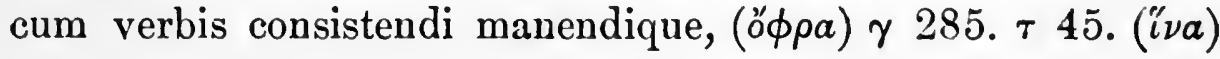
$\mu$ 185. $\pi 369$.

Animadvertendum est in parte plus dimidia horum exem- 
plorum verbo principali, quod in persona prima futuri vel subiunctivi aut in imperativo aut in infinitivo e verbo iubendi pendente sit positum, notionem voluntatis inesse; quam ob rem enuntiata finalia, quæ item voluntatem notant, facillime adiunguntur. ${ }^{1}$

Enuntiata relativa, cum easdem ob causas quas adverbialia haud facile cum infinitivo comparantur, tum propriam habent ambiguitatem; nam quale sit enuntiatum non pronomine relativo sed solo modo verbi indicatur. Itaque in laxiore modorum usu Homerico sæpissime ambigitur, ut hunc locum, $\lambda 134$ sq.

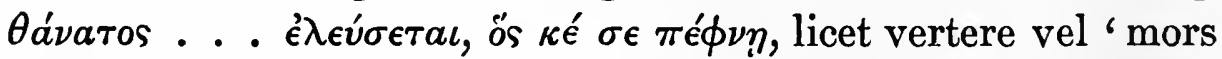
veniet quæ te interficiet' vel 'mors veniet quæ te interficiat.' Sed quod finem quasi circuitione significant et per pronomen relativum ad certum vocabulum enuntiati principalis referuntur, eo hæc enuntiata infinitivis propius accedunt. Neque ea in quibus est optativus cum $\kappa \epsilon \nu$ aut $\stackrel{\nu}{\nu}$ coniunctus prætereunda sunt, quippe quæ præ se ferant vim consecutivam. Paucissima vero in hoc genere cum infinitivis possunt comparari : $\sigma 334$

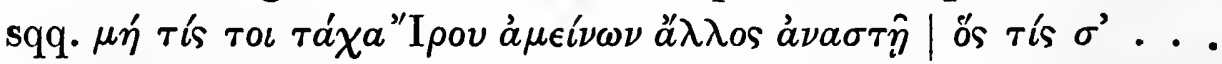

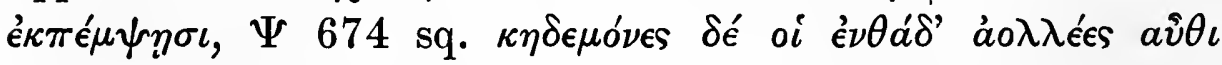

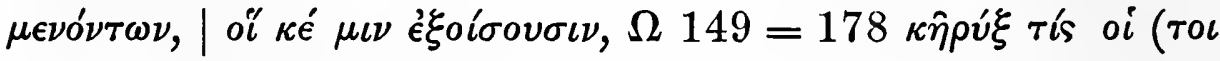

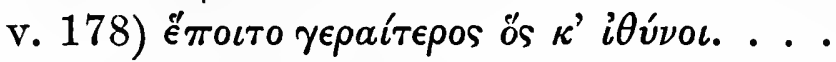

${ }^{1}$ Vide Hentze, C., Zur Entwickelungsgeschichte der Finalsätze, Philologus, 65 , pp. 172 sqq., 178 sqq. 


\section{CAPUT II}

\section{OBIECTUM VERBI PRINCIPALIS FST SUBIECTUM INFINITIVI}

A verbis mittendi, quibuscum sæpissime iunctus est infinitivus, ordiemur.

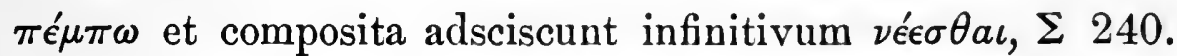
$\Phi 47$ sq. ${ }^{1}$ 598. $\delta$ 8. $\nu$ 206. $\phi$ 374. $\psi 23$; infinitivos aliorum verborum eundi, $\Pi 575.671=681 .^{2} \delta 29 . \xi 396 \mathrm{sq} . v 361 \mathrm{sq}$. ; infinitivos alia significatione, A $442 \mathrm{sqq}$. $\Gamma 116 \mathrm{sq}$. II $240 \mathrm{sq}$. $454 .^{3}$

Hæc exempla non sunt certis verbis concepta, nisi quæ continent $\nu \epsilon^{\prime} \in \sigma \theta \iota$ infinitivum excipimus, qui semper est in fine versus nec multum ad sententiam adfert. Sed cum verbum principale locum certum non habeat, haud scio an hanc negemus esse formulam.

¿ $\eta \mu \iota$ et composita. Digna sunt quæ separatim tractentur $\pi \rho \circ i \eta \eta \iota$ et composita, quæ sæpe adiungunt infinitivos significationem habentes eundi, $\Gamma 118$ sq. $O 254$ sq. P 708 sq. $\beta 147$.

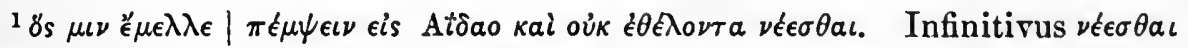
cum $\pi \dot{\epsilon} \mu \psi \epsilon \iota \nu$ videtur esse coniungendus, cf. $\Sigma 240$; sed etiam fieri potest ut ab

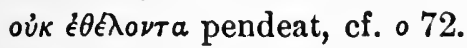

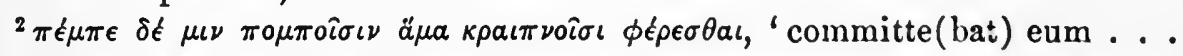
ferendum.' Multi, velut Ameis-Hentze ad loc., $\mu \nu \nu$ pro obiecto $\phi \epsilon \rho \epsilon \sigma \theta a \iota$ infinitivi habent, ut hæc sit sententia: 'committe(bat) eum ducibus celeribus ut secum ferrent.' Cf. $\Pi$ 454. $\omega 419$. Sed $\pi \dot{\epsilon} \mu \pi \omega$ duobus tantum locis, $\pi 83$ sq. $\omega 419$, dativum cum infinitivo adsciscit, nec forma media huius infinitivi neque ¿ $\mu a$ adverbium hac constructione explicantur. Cf. A 592, ubi $\phi \epsilon \rho \delta \mu \eta \nu$ passive dictum est de eo qui lapsu per aërem fertur.

${ }^{3} \pi \epsilon \mu \pi \epsilon \iota \nu$ (pro imperativo) $\mu \nu$ Өá $\nu a r \delta \nu \tau \epsilon \phi \epsilon \in \epsilon \iota \nu \kappa a i \nu \eta ́ \delta \nu \mu o \nu{ }^{\alpha} \Upsilon \pi \nu 0 \nu$. AmeisHentze, adn. et Anh. ad loc., $\mu \iota \nu$ accusativum ad $\pi \epsilon \mu \pi \epsilon \iota \nu$ relatum ac $\theta a ́ \nu a r o \nu$ esse subiectum $\phi \epsilon \in \epsilon \iota \nu$ infinitivi existimant. Sed accusativus qui ad solum infinitivum finalem, non ad verbum principale sit relatus, nullo alio loco apud Homerum invenitur. Quare satius est, $\mu \iota \nu$ ad $\phi \epsilon \rho \epsilon \iota$ relato, constructionem

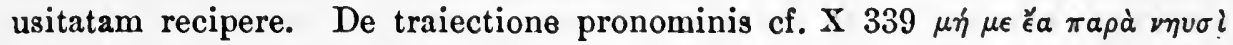

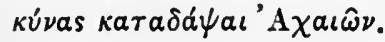


$\gamma 183 . \delta 161$ sq. $\kappa 25 . \tau 468$; ducendi, ferendi, vocandi, K 125 , P 545 sq. $\theta 399=\sigma 291 . \mu 9$ sq. $\nu 64$ sq. $\xi 26$ sq. $\psi 44.51$; dicendi, discendi, I 442.520. K 388.562 sq. $\Lambda$ 201.649. $\delta$ 681 sq. 829. $८ 88=\kappa$ 100. $\kappa$ 155. Verbum simplex ("i $\eta \iota$ )

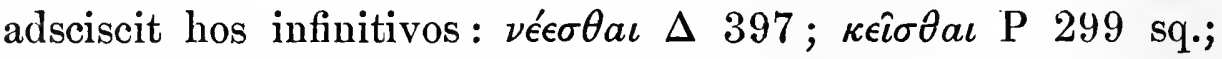

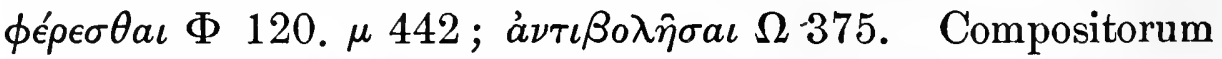

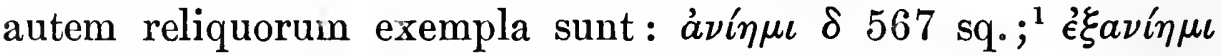

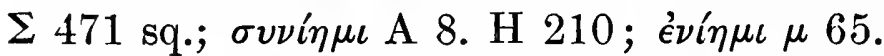

Præter verba mittendi alia complura infinitivum adsciscunt, sed plerumque semel bisve singula. Sunt autem : ă $\gamma \omega$ et composita, N 602 sq. $\delta 36 . \theta$ 529. $\xi 272=\rho 441$; ò $\pi a ́ \zeta \omega \nu 68$;

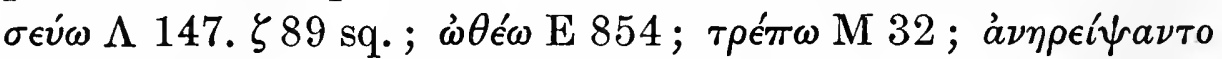

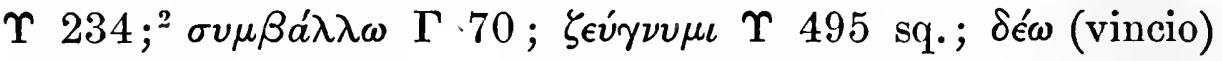
$\Omega 15 ; \pi i ́ \tau \nu \eta \mu \iota \Phi 6$ sq. ; $^{3} \delta \iota \alpha \kappa o \sigma \mu \epsilon^{\prime} \omega$ B 476 sq.; à $\nu \epsilon \hat{\imath} \sigma a$ (in sede collocavi) $\Xi 209 ;^{4} i \sigma \tau \eta \mu \iota$ et composita $\Delta 156.298$ sq.;

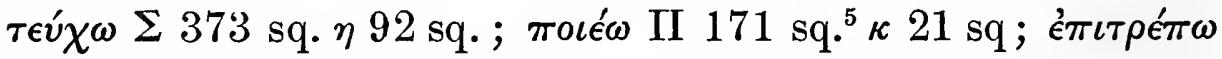

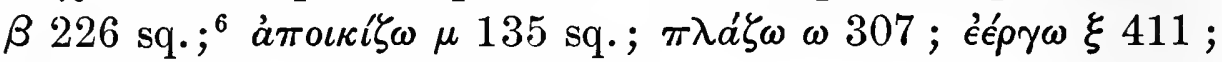

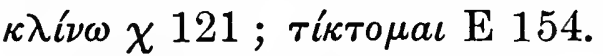

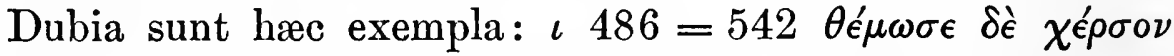

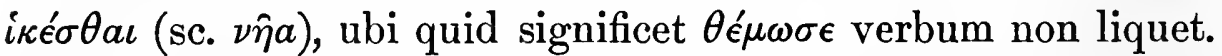
Quod si idem valet atque $\eta^{\prime} \gamma \iota \sigma \epsilon$, ut Aristarchus interpretabatur,

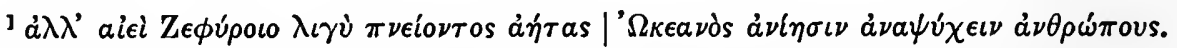
Meierheim., op. cit., p. 60, ' $\Omega \kappa \epsilon a \nu d s$ esse subiectum infinitivi facit, sed perperam, ut videtur.

${ }^{2}$ Vide Leaf ad loc., et van Leeuwen, Ench., \& 224. 1, de hoc verbo vocibus $\dot{\alpha} \rho \pi \dot{\zeta} \zeta \omega$ et "A $\rho \pi v \iota a$ cognato.

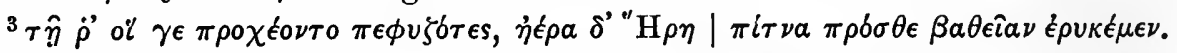
Meierheim, op. cit., p. 60 , "H $\rho \eta$ pro subiecto infinitivi habet; sed cf. $\Phi 59$. $62 \mathrm{sq}$., ubi res est huius verbi subiectum, deque sensu E 316.

4 Vide van Leeuwen, Ench., § 220. 2, de hoc verbo, quod constat ex $i \zeta \omega$ ac non ex i $\eta \mu$, ut olim videbatur, esse derivatum.

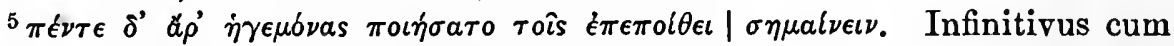
$\pi \circ \imath \dot{\gamma} \sigma \alpha \tau$, non cum $\dot{\epsilon} \pi \epsilon \pi$ ol $\theta \epsilon \iota$ videtur coniungendus.

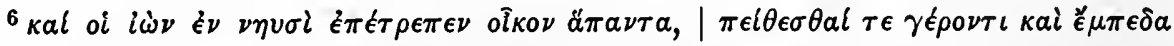
$\pi a ́ \nu \tau a ~ \phi v \lambda \alpha ́ \sigma \sigma \epsilon \iota \nu$. Versum 227, quem in margine habet cod. G., propter constructionem mutatam delevit van Herwerden, quem secuti sunt van Leeuwen et Mendes in editione sua. 
infinitivus vim habet consecutivam; sin est 'coëgit,' infinitivus explet sententiam.

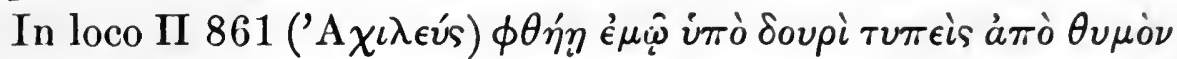
ỏ $\lambda \epsilon \sigma \sigma a \iota$, Leaf et Ameis-Hentze, sententiam van Herwerdeni ${ }^{2}$ secuti, $\tau v \pi \epsilon i s$ participium cum $\phi \theta \eta_{\eta}^{\prime}$ coniunctum esse volunt atque infinitivum pro consecutivo habent, ne e $\phi \theta a ́ v \omega$ verbo contra consuetudinem linguæ Græcæ pendere videatur. Sed hoc loco durissimus est infinitivus consecutivus, præsertim cum

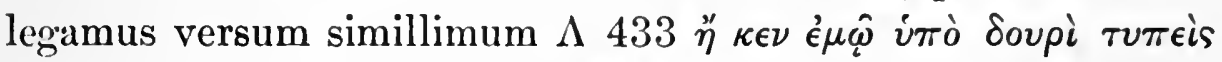

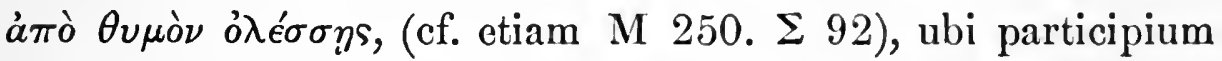
necessario ad ỏ $\lambda \epsilon ́ \sigma \eta \eta s$ est referendum. Neque infinitivus cum $\phi \theta a ́ v \omega$ coniunctus, ut rarissimus est, sic apud bonos scriptores

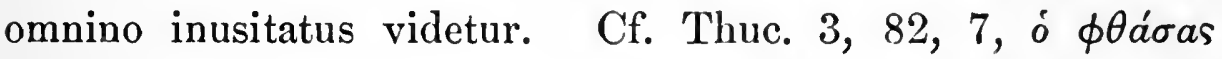
$\theta a \rho \sigma \hat{\eta} \sigma a \iota$ (sic codd. omnes), unde apud Homerum quoque infinitivum ad concursum participiorum vitandum adhibitum esse suspicere.

Alia vero ratione de verbis dubitari potest in quibus propria et translata significationes sæpe sunt ita commixtæ ut lateat natura infinitivi cum iis coniuncti. Quæ cum simillima sint verbis intransitivis iam in capite primo tractatis, eodem fere modo exempla in quibus vis finalis maxime apparet hic profe-

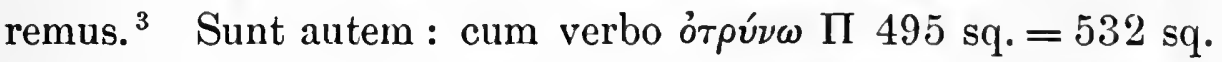
$\Psi$ 111. $\Omega 302$ sq. $\xi 261=\rho 430$; éáw E 684 sq. 847 sq. $\Theta 125$ sq. O 472 sq. T 8 sq., (omnibus locis rox est éáw

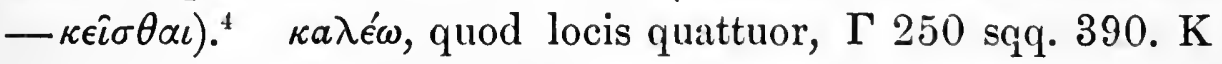

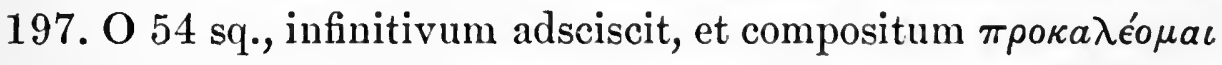

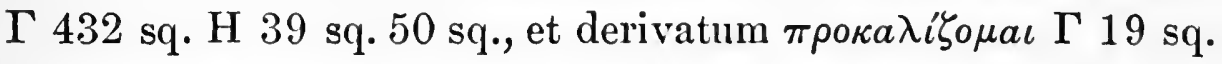

${ }^{1}$ Prellwitz, W., Etymologisches Wörterbuch der gr. Sprache, ed. 2, Göttingen, 1905, p. 181 ; Meyer, L., Handb. der gr. Etymologie, Leipzig, 1901, vol. III, p. 453.

${ }^{2}$ Hermes, 16, p. 360.

${ }^{3}$ Plura exempla infinitivi cum his verbis coniuncti protulit Albrecht, C., De Accus. cum infin., Curtius Studien, 4, pp. 27 sqq.

" $\mathrm{Si}$ in hac voce éáw 'relinquo' interpretamur, qua vis ipsi verbo nonnumquam videtur inesse, cf. I 260 , constructio finalis est ; sed fortasse hæc significatio per brachylogiam ex conformatione ipsa éá 
$\Delta$ 389. $\theta$ 228, videntur potius inter verba iubendi referenda (cf. $\kappa e ́ \lambda o \mu a \iota$ et $\kappa \epsilon \lambda \epsilon u ́ \omega)$. Neque de $\pi \epsilon \delta a ́ \omega$ cum infinitivo con-

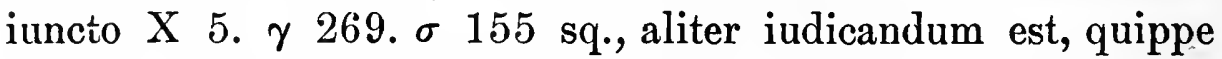
quod iis locis de numine divino dictum per translationem vim habeat cogendi. Atque aipéoraı, 'eligo,' in loco B $127 \mathrm{~T} \rho \omega ́ \omega \nu \delta$ '

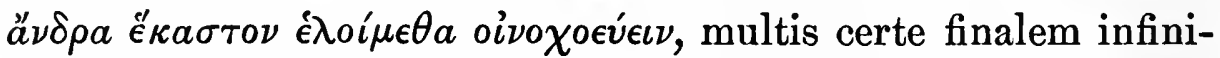
tivum adsciscere videtur; verum si quidem notio finis ipsi verbo inhæret, - nam quid sit eligere nisi munus appareat ad quod fungendum eligitur? - infinitivus, qui alterius accusativi est loco, ad explendam sententiam necessarius est. Quam ob causam haud scio an a genere finali hoc exemplum sit secernendum.

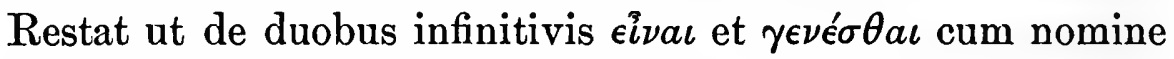
prædicato coniunctis nonnulla disputemus. Quos ideo separatim tractare oportet, quod et liberius quam ceteri usurpantur et plerumque tam supervacanea videntur ut omissis nomina sola idem valeant. ${ }^{1}$ Sed hic infinitivi usus gratam quandam ubertatem optimeque orationi epicæ convenientem efficit; quam ob rem non est mirandum si in carminibus Homericis frequentatur.

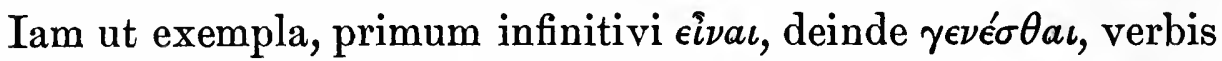
principalibus subiecta proferamus, eîva invenitur coniunctus

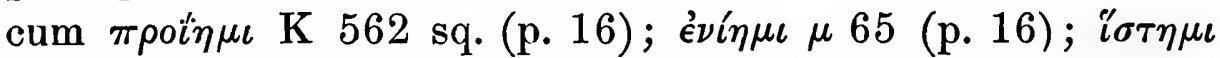

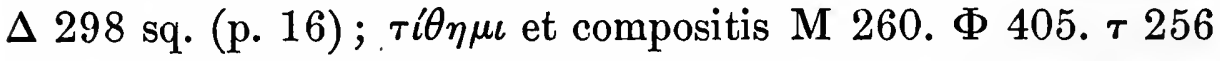

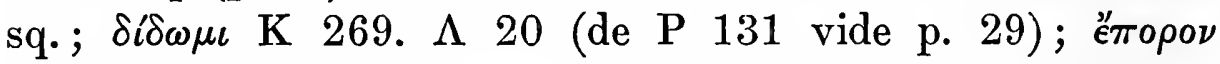

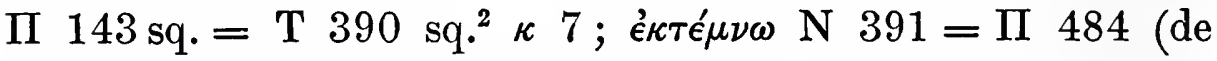

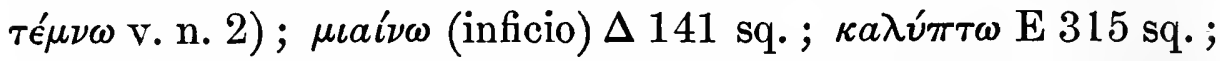

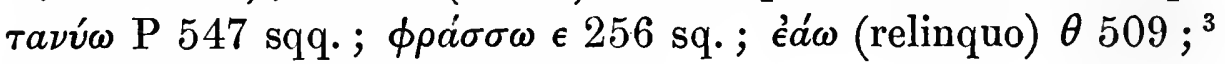
$\nu \eta \epsilon^{\prime} \omega \tau 64 ;{ }^{4} \lambda \epsilon^{\prime} \gamma \omega$ (colligo) $\omega 224$.

${ }^{1}$ Exempla brevioris constructionis contulit Hentze, Phil., 65, p. 163.

${ }^{2}$ Codd. plerique inter lectiones $\pi \delta \rho \epsilon$ et $\tau \alpha \mu \epsilon$ ita fluctuant ut $\pi 6 \rho \epsilon \Pi 143$, $\tau \dot{\alpha} \mu \epsilon$ T 390 habeant. Edd. plerique utroque loco $\pi \delta \rho \epsilon$ scribunt, sed Cauer et Ludwich $\tau a ́ \mu \epsilon$.

${ }^{3}$ Vide ne infinitivus sit complementi loco, ut vocatur, cf. p. 17, n. 4.

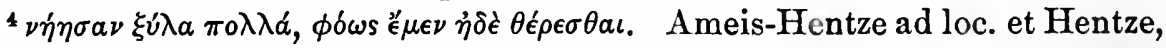
Phil., 65, p. 162, $\phi 6 \omega s$ subiectum $\epsilon^{\prime} \mu \epsilon \nu$ infinitivi arbitrantur, unde sententia huiusmodi evenit: 'coacervarunt ligna multa, ut lumen (præsto) esset atque (ipsi) calescerent,' quæ mihi durissima videtur constructio. Melius $\phi \delta \omega s$ 


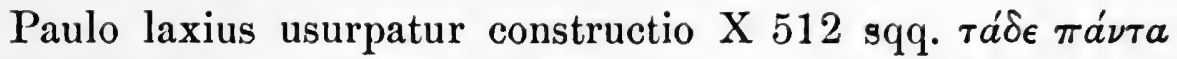

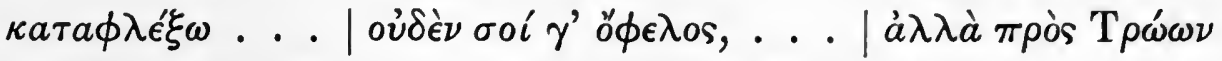

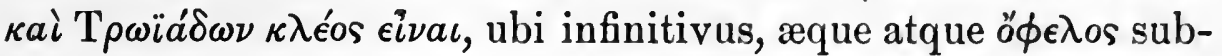
stantivum, non magis ad $\tau a ́ \delta \epsilon$ accusativum quam ad enuntiatum universum referendus est.

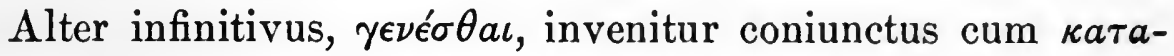
$\lambda \epsilon i \pi \omega \mathrm{P} 151 . \gamma 271$; $\dot{\epsilon} \kappa \beta a ́ \lambda \lambda \omega$ o 480 sq. (his locis est vox

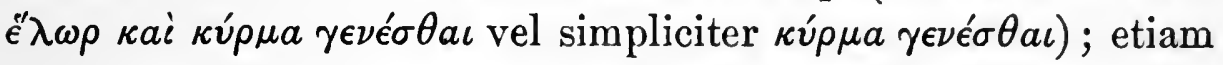

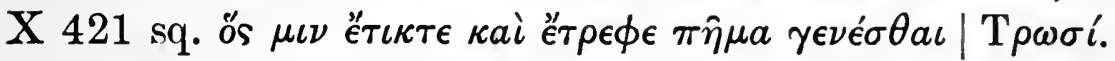

Præcipue vero laudandus est locus $\rho 223$ sq. тóv $\kappa^{\prime} \epsilon l^{\prime \prime} \mu o \iota$

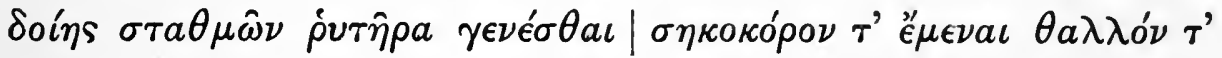

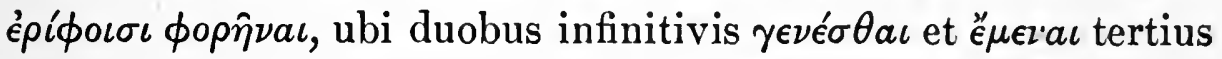
adeo, qui nisi illi antecederent vix usurparetur, accedit.

De aliis constructionibus. - Participium futuri apud Homerum multo minus sæpe cum obiecto verbi principalis quam cum subiecto est coniunctum. Quam rem hic commemoratam repetemus cum in extrema parte summam materiæ explicabimus; nunc autem tantummodo exempla enarramus. $\pi \epsilon ́ \mu \pi \omega$ et composita adsciscunt participium $\Theta 367$ sq. a 93 sq. $\lambda 623 ; \pi \rho o-$ in $\eta \iota$ et composita $\Sigma 58$ sq. $=439$ sq. $\pi 328$ sq.; $\pi$ poïá $\lambda \lambda \omega \Theta 365$;

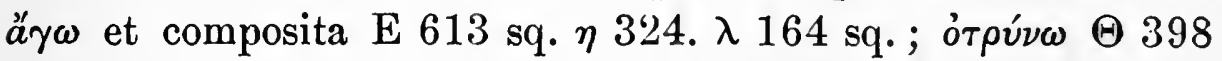

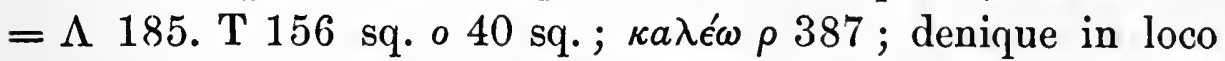

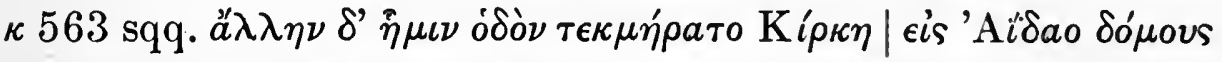

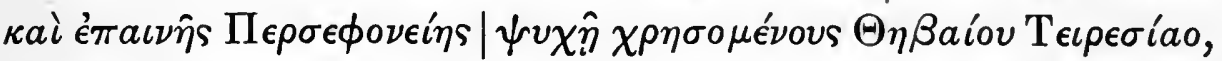

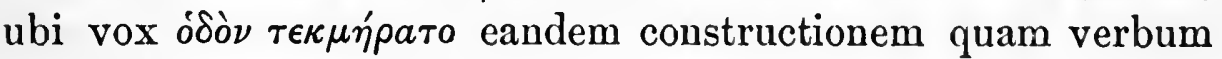
mittendi adsciscit. ${ }^{1}$

Enuntiatorum finalium eodem discrimine quo in capite superiore usi hæc exempla infinitivo conferemus. $\pi \epsilon ́ \mu \pi \omega$ et

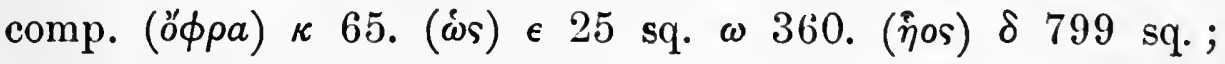

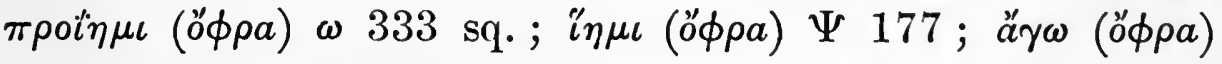

predicati loco ducas et $\xi \hat{v} \lambda \alpha$ ad utrumque infinitivum ita referas ut sit alterius subiectum, cum altero quasi instrumentum actionis audiendum : ' . . ligna qua lumen essent et (quibus ipsi) calescerent.' фáos in re dictum est etiam

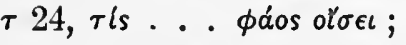

${ }^{1}$ Versum 565 delevit Monro, fortasse quod e v. 492 esset translatus. 


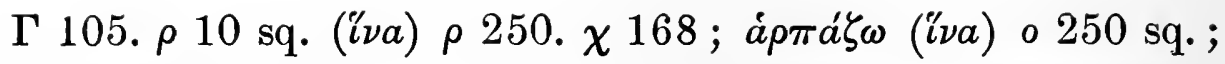

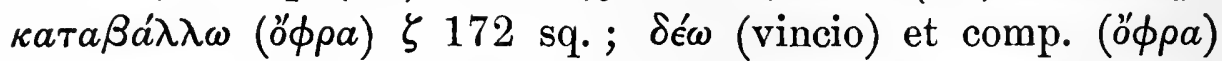

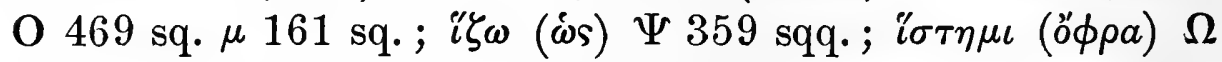

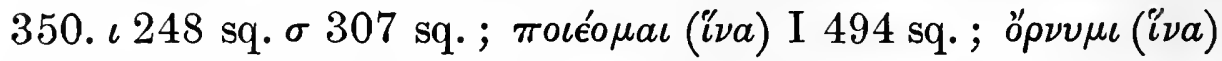

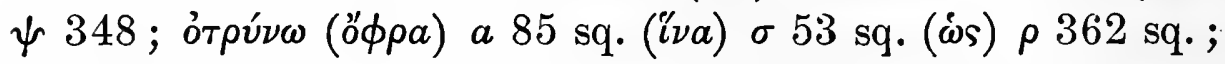

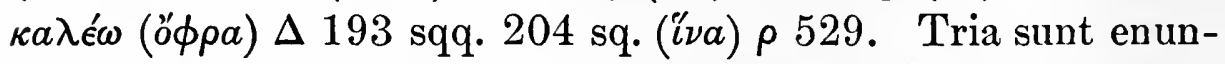

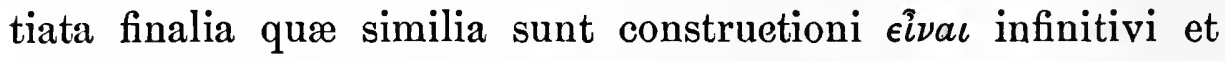

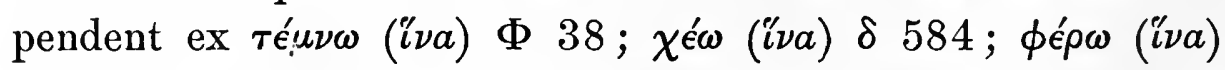
$\iota 233 \mathrm{sq}$. Animadvertendum est duas fere partes horum exemplorum esse in Odyssea.

In is enuntiatis relativis quæ cum infinitivis huius generis comparari possunt pronomen est in nominativo positum et ad accusativum in enuntiato principali relatum. Quorum numerus præ iis quæ in capite superiore tractavimus satis magnus est; sed in his quoque exemplis vim finalem vel consecutivam sententia universa potius quam forma constructionis indicat. Quam ob rem non mirum si enuntiata principalia plerumque voluntatem, multo minus sæpe rem gestam notant. $\quad$ Voluntatis autem notio inest iis locis, in quibus pronomen relativum modum subiunctivum cum $\kappa \epsilon$ particula coniunctum adsciscit,

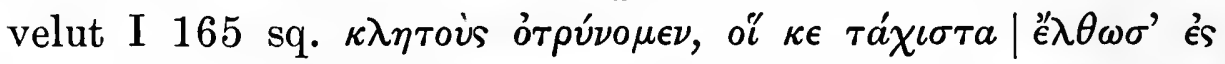
$\kappa \lambda \iota \sigma i ́ \eta \nu .$. Reliqua verba principalia sunt : é $\pi \iota \theta \dot{\eta}^{\prime} \sigma \epsilon \Delta 190$ sq. ; $\phi \epsilon \rho \epsilon ́ \mu \epsilon \nu$ (antecedente verbo iubendi) $\Omega 119=147=176$

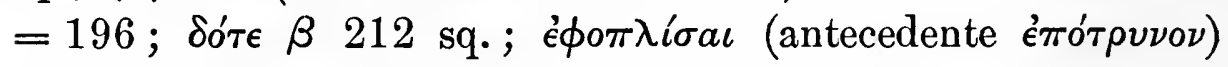

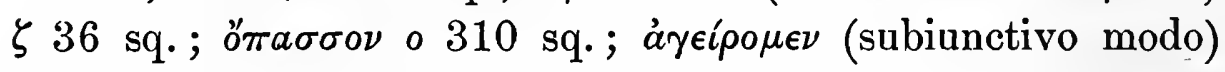

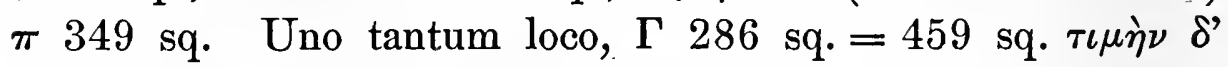

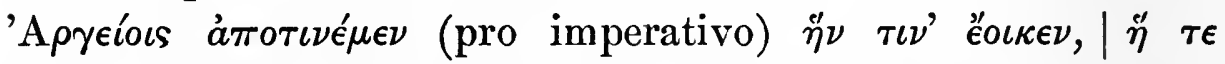

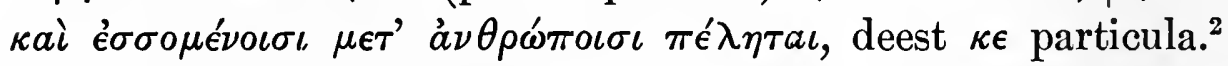
Futurum tempus indicativi, ut apud Atticos est usitatissimum in huiusmodi enuntiatis, sic apud Homerum vix invenitur, nisi

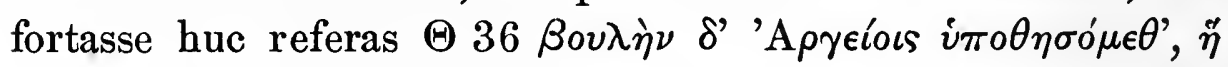

${ }^{1} \mathrm{Cf}$. quæ de enuntiatis finalibus dicta sunt pp. $13 \mathrm{sq}$.

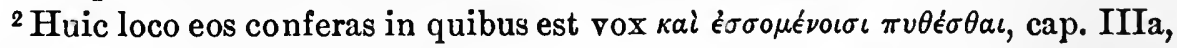
p. 24. 


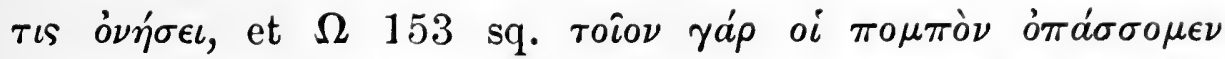
'A $\rho \gamma \epsilon \iota o^{\prime} \nu \tau \eta \nu, \mid$ òs ă $\xi_{\epsilon \iota} \ldots$... (sed cf. locum consimilem $\Omega 182$

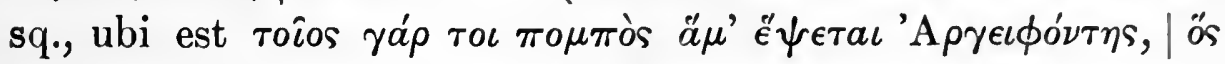
$\sigma^{\prime} \stackrel{a}{a} \xi \epsilon \iota . . .$, nec finis notari videtur).

Optativus, cum $\kappa \epsilon$ coniunctus, est in enuntiatis quæ ex his vocibus pendent: $\theta \dot{\eta} \sigma \omega \Theta 289$ sqq.; é $\nu \theta \dot{\eta} \sigma \omega \in 166$; öp $\sigma o v \sigma a \Phi$

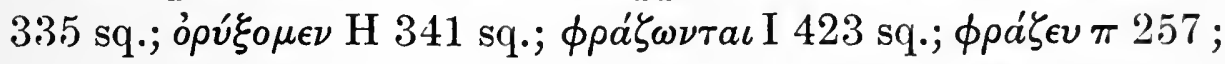

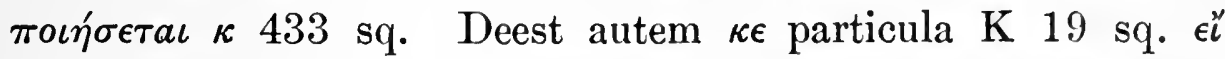

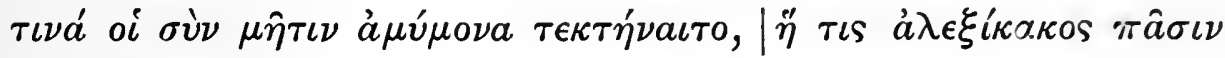

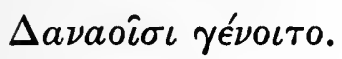

Iam duobus omnino locis enuntiato principali voluntas non notatur, ut e secundario significatio finalis colligenda sit: $\rho 382$

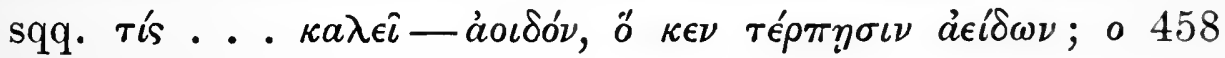

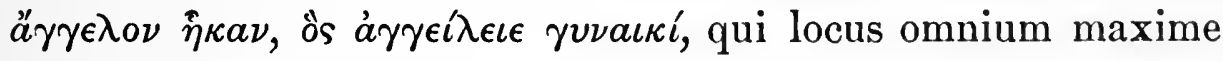
vim finalem præ se fert.

De constructione mutata. - De duobus pluribusve infinitivis inter se coniunctis non est opus disputato, nisi diversa ratione uterque ab enuntiato principali pendet, ut $\beta 226$ sq. (vid. p. 16, n. 6 ), $\tau 64$ (vid. p. 18, n. 4), ubi subiecta sunt diversa ; $\mu 135$

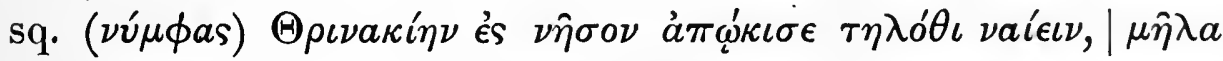
$\phi v \lambda a \sigma \sigma \epsilon ́ \mu \epsilon \nu a \iota . . .$, ubi alter infinitivus pendet a toto versu antecedente. Neque inutile est eos locos adferre in quibus infinitivum finalem vel consecutivum enuntiatum finale sequitur, ut appareat constructionem utramque diverso modo ad verbum principale relatam esse. Namque $\Pi 575 \mathrm{sq} . \pi \epsilon \epsilon \pi o \nu$ é $\pi \epsilon \sigma \theta a \iota$

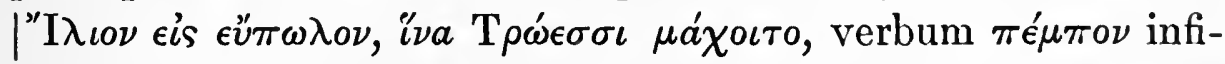
nitivusque $\ddot{\epsilon}^{\prime \prime} \pi \epsilon \theta \theta$ a quasi in unam notionem coierunt, cui accedit

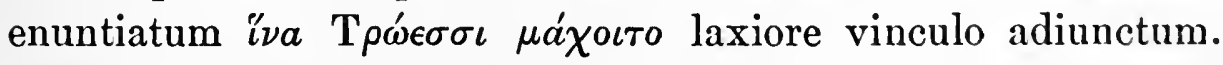
Reliqua exempla sunt: A 442 sqq. E 315 sqq. $\Upsilon 234$ sq. (cf. o $250 \mathrm{sq}.) \kappa 25 \mathrm{sq} . \xi 26 \mathrm{sqq}$. 


\section{CAPUT III}

\section{De DIVISIONE hUIUS CAPITIS.}

In plerisque huius capitis exemplis hæc ratio inter verbum et infinitivum intercedit, ut idem vocabulum sit utriusque obiectum, subiectum autem infinitivi dativus cum verbo con-

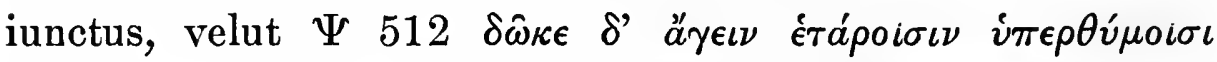
yvvaîka. Sed cum aliis locis dativus aliis accusativus sic positus non inveniatur, necesse est hoc genus in duas partes dividere, quarum una accusativo eodem modo ad infinitivum et ad verbum relato facile definitur, altera exempla constructionis vel per dativum vel etiam per alium casum formatæ continet.

A. Obiectum verbi principalis est obiectum infinitivi.

Verbum $\delta i \delta \omega \mu \iota$ frequentissimum in hac constructione est atque infinitivos verborum agendi, ferendi, habendi præcipue adscis-

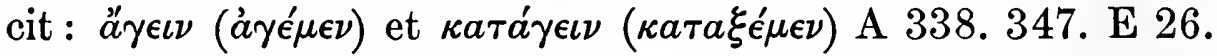

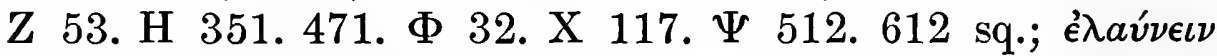

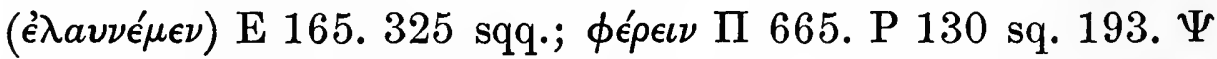

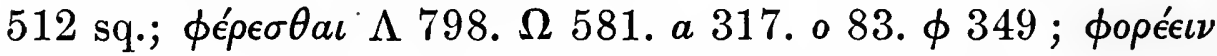

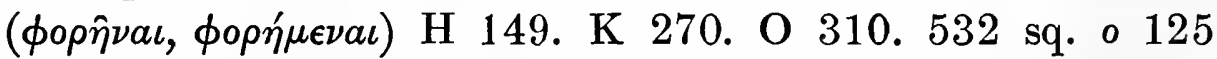

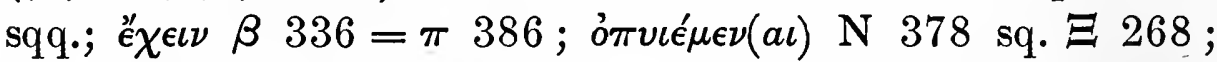

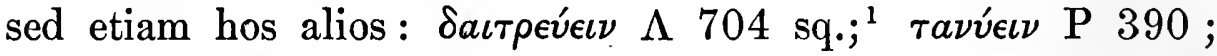
$\kappa a \tau a \delta \eta \mu о \beta о р \hat{\eta} \sigma a \iota \Sigma 301 ; \delta a ́ \sigma a \sigma \theta a \iota \Psi 21 . \sigma 87 ; \delta a \pi \tau \epsilon ́ \mu \epsilon \nu \Psi$

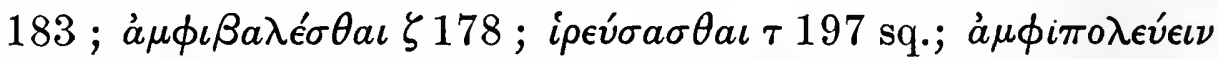
$v 78 .^{2}$ Reliqua verba quæ huiusmodi infinitivos adsciscunt hæc

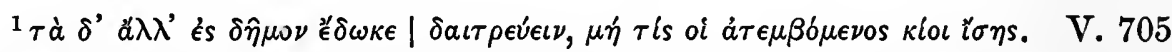
omisit Zenodotus, damnavit A ristarchus multique recentiores tamquam ex $\iota 42$ conflatum; defenderunt autem Gemoll, Hermes, 18, pp. 62 sq., et Leaf ad loc.

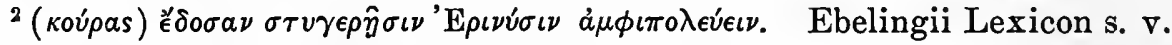
$\dot{a} \mu \phi \iota \pi \circ \lambda \epsilon \omega^{\omega} \omega$, et Pierron ad loc., $\dot{a} \mu \phi \iota \pi 0 \lambda \epsilon \epsilon_{\epsilon \iota \nu}$ 'servire' interpretantur atque ad кoúpas referunt, ut sit constructio generis II. Sed melius est significationem 


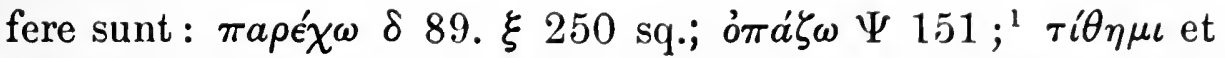
comp. $\Pi 223 . \Psi 263 . \Omega 646=\delta 299=\eta 338 . \epsilon 196$ sq. $\theta 69$ sq. $\rho 259$ sq. (de A 291 vide n. 2 , de $\Theta 188$ sqq. n. 3); $\beta a ́ \lambda \lambda \omega$ et comp. $N 35$ sq. $\epsilon$ 331. $\kappa 242$ sq.; $\pi \epsilon \epsilon \pi \omega \pi 83$ sq. $\omega 419$;

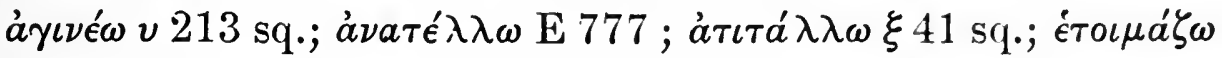
T 197 ; $\lambda \epsilon i \pi \omega$ et comp. B 107 sq. $\epsilon 343$ sq. ${ }^{4} \pi 296 ; \mu \epsilon \theta i \eta \eta \iota$ P 418 sq.; $\phi \rho a^{\prime} \zeta \omega \theta 68 .^{5}$

Vim insignem habent exempla in quibus dativus minus ad verbum quam ad infinitivum est relatus, ut huic quasi subiectum

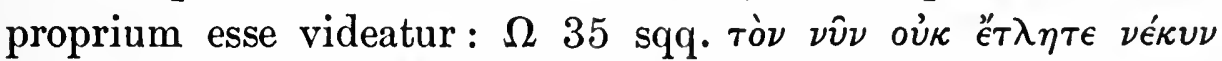

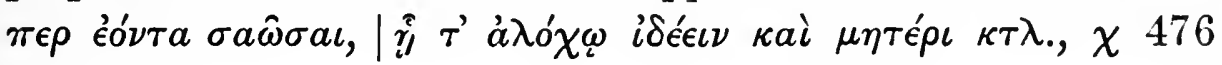

curandi, hoc est, puniendi infinitivo attribuere, ut de Furiis sit dictus. Sic

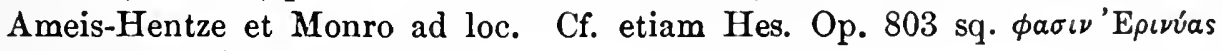

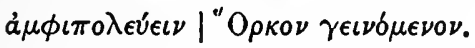

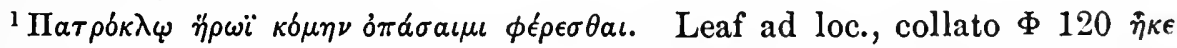
$\phi \epsilon ́ \rho \epsilon \theta a \iota$, infinitivum passive dictum arbitratur; sed cum locus valde similis sit exemplis supra laudatis vocis $\delta \hat{\omega} \kappa \epsilon \ldots \phi \hat{\phi} \rho \epsilon \sigma \theta a l$, vix est dubitandum quin hic infinitivus mediam et transitivam habeat significationem.

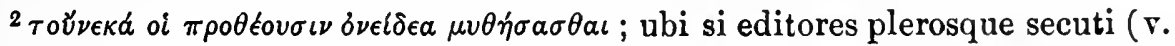
Ameis-Hentze, Anh. ad loc.) $\pi \rho \circ \theta \epsilon o v \sigma \iota \nu$ idem quod $\pi \rho \circ \tau \imath \epsilon \epsilon a \sigma \iota \nu$ esse statuimus, infinitivus inter hæc exampla referendus; at obstat verbi forma inusitata nec satis explicata. Sin eam a $\pi \rho 0 \theta \dot{\epsilon} \omega$, 'procurro,' ducimus, quod nonnulli sunt conati, vertimusque 'convicia ei procurrunt ut (ea) dicat,' infinitivus parti alteri huius generis subiciendus. Sed cum hæc quoque interpretatio sit durissima, fatendum est locum obscuriorem esse quam ut infinitivi syntaxin illustret.

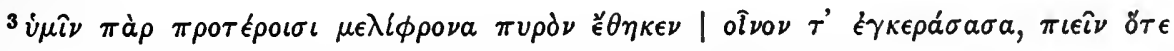
$\theta v \mu d s$ á $\nu \omega ́ \gamma o \iota, \mid \not ौ \epsilon \mu o l, \kappa \tau \lambda$. V. 189 damnavit Aristarchus multique recentiores, ne equi Hectoris vinum bibere viderentur. Si vero retineri potest, infi-

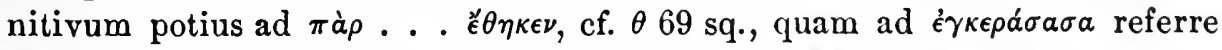
oportet, quare male post $\pi \iota \epsilon \hat{\nu} \nu$ videntur distinxisse Monro et Allen.

${ }^{4} \sigma \chi \epsilon \delta i \eta \nu$ á $\epsilon^{\prime} \mu o \iota \sigma \iota \phi \epsilon \in \epsilon \sigma \theta a \iota \mid \kappa a ́ \lambda \lambda \iota \pi{ }^{\prime}(\epsilon)$. De infinitivo utrum mediam an passivam habeat significationem ambigitur ; sed collatis que paulo antecedunt,

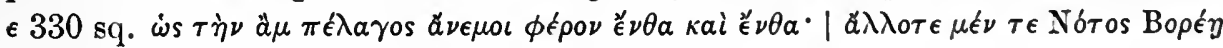
$\pi \rho \circ \beta a ́ \lambda \epsilon \sigma \kappa \epsilon \phi \epsilon \rho \epsilon \sigma \theta a l$, media est probabilior.

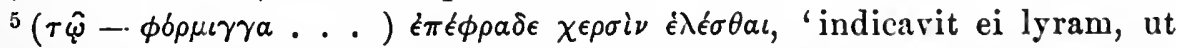
manibus prehenderet' ; sic enim locus vertendus, cum apud Homerum $\phi \rho a ́ j \omega$ sit 'indico,' non 'dico' vel 'iubeo.' Vide Lehrs, Aristarchus, ed. 3, pp. 84 sqq. 


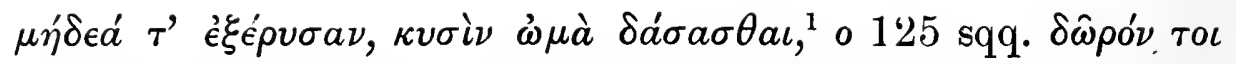

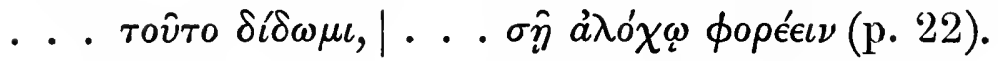

Sed dativum esse subiectum infinitivi maxime apparet in ea

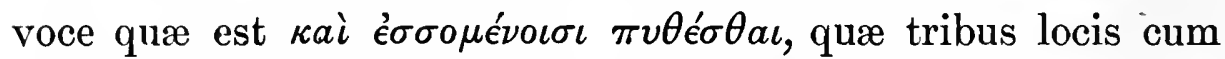
verbis actionem significantibus coniuncta est : X 305 à $\lambda \lambda a ̀$ à $\mu a$

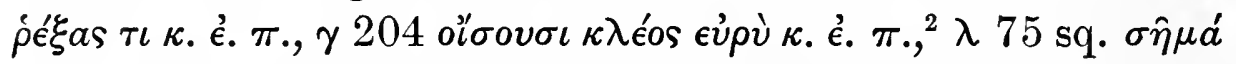

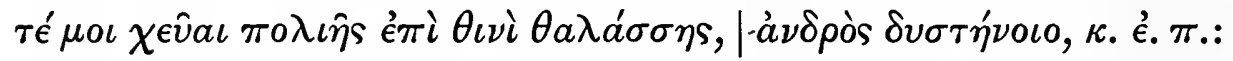
tribus autem locis, B 119. $\phi 255$. $\omega 443$, cum verbis statum significantibus, vide p. 34 . In his quidem exemplis é $\sigma \sigma o \mu e ́ v o \iota \sigma \iota$ dativus cum infinitivo solo coniungi potest, sed in principiis huius constructionis videtur ad verbum quoque fuisse relatus.

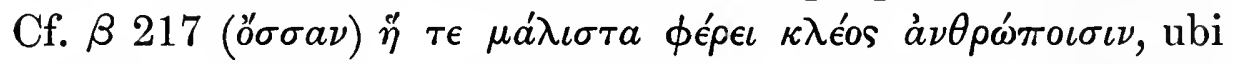
$\pi v \theta \epsilon ́ \sigma \theta a \iota$ infinitivus possit adiungi. Verum ut est apud Homerum, vox certis verbis concepta non multum ab adiectivo differt, ut X 305 vertere possimus 'sed re aliqua magna facta et cuius sit fama perennis.' Animadvertendum est é $\sigma \sigma o ́ \mu \epsilon \nu o s$ participium, exceptis locis A 70. $\lambda$ 433, in hac sola voce occurrere et in enuntiatis finalibus eiusdem significationis $\Gamma 287=460$. Z 357 sq. $\theta 580$.

Cum verbis dandi verba accipiendi tractare oportet, quippe quæ eandem actionem ratione diversa notent. Duo sunt exem-

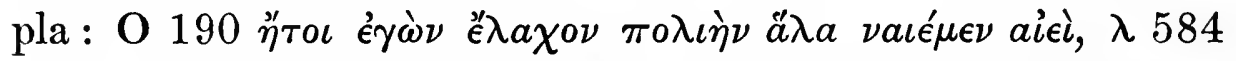

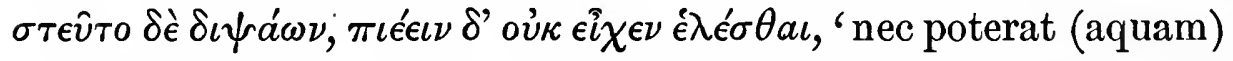
capere ut biberet.' Non fugiet lectorem hæc exempla, cum idem sit verbi et infinitivi subiectum, in primo quoque genere tractari potuisse.

Neque hoc genus locis caret ambiguis, in quibus incertum est accusativus ad verbumne sit referendus ut infinitivus effectum remotiorem significet, an ad infinitivum qui artius cum verbo cohæreat. Quæ dubitatio maxime in $\delta i \delta \omega \mu \iota$ verbo oritur cum

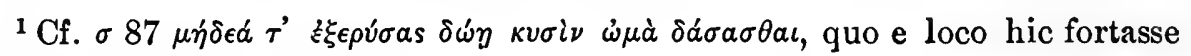
per contractionem ortus est.

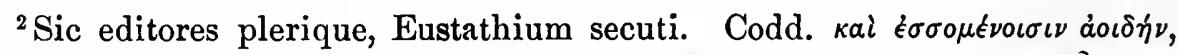
quam lectionem tutati sunt van Leeuwen et Mendes, collato $\theta 580$ iva $\bar{j} \sigma \iota$ kai $\dot{\epsilon} \sigma \sigma o \mu t \nu 0 \iota \sigma \iota \nu \dot{a} o \iota \delta \dot{\eta}$. 
de numine deorum dictum est; nam quamquam multis locis

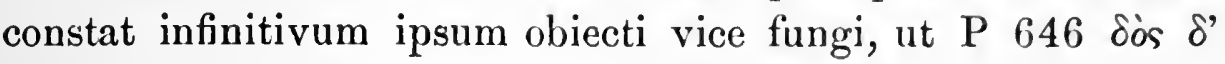

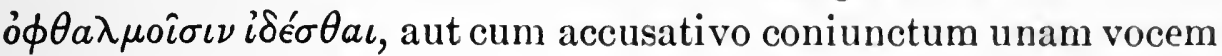

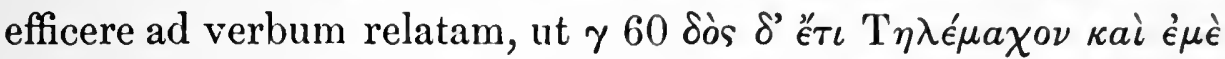

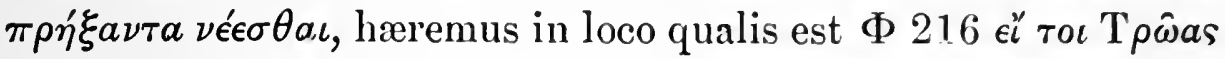

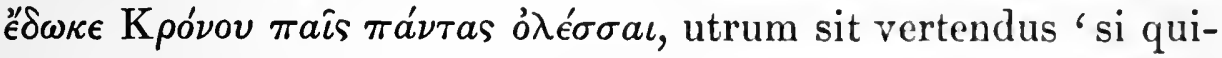
dem Saturni filius Troës tibi dedit omnes interimendos,' an '. . . dedit tibi ut Troës omnes interimeres.' Neque enim absolute statui potest quo modo verti oporteat, quod ipsa ambiguitate hæc constructio ex illa est orta. Sed ubi $\delta \delta^{\prime} \delta \omega \mu \iota$ de dis regentibus res humanas dictum est, in plerisque certe exemplis manifesto est 'concedo,' 'statuo,' neque in ullo ab hac significatione prorsus abhorret; quare præstat sic in omnibus interpretari infinitivumque accusativi loco cum verbo positum statuere. Quæ autem exempla maxime præ se ferunt finalis constructionis speciem hæc sunt: $\Pi 799$ sq. $(\pi \eta \dot{\eta} \lambda \eta \kappa a) Z \epsilon \dot{s}{ }^{~ " E \kappa \tau o \rho \iota ~} \delta \hat{\omega} \kappa \epsilon \nu \mid \grave{\eta}$

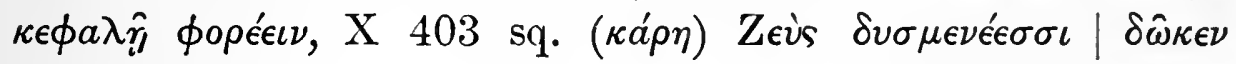

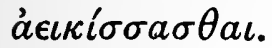

Eadem fere in alia verba cadunt, namque $\lambda a \gamma \chi^{a} \nu \omega$ videtur infinitivum pro accusativo adsciscere $\Psi$ 356.357. $\Omega$ 400. De verbis docendi confer locum ambiguum $v 72$ ép $p a \delta^{\prime}$ 'A $\theta \eta v a i ́ \eta$

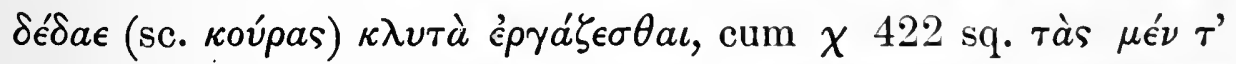

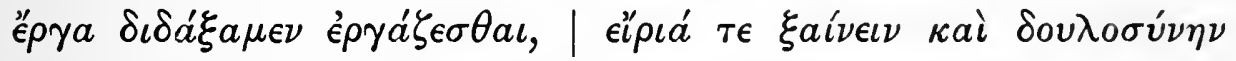

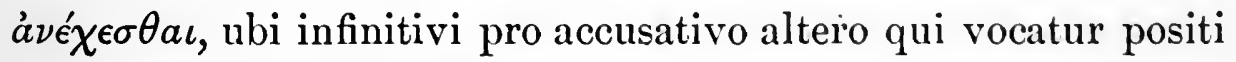
videntur neque effectum notare. Cf. etiam $a 384 \mathrm{sq}$.

B. Alia ratio intercedit inter infinitivum et casum obliquum cum verbo principali coniunctum.

Exempla huius partis varia ac difficilia sunt ad disponendum ; sed in principio ea ponimus in quibus accusativus cum verbo coniunctus ad infinitivum aliquo pacto referri potest. Nonnumquam enim id significat quo fit aut in quo fit actio per infinitivum notata, velut, antecedente $\delta i \delta \omega \mu l, \mathrm{~B} 612$ sq. av่tòs 


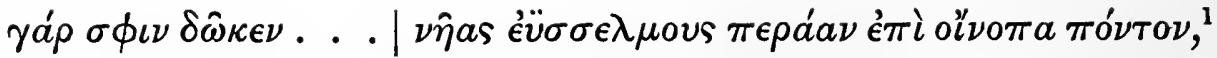

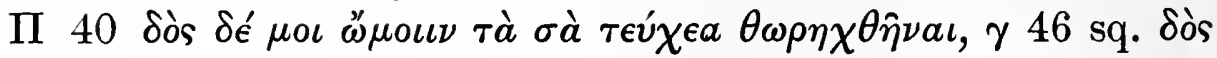

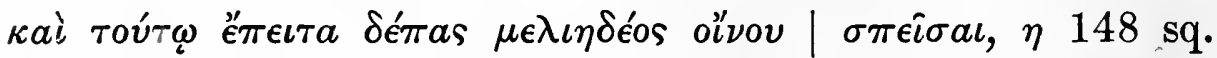

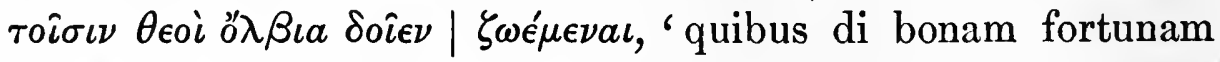

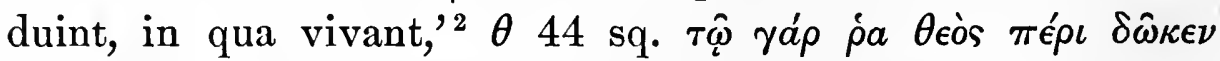

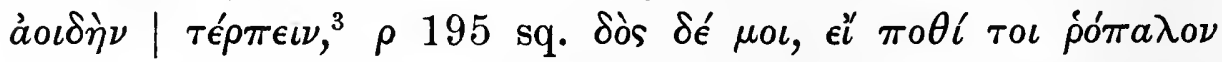
$\tau \epsilon \tau \mu \eta \mu \epsilon^{\prime} \nu o \nu$ '́ $\sigma \tau i, \mid \sigma \kappa \eta \rho i \pi \tau \epsilon \sigma \theta^{\prime}(a i)$. Similis constructio cum

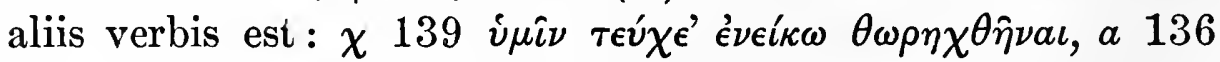
$\mathrm{sqq} .=\delta 52 \mathrm{sqq} .=\eta 172 \mathrm{sqq} .=\kappa 368 \mathrm{sqq} .=0135 \mathrm{sqq} .=$

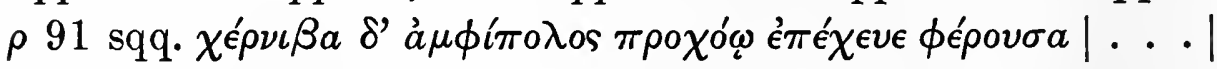

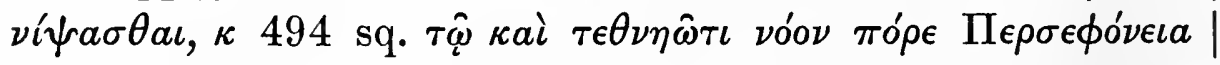

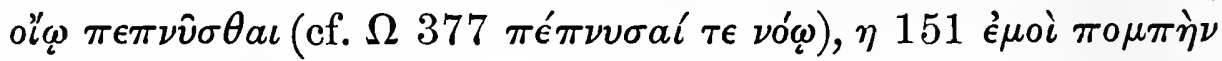

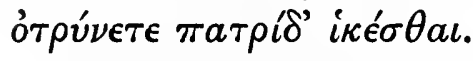

Alia vero ratione accusativus ad infinitivum relatus est his

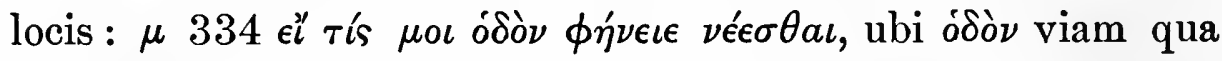

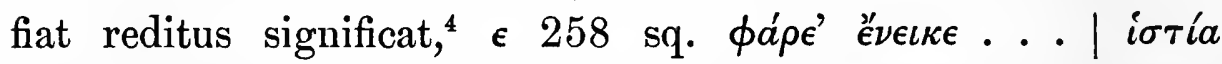
$\pi \circ \iota \eta^{\prime} \sigma \sigma \theta a \iota$, ubi ex accusativo genetivus materiam significans

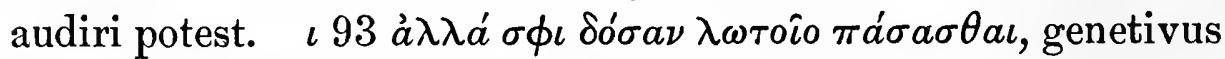
partitivus accusativi vicem obit et cum verbo et cum infinitivo. ${ }^{5}$ Non huc est referendus locus $\psi 78 \mathrm{sq}$. é $\gamma \grave{\omega} \nu$ é $\mu \epsilon^{\prime} \theta \epsilon \nu \pi \epsilon \rho \iota \delta \dot{\sigma} \sigma o \mu a \iota$

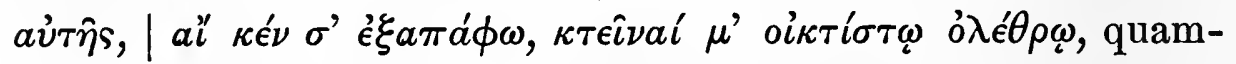
quam nonnulli (Pierron, Hayman) infinitivum esse consecutivum putant; nam hoc verbum, quod est 'pignus do,' constructionem interrogationis obliquæ adiungere solet, ut $\Psi 485$ sq.; Aristoph. Ach. 772. 1115. Eq. 790. Nub. 644. Quare melius, ut voluerunt Düntzer et Ameis-Hentze, infinitivum pro imperativo positum ducas, pleniore distinctione post aủं $\hat{s}$ facta.

${ }^{1}$ Ebelingii Lexicon, s. v. $\pi \epsilon \rho \bar{a} \omega$, $\nu \hat{\eta} a s$ pro subiecto infinitivi habet. At significatio non est 'eis concessit ut naves mare transirent,' sed 'eis naves dedit quibus mare transirent.'

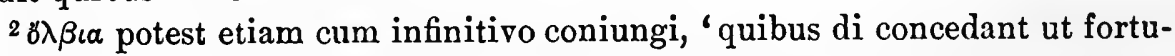
nate 'vivant,' sed illa interpretatio melior, præsertim cum conferas $\theta 413=$

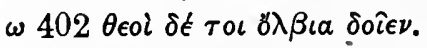

${ }^{3}$ Codd. aliquot $\tau \epsilon \rho \pi \nu \eta \dot{\nu}$.

4 Vide Kühner-Gerth, Gramm., \& 410, 5.

${ }^{5}$ Genetivus cum solo infinitivo coniungi potest, sed nihil impedit quin a

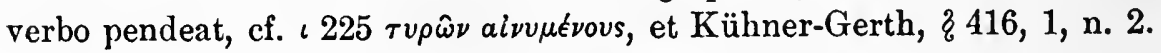


Quo modo ab his exemplis transeatur ad ea in quibus accusativus non sit ad infinitivum relatus, apparebit si infinitivo generis IIIa alterum laxiore constructione accedere posse intellexerimus. Quod factum est in nonnullis exemplis supra

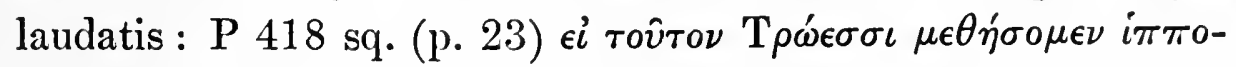

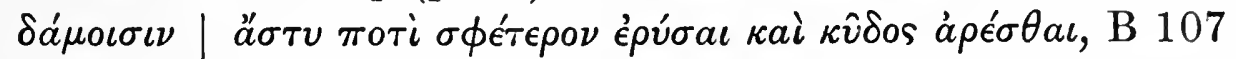

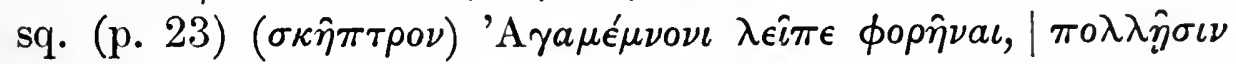

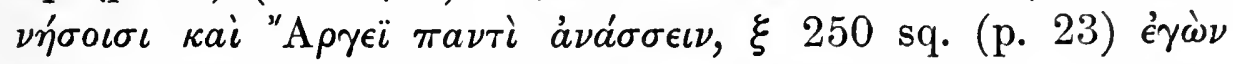

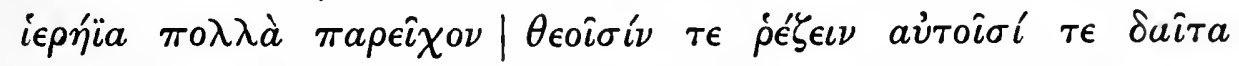

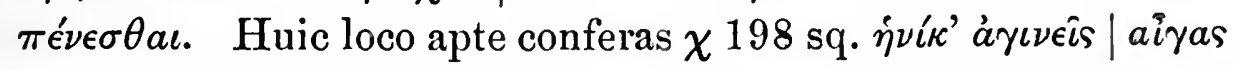

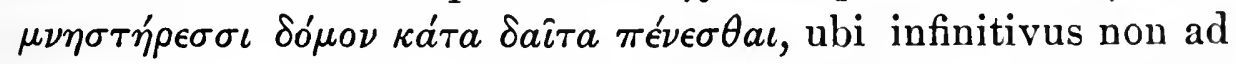
accusativum sed ad dativum solum referri potest. Simili

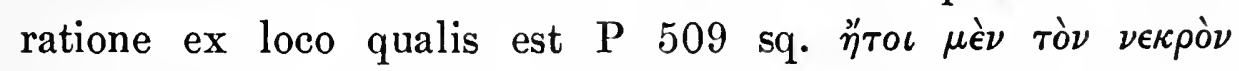

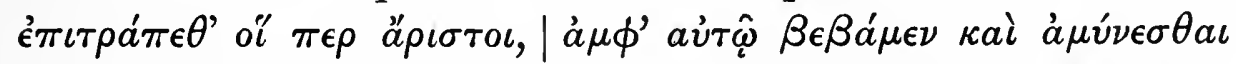
$\sigma \tau i \chi \chi a s ~ a ̉ \nu \delta \rho \hat{\omega} \nu$, fluxit constructio quæ est E $750 \mathrm{sq} .=\Theta 394 \mathrm{sq}$.

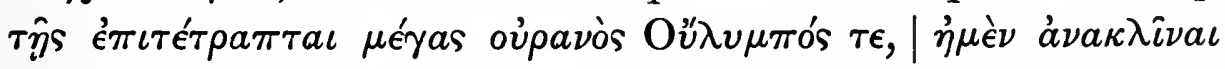

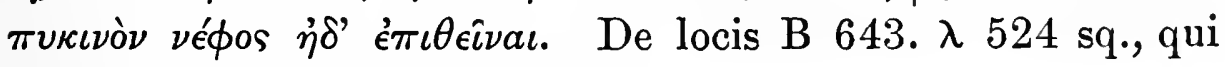
specie huic sunt similes, vide n. 1 .

Proprius autem locus est his exemplis tribuendus in quibus enuntiatum principale significationem dandæ facultatis habet, ut sibi infinitivum aliquanto artius adiungat: B $451 \mathrm{sq} . \dot{\epsilon} \nu \delta \grave{\epsilon}$

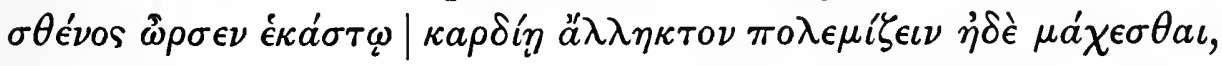

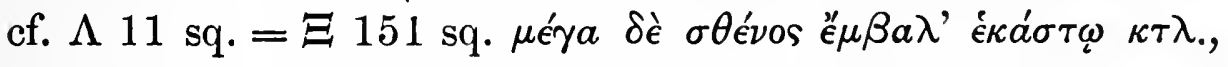
$\Lambda 192$ sq. тót

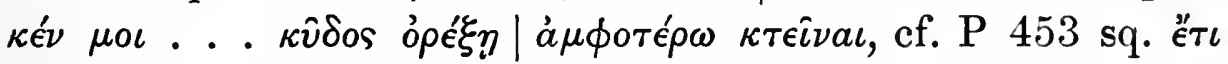

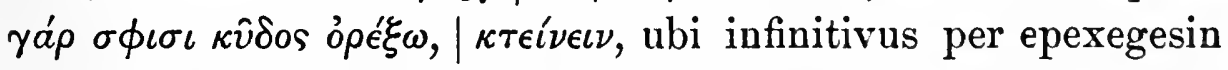
positus videri potest; sed cf. O 596 sqq., ubi hæc vox enuntiatum finale adsciscit. Huc accedit $\gamma 205$ sq. aì $\gamma \grave{a} \rho$ émoì

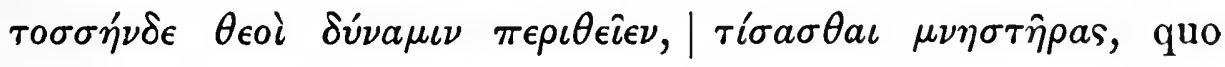

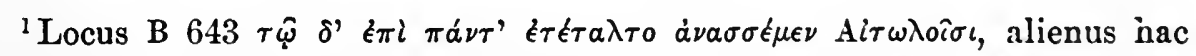
constructione videtur, sive infinitivum per epexegesin $\pi a ́ v \tau \alpha$ adiectivo in

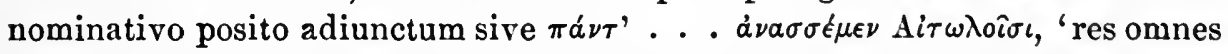
regere Aetolis,' subiectum esse verbi impersonaliter dicti statuimus. In vv.

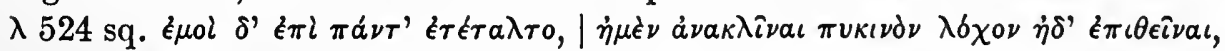
necesse est ut infinitivus sit epexegeticus, nisi fortasse versus 525 , quem omisit Aristarchus, ex E 751 interpolatus est. 
loco $\tau \sigma \sigma \sigma \eta^{\prime} \delta \delta$ non ad infinitivum sed ad versus antecedentes respicit.

Iam ad voces actionem intransitivam significantes accedamus, quæ magni sunt momenti ad infinitivi constructionem declaran-

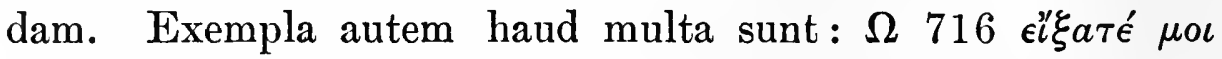

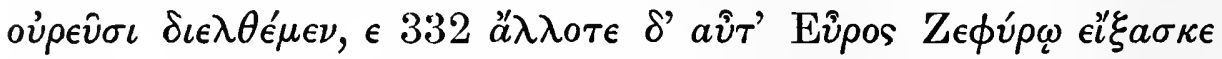

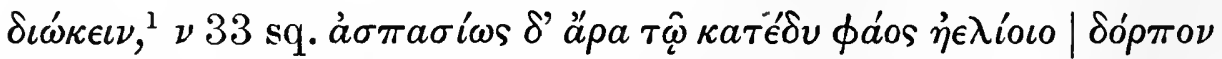

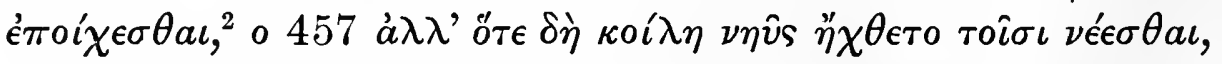
'sed ubi cava navis is erat onerata ut redirent,' $\Sigma 211$ sq.

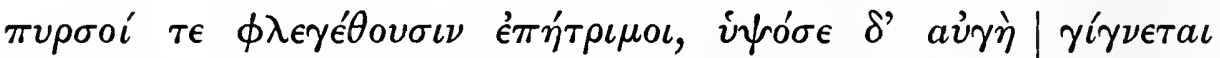

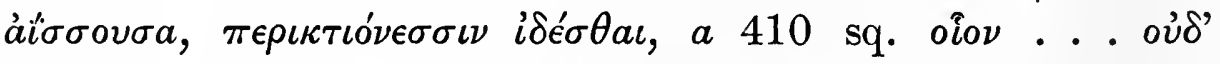
i $\pi \epsilon \in \epsilon \iota \nu \epsilon \mid \gamma \nu \omega ́ \mu \epsilon \nu a \iota$, 'nec remansit ut (eum) nosceremus,' ‘ 143

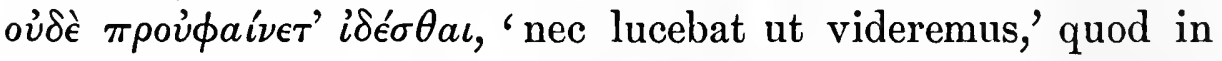
hac constructione unum est exemplum verbi impersonalis.

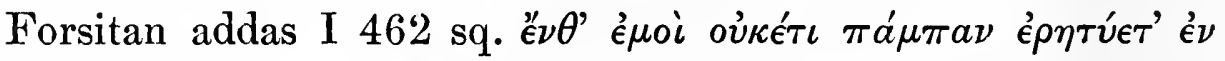

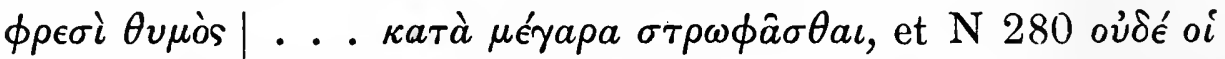

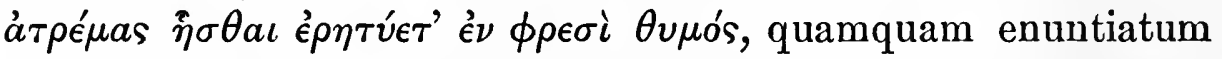

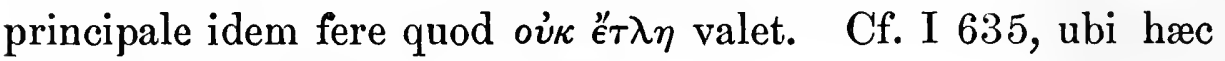
vox absolute posita est.

De aliis constructionibus in genere III. - Cum pro infinitivis huius generis participium futuri non substituatur apud Homerum, ${ }^{3}$ sola enuntiata adverbialia et relativa sunt tractanda. Quæ in parte priore admodum raro pro infinitivo posita sunt,

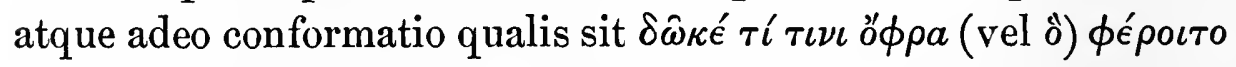
videtur omnino inusitata. Sed alia verba, quibuscum infinitivus non inveteravit, enuntiata finalia nonnumquam adsciscunt: $\theta$

${ }^{1}$ Non est necesse, $\sigma \chi \epsilon \delta i \eta \nu$ accusativo audito, verbum transitive dictum statuere, cf. Meierheim, op. cit., p. 42.

${ }^{2}$ Ameis-Hentze, et Monro in editione Odysseæ XIII-XXIV, Oxf. 1901, ad loc., infinitivo ḋ $\sigma \pi \alpha \sigma i \omega s$ adverbium definiri arbitrantur, 'gratum, quod cenam curare possit, est ei solem occidere.' Sed fieri non potest quin vocabula coniuncta sint alio modo: 'gratum est ei solem occidere, ut cenam curare possit.'

${ }^{3}$ In lingua Latina participium quod gerundivum vocatur in locum infinitivi succedit, vide Draeger, Hist. Syntax der lat. Sprache, ed. 2, vol. II, pp. 822 sqq. 


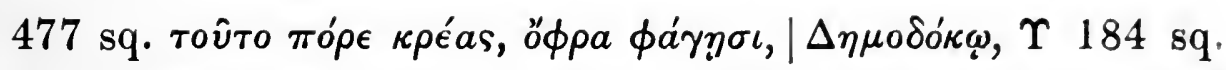

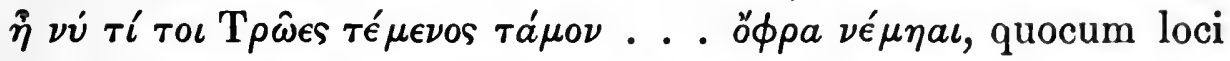

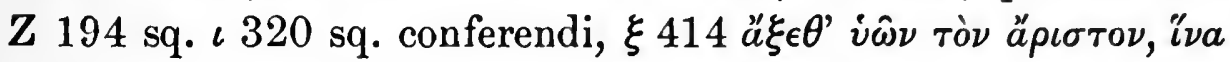

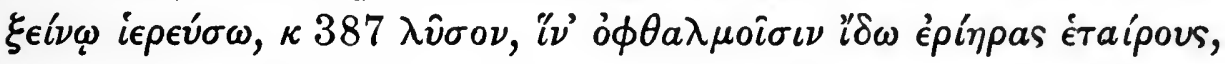

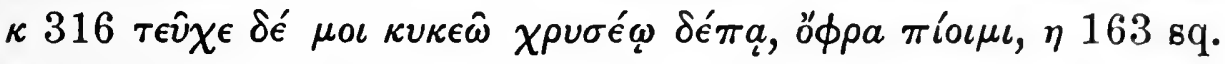

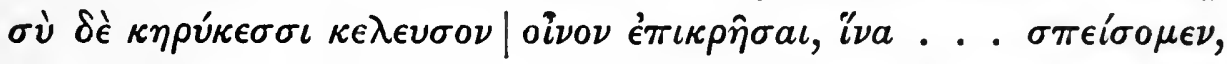
ef. $\eta 179$ sqq. $\quad$ Z 258 sqq. Duo tantum enuntiata relativa hic

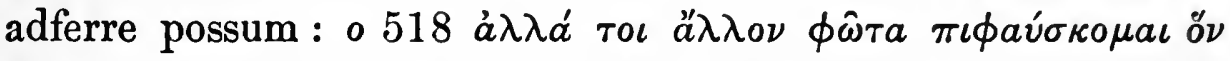

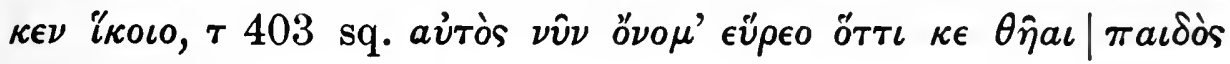
$\pi a \iota \delta i \phi i \lambda \omega .^{1}$

In altera parte, ubi laxius infinitivus cum enuntiato principali coniunctus est, plura exempla præsto sunt ad comparandum;

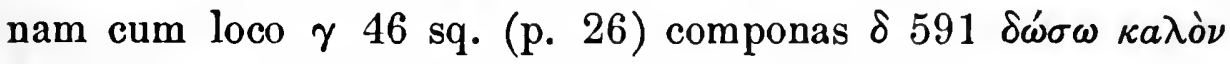

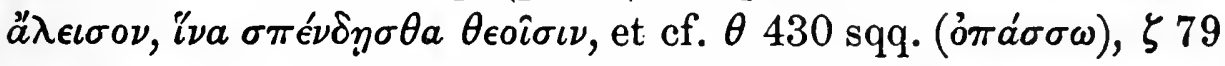

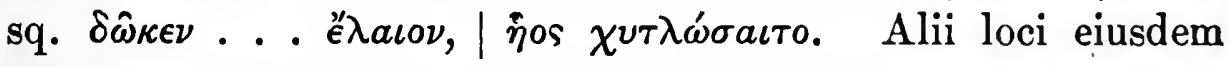

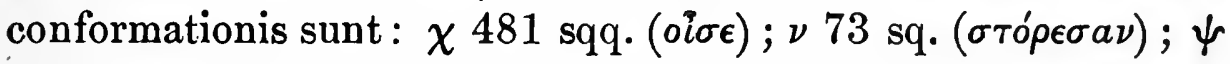

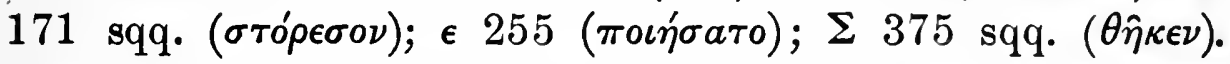
Nec raro enuntiata finalia cum vocibus quæ 'facultatem dare'

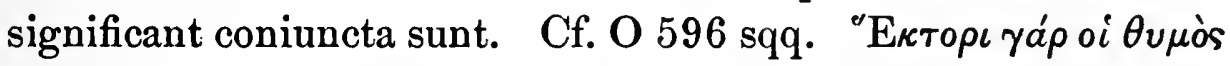

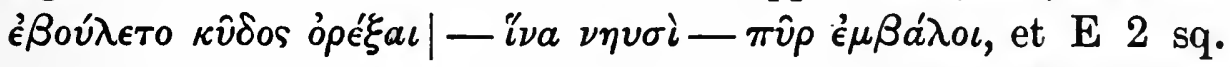

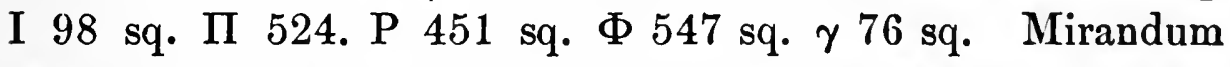
est autem enuntiata relativa vix inveniri præter hæc : $\triangleleft 356$ i $\nu a$ $\tau o \iota \delta \hat{\omega} \xi \epsilon i \nu l o \nu \grave{\phi} \kappa \epsilon \sigma \dot{v} \chi a i ́ p \eta s$, et fortasse $\Xi 240$ sq. $\dot{v} \pi \dot{o} \delta \dot{\epsilon} \theta \rho \hat{\eta} \nu v \nu$

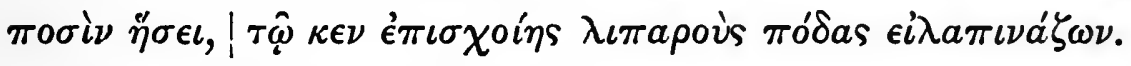

De constructione mutata. - Iam (p. 27) exempla enarravimus in quibus constructiones generis IIIa et IIIb mixtæ sunt, sed etiam ad infinitivum generis III, mutato subiecto, infinitivus

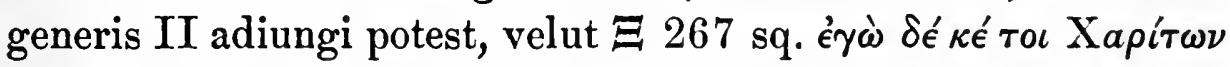

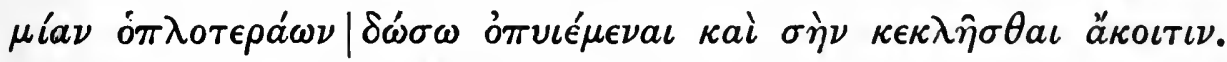

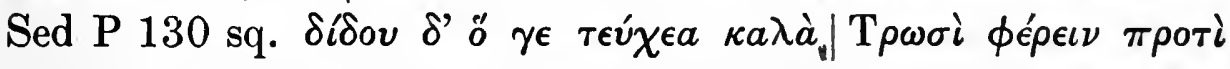

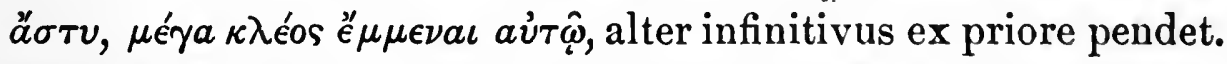
Infinitivum finalem excipit enuntiatum finale $\Lambda 704$ sq. (cf. p. 22, n. 1). $\pi 83$ sq. 296 sq. $\tau 197$ sq., enuntiatum expectationem significans (cum $\left.a \iota^{\prime} \kappa \epsilon\right) ~ \Lambda 798$ sqq. $\Pi 40$ sqq. $\Sigma 211$ sqq.

${ }^{1}$ V. 1l. $\theta \epsilon i \eta s, \theta \epsilon \hat{\imath}$. 


\section{CAPUT IV}

\section{INFINITIVUS PENDET EX ENUNTIATO STATUM SIGNIFICANTE}

Infinitivi huius generis vix appellandi sunt finales, quoniam finis in agendo solet esse situs ; sed cum id notent quod e statu rerum fieri potest, (quare non male 'potentiales' eos dicas), vim consecutivam habere videntur adeo ut eos sub hanc constructionem subicere liceat. Sed ut appareat inter hos et illos quos supra tractavimus rationem quandam intercedere, hæc exempla

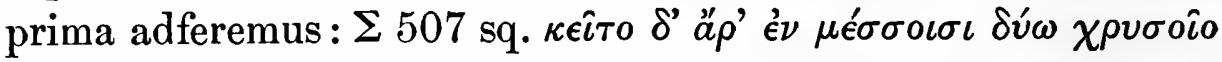

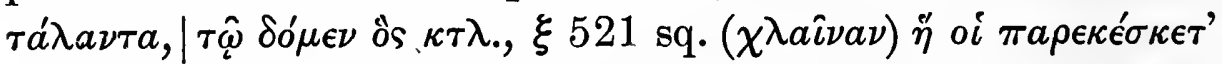

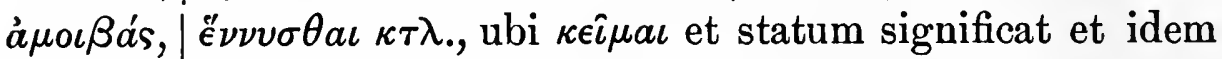

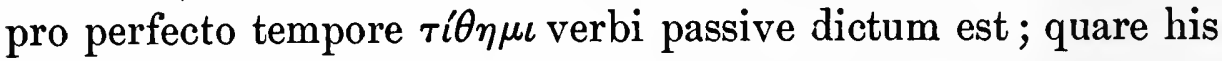

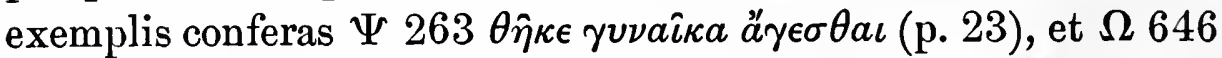

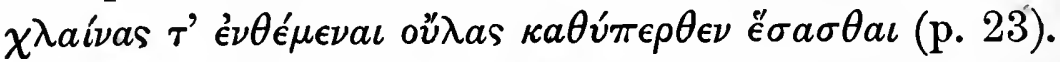

Sed in plerisque huiusmodi enuntiatis verbum substantivum aut positum aut audiendum est; ex quibus ea quæ positionem

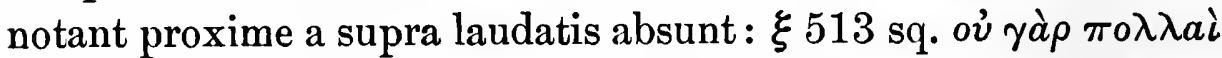

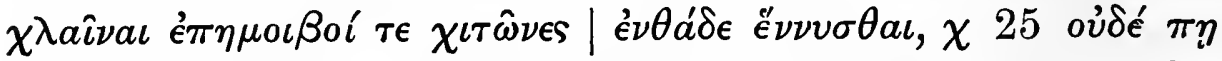

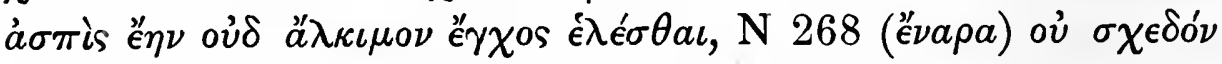
$\grave{\epsilon} \sigma \tau \iota \nu$ é $\lambda \epsilon ́ \sigma \theta a \iota$, quæ omnia cum exemplis generis IIIa compa-

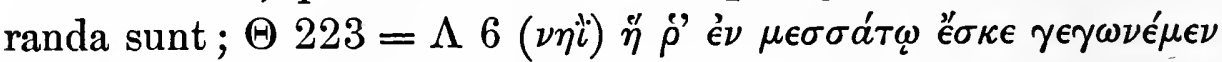

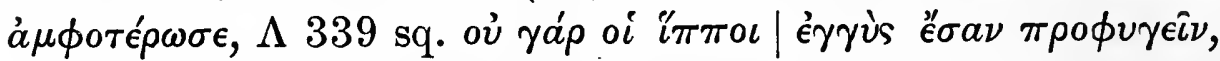

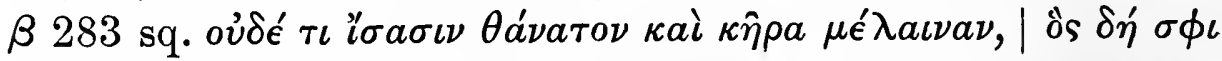

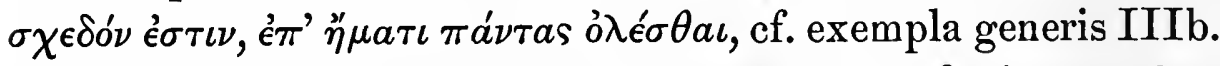

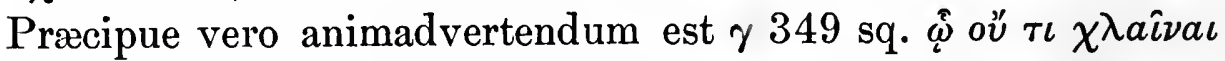

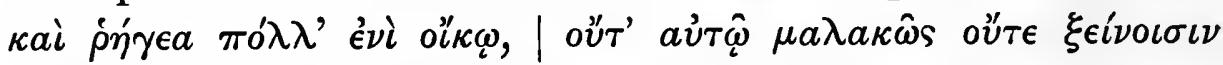
$\dot{\epsilon} \nu \epsilon u ́ \delta \epsilon \iota \nu$, ubi verbo cum $\dot{\epsilon} \nu$ composito indicatur subiectum enuntiati principalis locum significare in quo fiat actio infinitivi. ${ }^{1}$ Constructio quæ generis I habet similitudinem est T $140 \delta \hat{\omega} \rho a \delta^{\circ}$

${ }^{1}$ Vide Kühner-Gerth, Gramm., § 473, n. 12. 


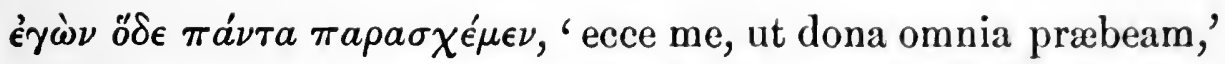

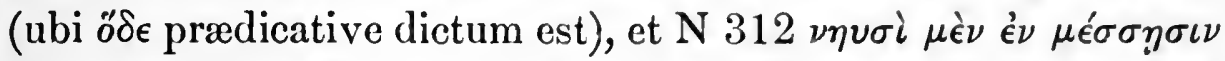

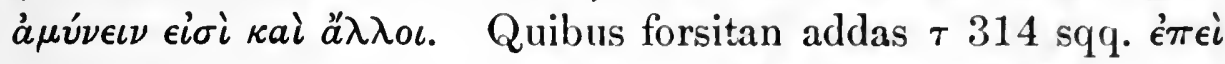

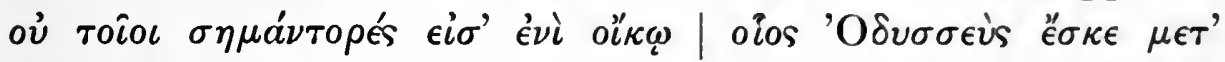

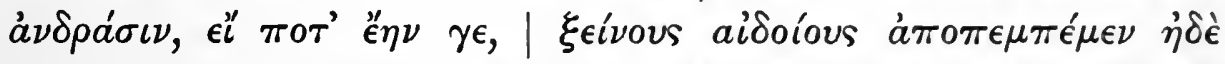

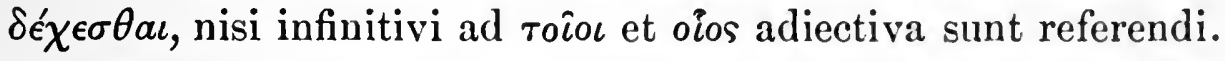

Notionem possessionis ex positionis facillime exsistere apparebit, collatis exemplis in quibus est $\pi a ́ p a$, 'præsto' (est,

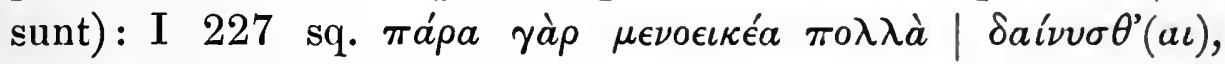

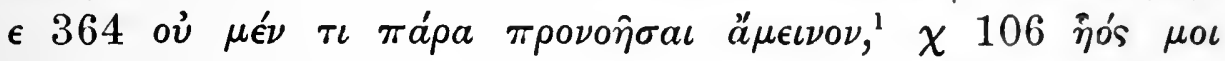

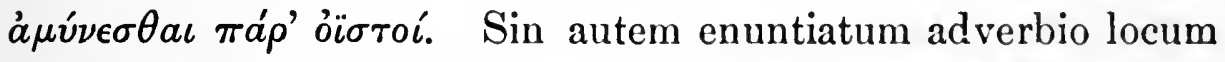
notante caret, possessionem apertius significat. Cf. Z 227 sqq.

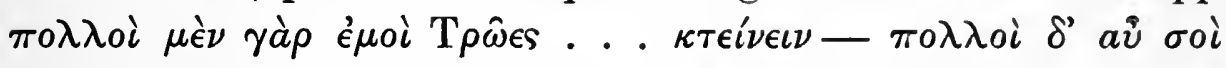

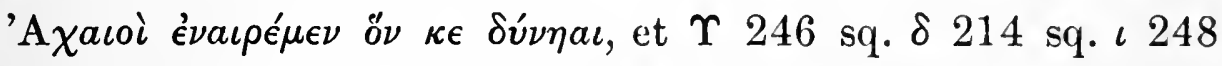
sq. $\xi 193$ sqq. $\sigma 371$, quæ exempla habent similitudinem generis

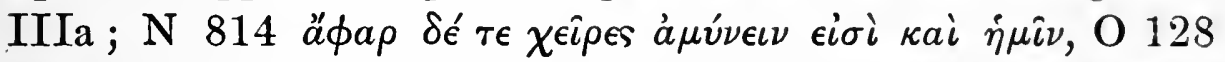
sq. $a 261$ sq. $\chi 116$, quibuscum confer genus IIIb. Locus $\gamma$ 349 sq. (p. 30) propter dativum huc quoque referri potest.

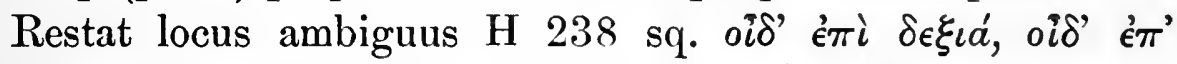

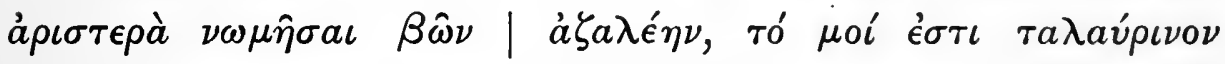
$\pi o \lambda \epsilon \mu i \zeta \epsilon \iota \nu$, quem si cum veteribus interpretemur 'scio versare scutum, quod est mihi quo firmiter pugnem,' exemplum sit constructionis consecutivæ. Sed melius est ró pronomen ad totum enuntiatum antecedens referre, hoc modo: 'scio versare scutum, id quod (quæ scientia) meo iudicio est firmiter pugnare,' ut infinitivum esse prædicative dictum appareat. ${ }^{2}$

Iam ad exempla venitur in quibus verbum substantivum absolute dictum est. Quæ quam parvo discrimine ab iis differant quæ supra tractavimus, apparebit si cum T $140 \delta \hat{\omega} \rho a \delta^{\prime}$

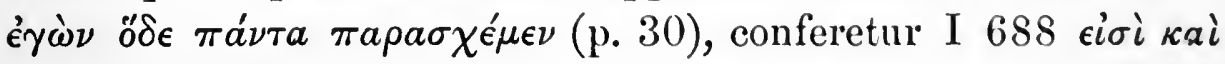

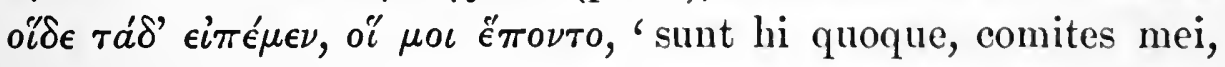

${ }^{1} \mathrm{Si} \pi a ́ \rho a$ impersonaliter dictum statuimus, id quod haud raro fit apud poëtas Atticos, constructio accusativi cum infinitivo coniuncti evenit; sed aliud exemplum huius vocis impersonaliter dicte non est apud Homerum.

${ }^{2}$ Sic Leaf et Ameis-Hentze ad loc. 
qui hæc narrare possint.' ${ }^{1}$ Sed subiectum verbi plerumque nullam ad certam personam vel rem spectat, ut $\xi 496 \mathrm{sq}$. $\dot{a} \lambda \lambda \alpha$

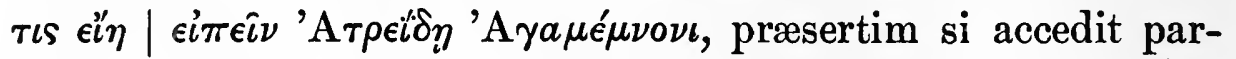

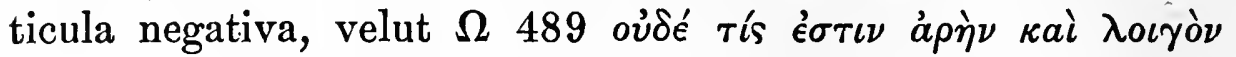
$\dot{a} \mu \hat{v} \nu a \iota . \quad$ Adde $\Omega 610 \mathrm{sq} . \beta 58 \mathrm{sq} .=\rho 537 \mathrm{sq}$. De $o 374 \mathrm{sq}$.

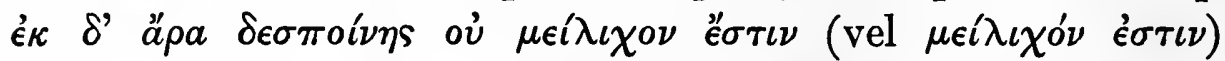

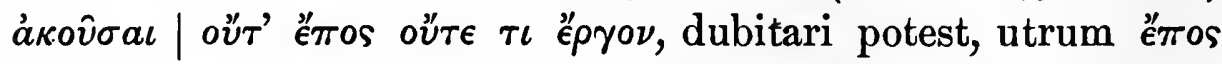
in nominativo positum sit, ut infinitivus sit consecutivus, an in accusativo, verbo impersonaliter dicto, ut constructio sit accusativi cum infinitivo coniuncti, id quod ex ordine vocabulorum veri est similius.

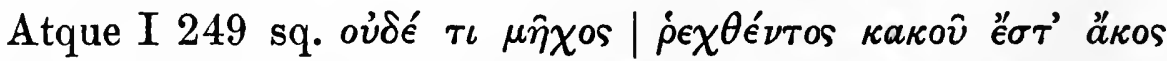

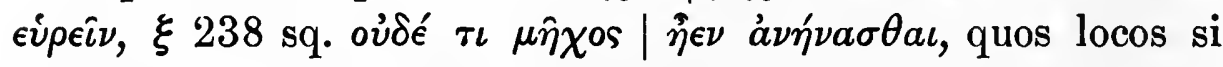
verbum pro verbo reddas, huc referre possis, enuntiatum principale necessario infinitivum adiungit ad sententiam explendam, quare ab hoc genere videntur abiudicandi. Confer constructionem infinitivi cum voce à $\nu a ́ \gamma \kappa \eta(\hat{\epsilon} \sigma \tau i)$ coniuncti, E 633 sq. $\Upsilon 251$ sq.

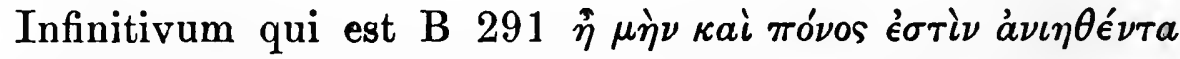
$\nu \in \epsilon \in \sigma \theta \iota$, multi $^{2}$ consecutivum esse statuunt, præsertim cum sententiæ totius loci optime conveniat interpretatio 'profecto labor (tantus) est ut quivis dolens revertatur.' At cum versum a ceteris seiunctum nemo non iudicet hoc significare: 'profecto labor est redire dolentem,' cf. Soph. Antigone 780 móvos

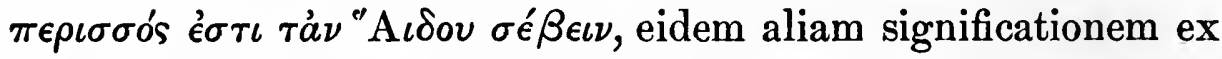
circumiacentibus haustam attribuere haudquaquam licet. Neque similes sunt loci adlati $\lambda 330$ sq., ubi $\Xi \rho \eta \epsilon u \delta \delta \epsilon \nu$ non est 'satis temporis est ad dormiendum,' sed 'tempus est dormire,' et $\beta$ 284 (p. 30), ubi positio adverbio notatur. Quibus de causis non videtur constructio tam dura huic loco inferenda, etiamsi emendationem facere, qualis est van Leeuwenii 'à $\nu$ í $\tau^{\prime}$ eै $\nu \theta^{\prime}$ à $\nu e ́ \chi \epsilon \sigma \theta a \iota$, necesse habeamus.

${ }^{1}$ Male vertit Leaf : 'qui me secuti sunt, hi præsto sunt ad hæc narranda.'

${ }^{2}$ De sententiis variis vide Leaf, et Ameis-Hentze, Anh. ad loc. 
His cum exemplis ea coniungi possunt in quibus alia verba statum significantia inveniuntur, velut $\lambda \epsilon i$ 'то $\mu a \iota$, ' reliquus sum,'

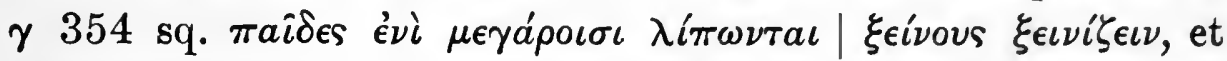
oi $\delta a$, 'scientia rei inest in mente,' B 213 sq. ös $\dot{\rho}$ '

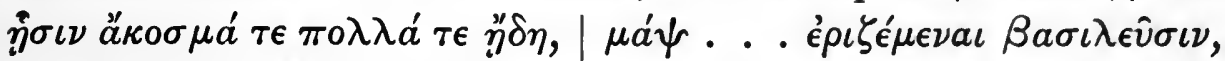

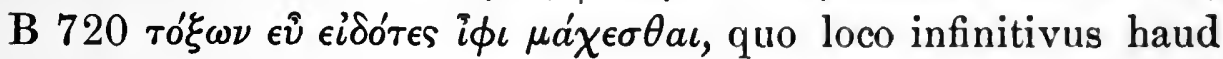
multum abest quin respectum notet. Ambiguus est locus $\pi$

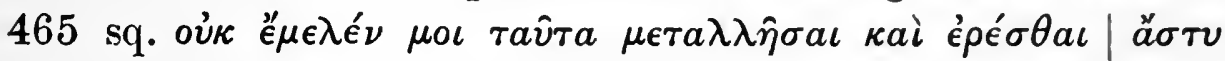
$\kappa a \tau a \beta \lambda \omega \sigma \kappa o \nu \tau a$, nam $\tau a \hat{v} \tau a$ utrum in nominativo an in accusativo sit positum non liquet; sed cum $\mu e ́ \lambda \epsilon \iota$ verbum nullo alio loco apud Homerum impersonaliter dictum sit, nominativus

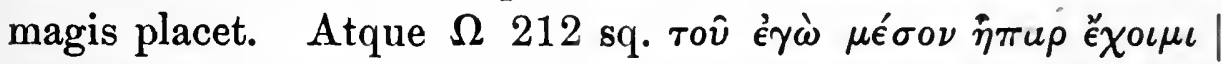

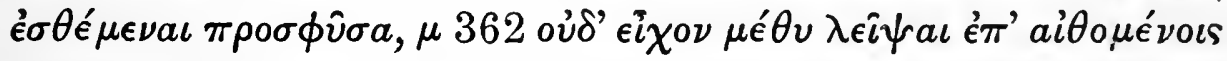

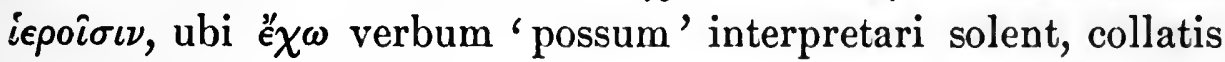
$\sigma 364$ aliisque locis, propriam tamen servare significationem potest, ut infinitivus sit consecutivus : ' . . . habeam iecur quod edim,' 'neque habuerunt vinum quod funderent. . . .' Sed hæc fortasse nimis exquisita nec tantopere infinitivo consecutivo favendum ut aliis constructionibus usitatis omnino præferamus.

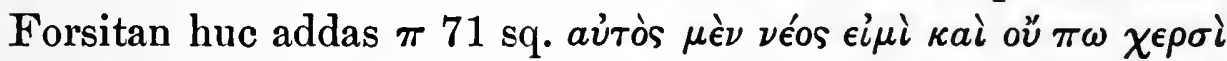

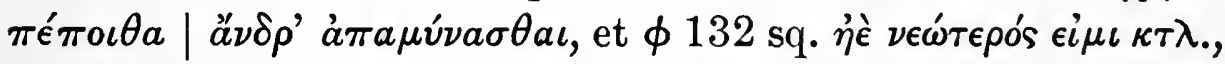
cf. Meierheim ${ }^{1}$ et Ameis-Hentze ad locc.; sed nihil videtur obstare quominus infinitivus ad $\nu$ éos ( $\nu \epsilon \omega ́ \tau \epsilon \rho o s)$ pertineat, voca-

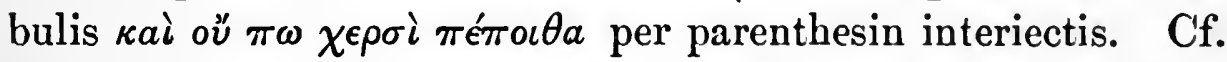

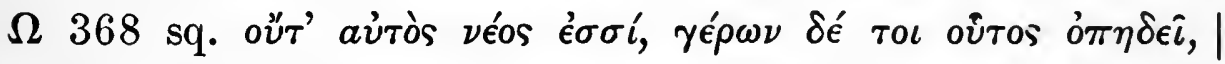
ă $\nu \delta \rho ' a ̀ \pi a \mu \nu ́ \nu a \sigma \theta a \iota$, ubi necesse est infinitivum ex adiectivo pendere, nisi fortasse v. 369 pro interpolato habetur.

Verba egendi, quæ verbis possidendi sunt similia, eadem

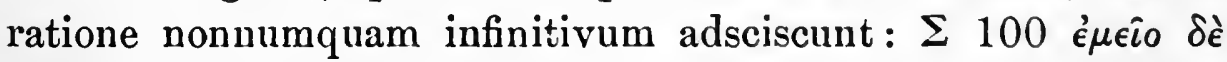

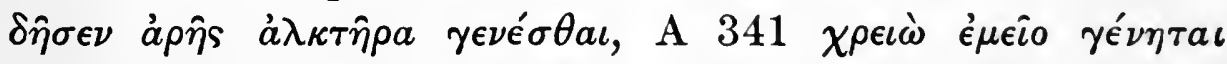

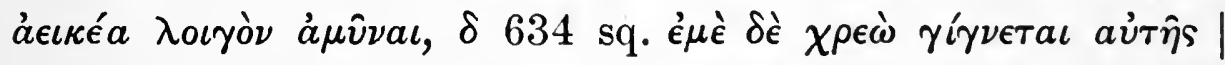

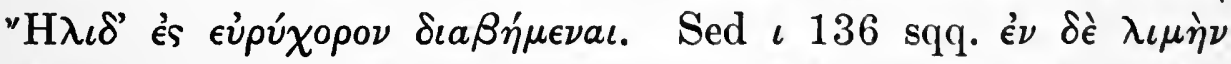

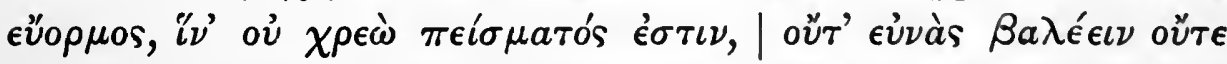

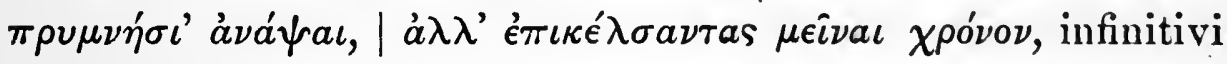

'Op. cit., p. 65. 
ad explicandum enuntiatum principale usurpantur neque effectum notant. Locus in primis dignus qui animadvertatur est Z 462

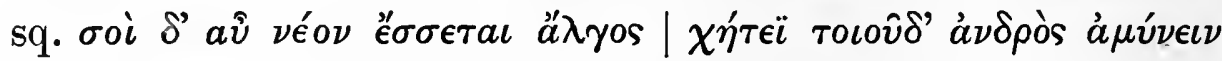

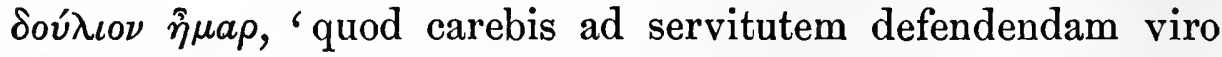
tali (qualis ego sum),' ubi infinitivus pendet a $\chi \eta^{\prime} \tau \epsilon \ddot{i}$ substantivo idem fere quod $\chi a \tau \iota \zeta o v \sigma \eta \eta$ participium valente. ${ }^{1}$

Una reliqua est forma enuntiati principalis, qua in forma est quidem nomen prædicatum, infinitivus autem non ex eo sed ex toto enuntiato pendet. Huiusmodi sunt $\Delta 262$ sq. $\sigma o ̀ \nu ~ \delta \grave{~} \pi \lambda \epsilon \hat{\epsilon} o \nu$

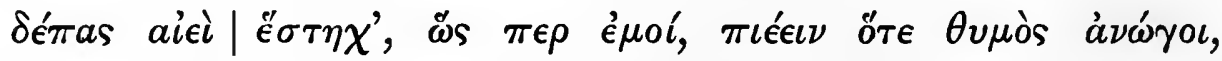

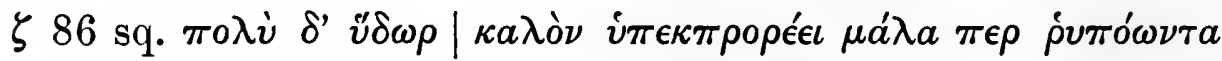
$\kappa a \theta \hat{\eta} \rho a \iota$, ubi $\pi o \lambda \dot{v}$ prædicative dictum est. Sed locis plerisque, ut fert rei natura, est $\epsilon i \mu i$ verbum. Huc in primis referas tria

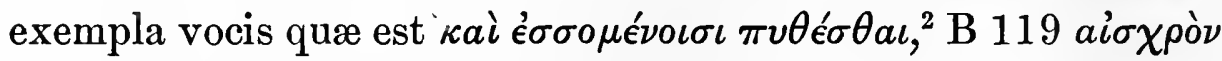

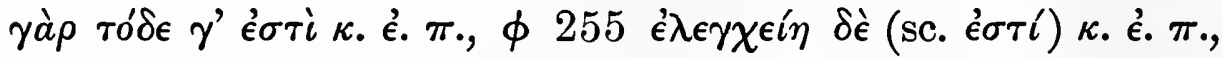

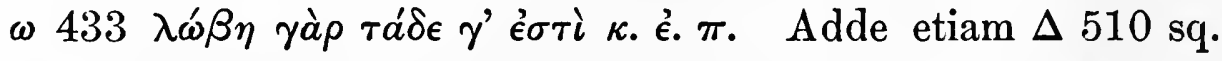

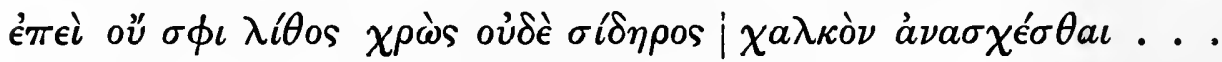

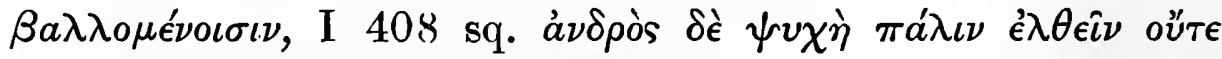

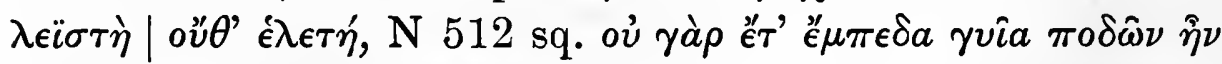

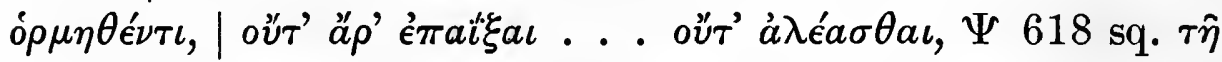

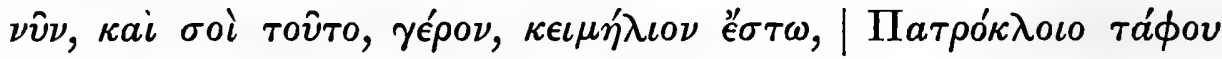

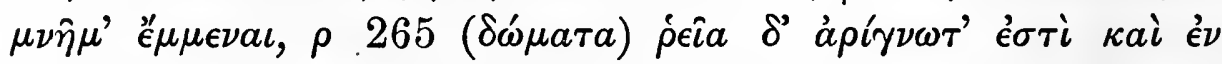

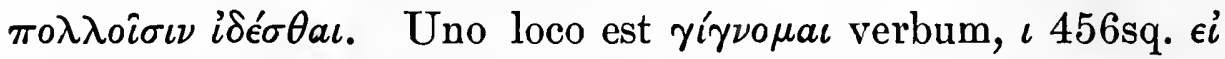

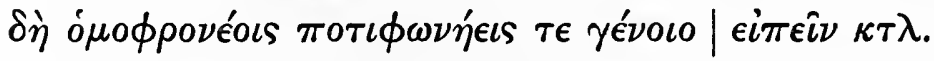

His autem exemplis demonstrari potest quæ ratio huiusmodi infinitivis cum iis qui respectum notant intercedat. Nam ut in

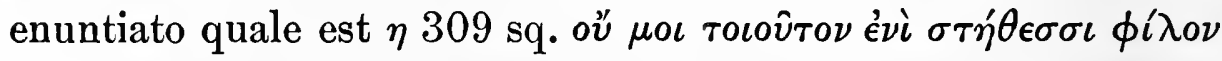
$\kappa \hat{\eta} \rho \mid \mu a \psi \iota \delta$ ' $\omega s \kappa \epsilon \chi o \lambda \hat{\omega} \sigma \theta a \iota$, ' non mihi in pectore cor tale est ut temere sim iratus,' notio effectus inest, sic infinitivus cum

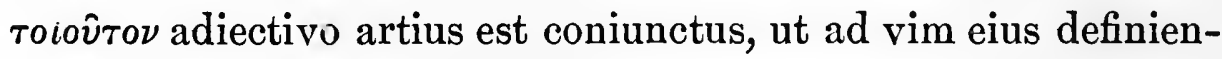

${ }^{1}$ Potest etiam infinitivus ad $\tau o \iota v \hat{\delta} \epsilon$ referri, 'quod carebis viro tanta virtute (quanta ego sum) in servitute defendenda,' vel potius '. . . viro eiusmodi ut servitutem defendat'; sed hæc nimis involuta videntur. Cf. Monro ad loc., in editione quinta Iliadis, vol. I, Oxf., 1899.

${ }^{2}$ Vide p. 24. 
dam usurpari videatur. Sed cum necessarius sit ad explendam sententiam, ab hoc genere seiungendus est. Quæ ratio magis etiam patefiet in enuntiatis comparativis, velut $\Omega 662 \mathrm{sq} . \tau \eta \lambda o^{\prime} \theta \iota$ $\delta^{\prime}{ }^{\prime} \lambda \eta \mid \dot{a} \xi \xi^{\prime} \mu \epsilon \nu$ é $\xi$ ö $\rho \epsilon o s$, ubi si infinitivus plane consecutivus esset, significatio eveniret: 'longe absunt ligna, ut e monte feramus'; sed re vera est illi contraria: 'longius absunt ligna, quam ut e monte feramus.' Hinc apparet infinitivum hoc loco ab $\tau \eta \lambda o^{\prime} \theta \iota$ adverbio maxime pendere. Sed infinitivos tractare qui singula vocabula circumscribunt non est huius operis.

De aliis constructionibus. - Enuntiata finalia cum his infinitivis, utpote qui plerique sint consecutivi, vix possunt

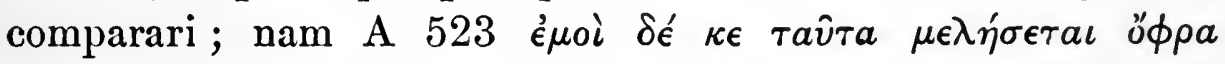
$\tau \in \lambda \epsilon ́ \sigma \sigma \omega$, ö $\phi \rho a$ coniunctio videtur tempus notare, cf. A 82,

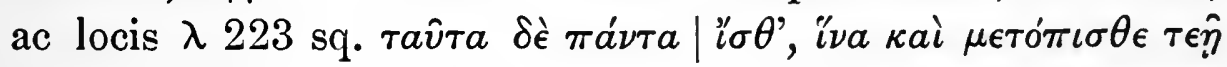

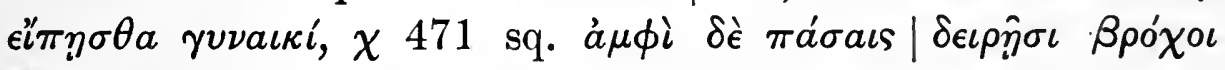
$\hat{\eta} \sigma \alpha \nu$, ö $\pi \omega s$ ök Enuntiata autem relativa sæpe pro infinitivo posita sunt, in quibus optativus solet esse modus, adiuncta $\kappa \epsilon$ particula. Exampla sunt hæc: antecedente voce $\pi a ́ \rho \epsilon \iota \iota \iota(\pi a ́ p a)$ E 192 $=\Xi 299 . \quad \delta 559 \mathrm{sq} .=\epsilon 16 \mathrm{sq} .=\epsilon 141 \mathrm{sq} .=\rho 145 \mathrm{sq} . ;$

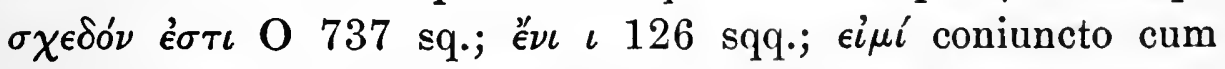
dativo, $\delta 166$ sq.; absolute posito, O 735 sq. His locis omnibus antecedit negatio vel interrogatio quæ est negantis. Alia verba enuntiatum relativum adsciscunt his locis : a 253 sq.

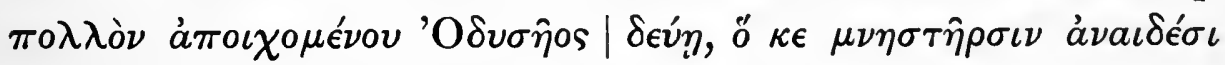

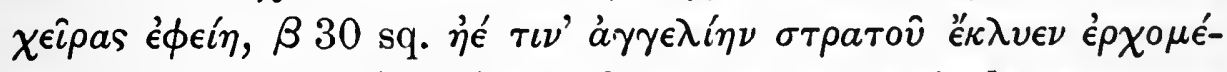

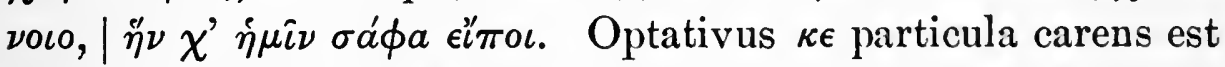

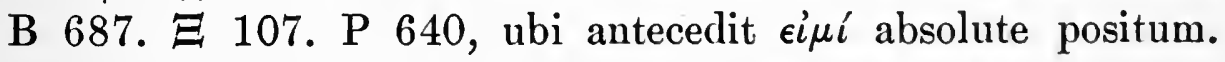
Subiunctivus cum $\kappa \epsilon$ coniunctus duobus tantum est locis, $\beta 42 \mathrm{sq}$.

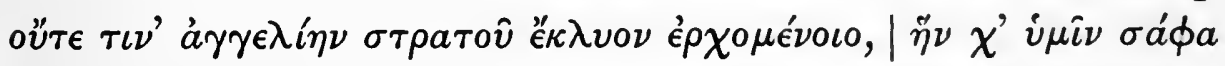

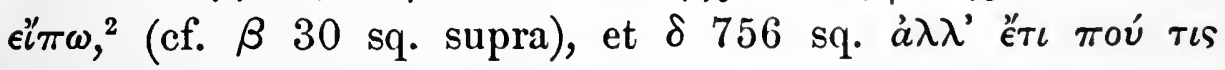

${ }^{1}$ De B 232, vide p. 36 .

${ }^{2}$ Locum suspectum defendit Delbrück, Synt. Forsch., I, p. 41, quod subiunctivo declaretur facilitas eius qui loquitur. Sed nonnulli, velut van Leeuwen et Mendes, ex coniectura Nauckii optativum reponere volunt, quo fiat usitatior modorum consecutio. 


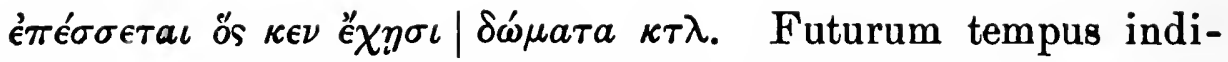

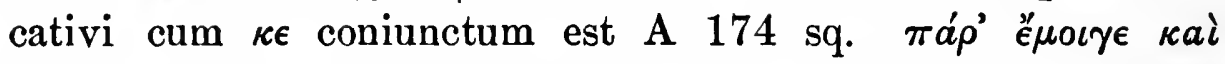

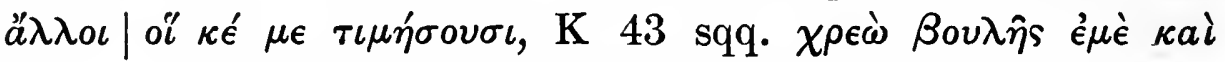

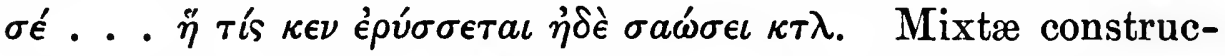

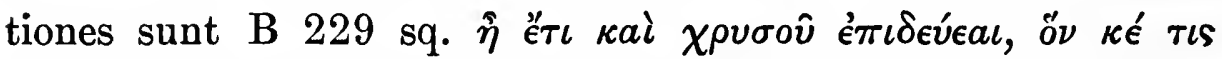

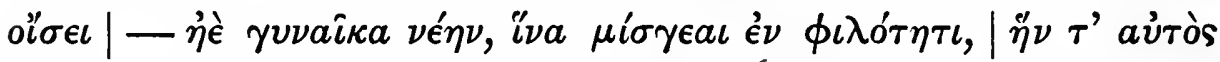

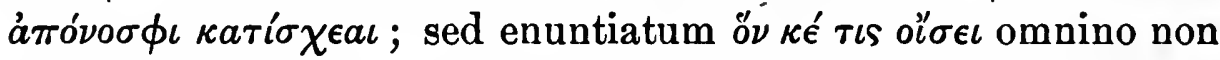
est consecutivum et quæ sequuntur fortasse pendent ex $\dot{\epsilon} \pi \iota \delta \epsilon v \in \epsilon \iota$ tamquam verbo volendi, quod suadet accusativus casus yvvaîka v. 232 . 


\section{CAPUT V}

\section{DE SYNTAXI GENERALI INFINITIVI FINALIS VEL CONSECUTIVI}

Cum iam quomodo infinitivi finales vel consecutivi cum enuntiato principali coniuncti sint exposuerimus, in hoc capite quæ ad eorum syntaxin universe pertinent, velut genera et tempora, breviter tractabimus. ${ }^{1}$

De infinitivi generibus. - Hoc unum est animadvertendum, passivum quod passivam habeat significationem esse rarissimum; nam qui infinitivi forma sunt passivi generis, re non

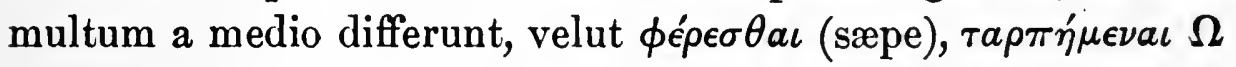
3, $\theta \omega \rho \eta \chi \theta \hat{\eta} \nu a \iota ~ \Pi$ 40. $\chi 139$. Cf. etiam infinitivos qui sunt $\mathrm{E}$ 854. I 463. $\Lambda$ 147. $\Xi 209 . \delta 36 . \kappa 495$. $\xi 411$. Nec vero

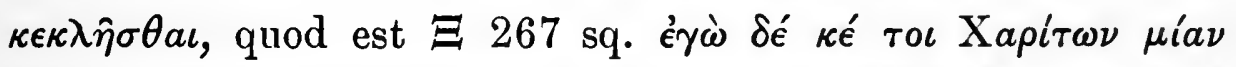

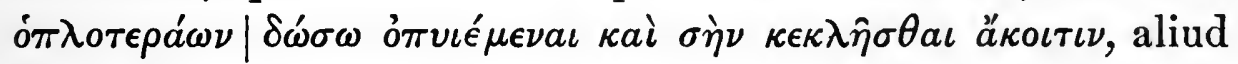
est nisi eiva gravius dictum, cf. $\Gamma$ 138. $\Delta 60$ sq. $\Sigma 365$ sq. Significatio autem passiva his locis apparet: N $602 \mathrm{sq} . \tau \grave{\nu} \nu \delta^{\prime}$

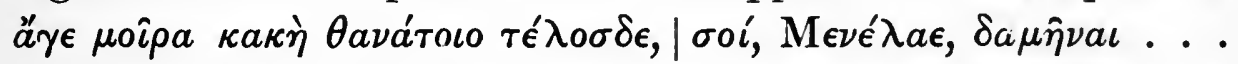
(sed fortasse infinitivus per epexegesin positus est); $\Omega 15$ "Ектора $\delta$ ' ‘̈ $\lambda \kappa \epsilon \sigma \theta a \iota \delta \eta \sigma a ́ \sigma \kappa \epsilon \tau o ~ \delta i ́ \phi \rho o v ~ o ̈ \pi \iota \sigma \theta \epsilon \nu$, quo loco si infinitivus active dictus esset, dura fuisset constructio generis primi. (De $\check{\epsilon}^{\prime} \lambda \kappa \epsilon \sigma \theta a \iota$ infinitivo medii generis non est cogitandum). Solet autem passivum vitari, constructione generis IIIa pro generis II posita, velut $\Psi 183 \delta \omega \dot{\sigma} \sigma \omega \rho \iota a \mu i \delta \delta \nu \pi v \rho \grave{\delta} \delta a \pi \tau \epsilon \epsilon \epsilon \nu$, pro eo

${ }^{1} \mathrm{Ut}$ appareat quibus in exemplis nitatur hæc disputatio, adnotandun est et ambigua prætermitti, quæ pp. 10 sq., 17 sq., 24 sq. tractata sunt, et quæ singula variis de causis ab hac constructione secrevimus. Vide P 489 sq. (p. 11); ‘ 486 $=542$ (p. 16); II 861 (p. 17); A 291 (p. 23, n. 2); $\theta 188$ sqq. (p. 23, n. 3) ; $\psi 78$ sq. (p. 26) ; B $643 . \lambda 524$ sq. (p. 27 , n. 1 ) ; H 238 sq. (p. 31 ); o 374 sq. I 249 sq. $\xi 238$ sq. B 291 (p. 32); $\Omega 212$ sq. $\mu 362 . \pi 71$ sq. $\phi 132$ sq. । 136 sqq. (p. 33). 
quod sit $\delta \omega \sigma \omega \ldots \delta a^{\prime} \pi \tau \epsilon \sigma \theta a \iota$, neque aliter res se habet in genere IV. ${ }^{1}$

Nec mirum si passiva significatio huic constructioni minus convenit; nam siquidem infinitivus initio fuit nomen actionis neque habuit ullum generis discrimen, ${ }^{2}$ coniciendum est passivum in recentioribus constructionibus, ne ambiguitas exsisteret, adhiberi cœptum, eoque minus in simplici atque aperta esse usitatum. Sed fatendum est nonnumquam in exemplis nostris ambiguitatem quandam tolerari, velut a 410 sq. ov่ $\delta$ ' $i \pi \epsilon ́ \mu \epsilon \iota \nu \epsilon$ $\gamma \nu \omega ́ \mu \epsilon \nu a \iota$, qui locus aut 'neque exspectavit dum nosceret' aut 'neque exspectavit dum nosceretur,' quæ vera est significatio, verti potest.

De infinitivi temporibus. - Tempora horum infinitivorum non declarant actio infinitivi utrum ante enuntiati principalis an postea an eodem tempore fiat; sed hoc tantum, per spatiumne, ut in præsenti, an puncto temporis, ut in aoristo, fiat, an denique sit perfecta. Quorum trium temporum præsens et aoristum maxime usurpantur, perfectum autem, ut rei natura fert, multo

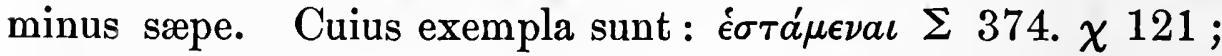

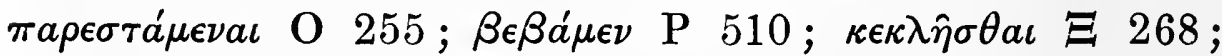
$\pi \epsilon \pi \nu \hat{v} \sigma \theta a \iota \kappa 495$; ac fortasse $\gamma \epsilon \gamma \omega \nu \epsilon ́ \mu \epsilon \nu \Theta 223=\Lambda 6 .^{3}$ Temporis futuri, cui proprius in oratione obliqua locus est, non sunt

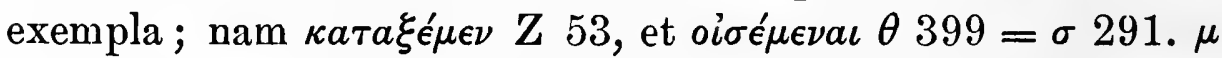
10 , sunt aoristi mixti quod vocatur. Nec locus O 544 sq. $\tau \grave{\omega}$

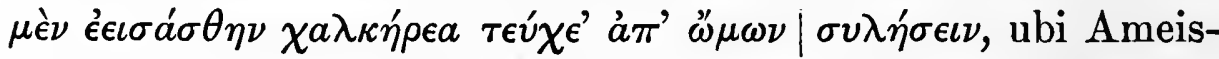
Hentze infinitivo sensum finalem tribuunt, huc est referendus,

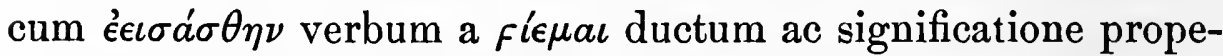
randi præditum optime possit infinitivum adiungere ad sententiam explendam. Similis usus temporis futuri est in infinitivis qui cum verbis $\mu e^{\prime} \mu о \nu a$ M 197 sq. aliisque locis, é $\phi о \rho \mu a ́ o \mu a \iota$ $\phi 399$ coniuncti sunt. ${ }^{4}$

${ }^{1}$ Cf. $\theta a \hat{v} \mu a ~ i \delta € \sigma \theta a \iota$ aliosque infinitivos cum adiectivis coniunctos.

${ }^{2}$ Brugmann, Gr. Gramm., ed. 3, §570.

${ }^{3}$ Vide van Leeuwen, Ench., §260, qui hanc formam ad aoristum refert.

${ }^{4}$ Vide Hentze, C., Idg. Forsch. 22, p. 289. 
De nominibus prædicatis cum infinitivo coniunctis. - E vocibus quæ ab infinitivo pendent sola nomina prædicata digna sunt memoratu. Quod enim vocabulum est quasi subiectum infinitivi, eius casum sequi solent, ut nominativus ad nominativum relatus sit, H 75. $\lambda 493$ (gen. I), $\Psi 618$ sq. (gen. IV); accusativus ad accusativum, ut sæpe fit in genere II ; ac dativus ad dativum, $\kappa 494$ sq. (gen. IIIb), $\Delta 510$ sq. $\gamma 349$ sq. $\iota 248$ sq. (gen. IV). Sed nomine prædicato arte cum infinitivo coniuncto, accusativus pro dativo esse potest, velut $\beta 284 . \xi 195$.

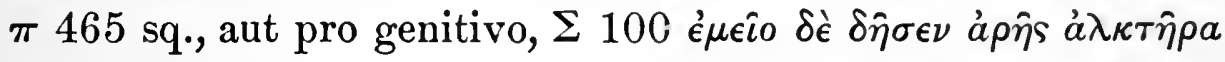
$\gamma \in \nu \epsilon \in \sigma \theta a \iota$. Quæ res cum in aliis constructionibus infinitivi ${ }^{1}$ tum in hac quoque documento est accusativum cum infinitivo coniunctum iam apud Homerum increbruisse adeo ut in alienis conformationibus nonnumquam exsisteret.

De ordine verborum. - Infinitivus finalis vel consecutivus cum vocabulis quæ ab eo pendent enuntiatum principale ex ipsa natura sequi solet, sed ita ut in fuso sermone epico membrum quod sit laxius ad hoc relatum post illum sæpe collocatum sit,

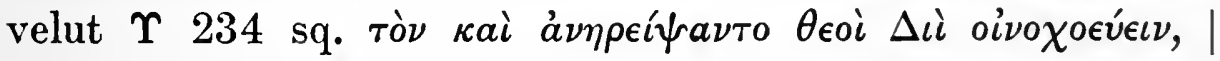

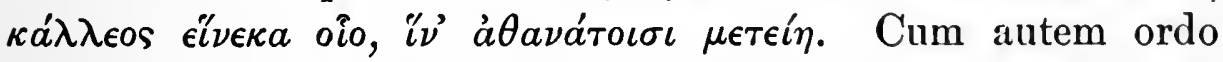
verborum in carminibus epicis sit magna ex parte in re metrica et rhythmica situs, omissa quæstione universa, ea exempla potissimum adferam quæ ab ordine solito discedere videntur.

Nam si qui infinitivus cum verbo principali unam notionem efficit, proximum ei locum tenere solet; quare nonnumquam fit ut vocabula cum enuntiato principali necessario coniuncta infinitivum sequantur et quæ ad infinitivum relata sint verbo antecedant. Cuius ordinis exempla satis multa sunt in certis conformationibus $\beta \hat{\eta} \delta$ ' iévaı similibusque generis I, et $\pi \varepsilon \mu^{\prime} \mu \epsilon$ $\nu \epsilon^{\prime} \epsilon \theta a \iota$ generis II, cf. $\Phi 598 . \delta 8 \mathrm{sq} . \phi 374 \mathrm{sq} . \psi 23 \mathrm{sq}$. Sed in aliis vocibus usitatis infinitivus, cum vim propriam servet, sæpe tamen proxime verbum collocatus est, velut $\pi \dot{\epsilon} \mu \pi o \nu$

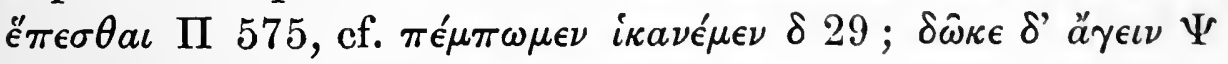

${ }^{1}$ Vide Monro, Hom. Gramm., § 240. 


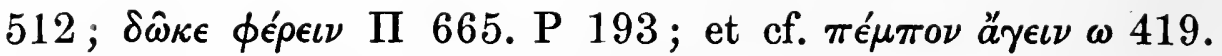

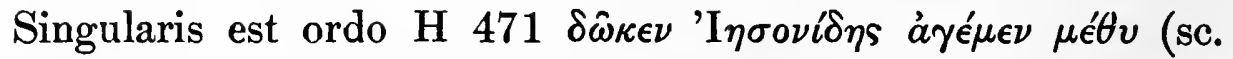

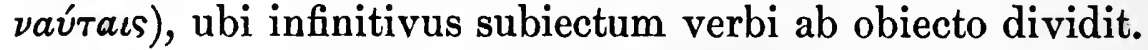

Iam fieri potest ut vocabulum ab infinitivo pendens et quod pronomen esse solet, in enuntiatum principale traiectum sit,

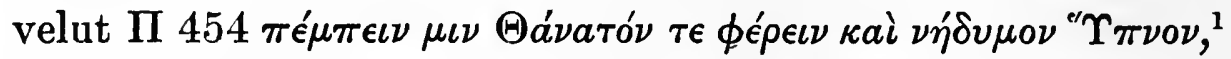

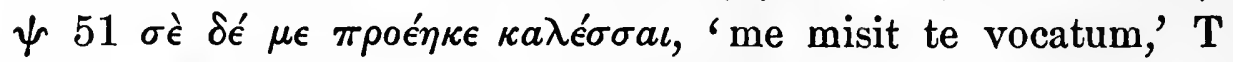
$140 \delta \hat{\omega} \rho a \delta^{\prime} \epsilon^{\epsilon} \gamma \dot{\omega} \nu$ ő $\delta \epsilon \pi a^{\prime} \nu \tau a \pi a \rho a \sigma \chi \epsilon ́ \mu \epsilon \nu$.

Pauca etiam sunt exempla infinitivi ante verbum collocati,

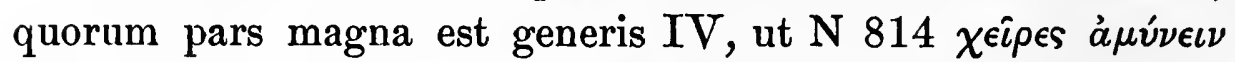
$\epsilon i \sigma i \kappa a i \quad \dot{\eta} \mu \hat{\imath} \nu$, cf. $\mathrm{N} 312.0128$ sq. $\chi 106.116$. Hic enim infinitivus tanto pluris est ponderis quam verbum ut priorem locum occupare liceat; atque eadem ex ratione explicandus est

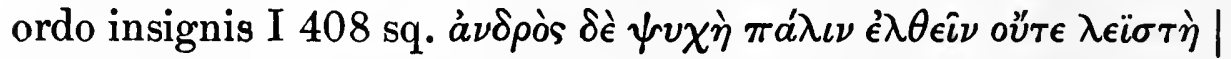

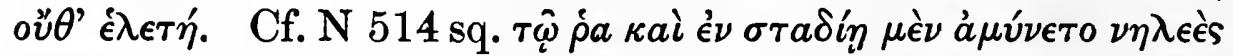

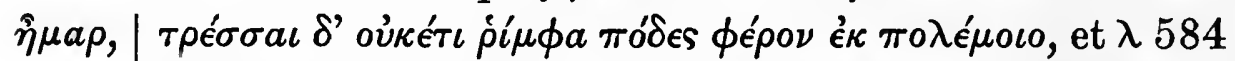

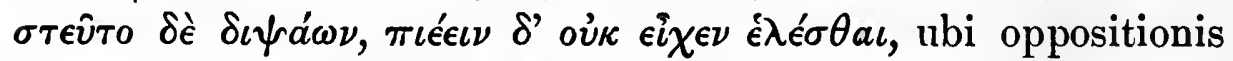
causa infinitivus ad initiun enuntiati traiectus est. In reliquis exemplis, e quibus quinque, I 520. K 562 sq. $\Omega 15 . \theta 399=\sigma$ 291. o 480 sq., sunt generis II, unum, $\epsilon 343$ sq., generis IIIa, causa ordinis minus aperta est; sed fortasse inde conici potest infinitivum iam artius cum enuntiato principali coniungi cœptum, ut ex additamento quodam sententiæ pars necessaria fieret.

${ }^{1}$ Cf. p. 15, n. 3. 


\section{CAPUT VI}

QUA DE hUIUS CONSTRUCTIONIS USU hOMERICO CONCLUDI POSSUNT

Quamquam constructio infinitivi finalis vel consecutivi non semper ab aliis plane discerni potest, nonnihil proderit ad summam rei tractandam exempla cuiusque generis, ut in re sane lubrica potest, enumerare. ${ }^{1}$

Hæc igitur verba ${ }^{2}$ infinitivos ${ }^{3}$ his locis adsciscunt:

in genere I

Verba Infinitivos Iliad. Odyss. Locis

\begin{tabular}{|c|c|c|c|c|}
\hline$\beta a l \nu \omega$ & $+i \epsilon$ val & 32 & 41 & 73 \\
\hline "6 & + alios & 9 & 3 & 12 \\
\hline$\mu \alpha \sigma \tau l \zeta \omega$ & $+\epsilon^{\lambda} \lambda \alpha^{\prime} a \nu$ & 3 & 4 & 7 \\
\hline alia & + varios & 22 & 7 & 29 \\
\hline
\end{tabular}

in genere II

$\begin{array}{ll}\pi \epsilon \mu \pi \omega & +\nu \epsilon \epsilon \sigma \theta a \iota \\ " & + \text { alios } \\ \pi \rho \circ \eta \eta \iota & + \text { varios } \\ i \eta \mu \iota & + \text { + } " \\ \text { alia } & +\epsilon i \nu a \iota \\ " & +\gamma s \nu \epsilon \sigma \theta a \iota \\ " & \text { + varios }\end{array}$

$\begin{array}{rrc}3 & 4 & 7 \\ 7 & 3 & 10 \\ 11 & 17 & 28 \\ 7 & 3 & 10 \\ 13 & 6 & 19 \\ 2 & 3 & 5 \\ \frac{15}{58} & \frac{13}{49} & \frac{28}{107}\end{array}$

in genere IIIa

\begin{tabular}{|c|c|c|c|c|}
\hline$\delta l \delta \omega \mu t$ & $+\not \gamma \epsilon \iota \nu$ et comp. & 10 & 0 & 10 \\
\hline " & + infinitivos ferendi & 9 & 4 & 13 \\
\hline “6 & + alios & 9 & 6 & 15 \\
\hline alia & + varios & 12 & 20 & 32 \\
\hline
\end{tabular}

${ }^{1}$ De locis prætermissis, vide p. 37, n. 1.

2 Verba composita, excepto $\pi \rho \circ \eta \eta \mu$, sub simplicia subiecta sunt.

${ }^{3}$ Loci in quibus duo aut plures sunt infinitivi ad naturam primi in genera dispertiti sunt. 
Verba Infinitivos Iliad. Odyss. Locis

in genere IIIb

$\begin{array}{ll}\delta i \delta \omega \mu \iota & + \text { varios } \\ \dot{\epsilon} \pi \iota \chi \epsilon \dot{u}^{\prime} \omega & +\nu i \psi \alpha \sigma \theta \alpha \iota \\ \text { alia } & \text { + varios }\end{array}$

in genere IV

$\begin{array}{ll}\text { eiml } & \text { + varios } \\ \text { alia } & +\end{array}$

Summa locorum

\begin{tabular}{|c|c|c|}
\hline 2 & 5 & 7 \\
\hline 0 & 6 & 6 \\
\hline 13 & 12 & 25 \\
\hline
\end{tabular}

His ex numeris, præsertim si enuntiata finalia cum adverbiis coniuncta, quorum summa est $459,{ }^{1}$ comparabuntur, hanc constructionem satis frequentem apud Homerum esse apparebit non modo in Iliade sed etiam in Odyssea recentiore carmine. Sed tamen exemplis diligentius excussis, dici potest in certo genere enuntiatorum proprium ei esse locum; namque in tribus primis eorum quæ definivimus enuntiatum principale solet habere vim 'terminativam,' (siquidem vocabulo a recentioribus ficto uti licet), quæ maxime in verbis qualia sunt $\pi \epsilon ́ \mu \pi \omega$, ï $\mu \iota, \delta i \delta \omega \mu \iota$ eminet. Neque enim casu factum est ut cum his tribus verbis, quæ facillime notionem effectus recipiunt, plurima essent constructionis exempla. Reliquis autem verbis, quæ vim habent circumscriptiorem, infinitivus eiusmodi coniunctus esse solet ut aut ipse talis sit qualis omnibus fere congruat, velut iévaı, $\nu \epsilon^{\prime} \epsilon \sigma a \iota, \phi e^{\prime} \rho \epsilon \theta a \iota$, aut, ut ita dicam, imaginem enuntiati cuiusque reddat, paulum immutata notione, velut $\Lambda 568 \tau \rho \omega \pi a ́ \sigma \kappa \epsilon \tau o$

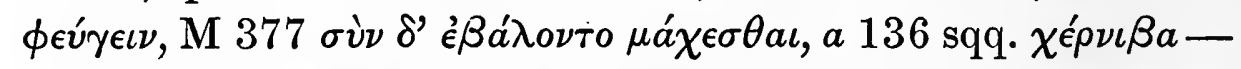

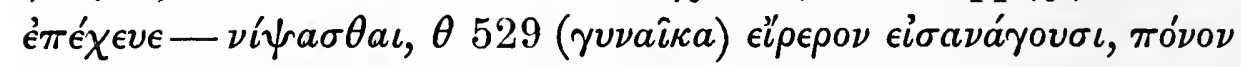

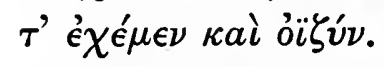

Hoc igitur dici potest, infinitivum non quemvis effectum sed eum qui natura vel etiam necessario fiat significare solere. ${ }^{2} \mathrm{Nec}$

${ }^{1}$ Weber, Absichtssätze, Pars I, p. 32. Enuntiata in quibus $\mu \eta \dot{~ p a r t i c u l a ~}$ vice coniunctionis fungi dicitur non sunt adnumerata.

${ }^{2}$ Vide quæ in hanc sententiam disputat Stahl, Kritisch-historische Syntax des gr. Verbums, p. 611. 
tamen desunt apud Homerum exempla usus laxioris, in quibus longe alia notio infinitivo atque enuntiato principali inest. Hæc maxime in iis generibus invenias ubi infinitivus aut cum enuntiato principali non est per accusativum ad utrumque relatum coniunctus (I, IIIb) aut proprium ac discretum habet subiectum (IIIa, IIIb). E genere I adferantur exempli causa $\Theta 253$ sqq. N 514 sq. (p. 9), I $322 . \Pi 74$ sq. X 474 (p. 11);

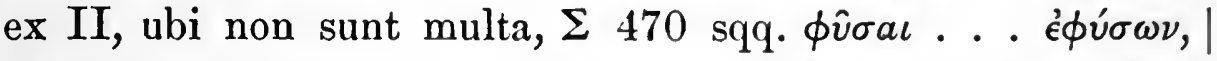

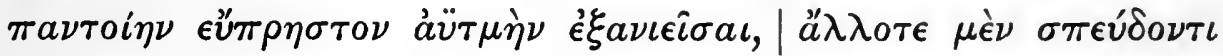

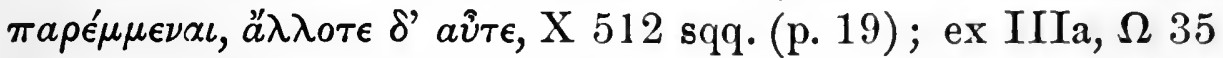

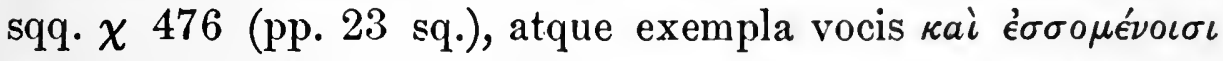

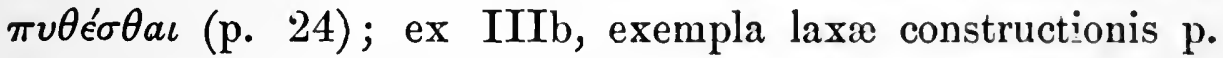
27 laudata ac $\Sigma 211$ sq. a 410 sq. $\nu 33$ sq. o 457 (p. 28). Qui loci, quamquam certo discrimine a ceteris seiungi nequeunt, argumento sunt iam in sermone epico infinitivum ad enuntiati secundarii similitudinem accedere cœpisse, quæ apud scriptores inferioris ætatis, adscita $\omega \sigma \tau \epsilon$ coniunctione, elaborata invenitur.

Sed apud Homerum duo tantum sunt exempla $\tilde{\omega} \sigma \tau \epsilon$ ita usur-

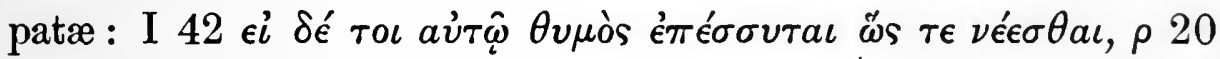

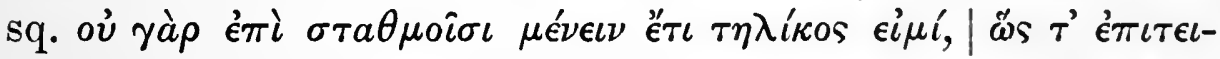
$\lambda a \mu \varepsilon^{\prime} \nu \omega \sigma \mu \alpha^{\prime} \nu \tau o \rho \iota \pi a^{\prime} \nu \tau a \pi \iota \theta \dot{\sigma} \sigma \theta a \iota$, neque quisquam in priore quidem loco, si $\varpi \sigma \tau \epsilon$ deesset, infinitivum esse consecutivum iudicaret.

Melius esse duximus exempla generis IV separatim tractare, quod propriam quandam habent conformationem ; nam quamquam constructio laxa sæpius invenitur, velut $\Theta 223$. $\beta 283$ sq. (p. 30), B 213 sq. 720. (p. 33), ac locis p. 34 excussis, in maiore parte exemplorum enuntiato principali significatur aliquid aut esse aliquo loco aut esse alicui aut esse simpliciter, infinitivo autem id quod per eum statum fieri potest. Ergo cum illo declaretur actio quibus ex rebus fiat, hoc qualis ipsa sit, infinitivus est pars sententiæ gravissima. Quæ res apparet in

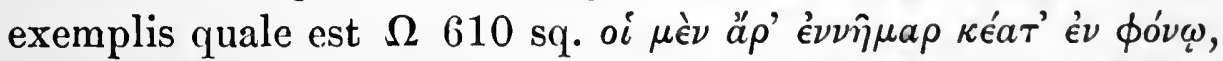

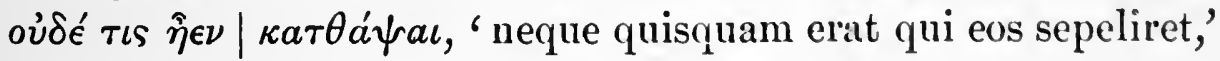


quod, sententia potius spectata, hoc valet: ' nec potuerunt sepeliri, quod nemo erat qui faceret.' Cum autem in eiusmodi locis enuntiatum infinitivo carere non possit, forsitan videantur constructioni consecutivæ abiudicandi ; sed quominus alio referantur hæc res aliquanto est impedimento, quod constructio

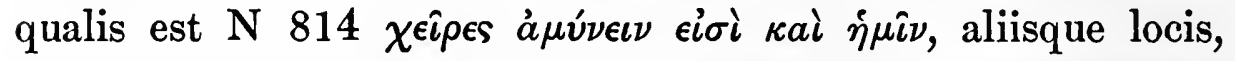
apud scriptores inferioris ætatis non 'multum vigebat, ${ }^{1}$ quippe cuius in locum successisset infinitivus qui subiecti instar e verbo impersonali aut voce idem valente pendet.

Iam si quæritur quare usus infinitivi finalis vel consecutivi apud Homerum non ultra processerit, duæ causæ præcipue sunt adferendæ ; una, quod aliæ constructiones infinitivi iam adoleverant, altera, quod nec forma casualis nec particula auxiliaris ei comitabantur quibus notio finis vel consecutionis plane indicare-

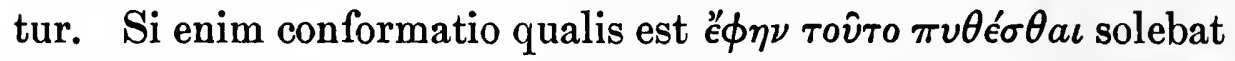
significare: 'dixi me hoc exquisisse,' molestum fuisset si potuisset significare: 'hoc dixi ut exquirerem. . . ' Qua ex re factum est ut infinitivi huiusmodi nisi in conformationibus usitatis ac simplicibus facile usurpari non possent. Quod aliarum linguarum consuetudine illustratur; nam si Vedicam spectamus, in qua infinitivus vim casualem haud obscure servat, huius constructionis usum videmus esse multo laxiorem. Cf. Rigveda 10, 116, 1 píbā sómam mahatá indriyáya, píbā vrtráya hantave, 'bibe somam ad magnum robur, bibe ad Vrtram occidendum.' Rigveda 8, 15, 3 élko vrtrāại jighnase índra jaítrā śravasy⿳亠二⿵冂ca yantave, 'solus hostes occidis, Indra, ad conferendam victoriam gloriamque."

Particulis autem auxiliaribus, quæ in linguis recentioribus infinitivo sæpissime coniunguntur, multumque ad usum finalem vel consecutivum adferunt, sermo Homericus omnino fere caret;

${ }^{1}$ Hic modus dicendi eo minus difficilis nobis quidem videtur, quod multum usurpatur in lingua Anglica; nam N 814 verti potest: 'We have hands to dejend ourselves with.'

2 Plura exempla profert Delbrück, Altindische Syntax, pp. 410 sqq., Kuhns Zeitschr., 18, pp. 94 sqq. 
nam ex iis quæ postea frequentabantur, $\check{\sigma} \sigma \tau \epsilon$, ut ante dictum est, duobus tantum est locis, neque articulus nec $\mu \eta^{\prime}$ vice coniunctionis fungens ${ }^{1}$ usquam infinitivo comitantur. Sed Homerus quod deerat alio modo facile explebat, indicata consecutione per enuntiatum principale adiunctum, velut A 5 multisque aliis locis.

Restat etiam ut quæramus num in is conformationibus quibus infinitivus videtur maxime convenire, aliæ constructiones eum loco movere cœperint. Quibus percensis vix potest adfirmari aut enuntiata relativa in generibus II et IV aut finalia cum adverbiis coniuncta in I, II, III infinitivi usum imminuisse, præsertim cum in IIIa sit omnium longe frequentissimus. Sed de participio futuri, quod est in generibus I et II, aliter res se habet. Nemo enim non animadvertit infinitivum multo

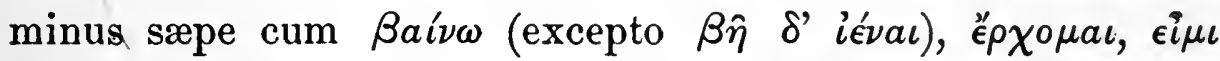
in genere I quam cum $\pi \epsilon \epsilon^{\prime} \mu \omega, \pi \rho \circ i \eta \mu$ in II esse coniunctum. Cuius rei, si ad naturam eorum verborum tantummodo spectamus, nulla exsistit causa ; sin autem intellegimus participium futuri in illo genere frequens, in hoc rarum esse, non est diffi cilis inventu. Nam si quidem id participium principio desiderium seu voluntatem notavit, ${ }^{2}$ desiderium autem solet esse eius qui actionem verbo significatam facit, satis est causæ cur participium apud Homerum plerumque ad subiectum pertineat. ${ }^{3}$ Quare conicere licet in genere I infinitivum iam a participio esse superatum sed in II locum etiam obtinuisse, quod illius usus nondum increbruisset.

1 Vide Brugmann, Gr. Gramm., ed. 3, § 577, 4.

${ }^{2}$ Vide Delbrück, Grundriss, IV, pp. 250 sq.

${ }^{3}$ Vide Hentze, Phil., 65, pp. 164 sqq. 


\section{PARS ALTERA : DE INFINITIVI CONSTRUCTIONE APUD CETEROS POETAS PRISCOS}

\section{Caput I: Hesiodus}

In recensendis exemplis Hesiodeis ${ }^{1}$ eandem quam in Homericis sequemur dispositionem.

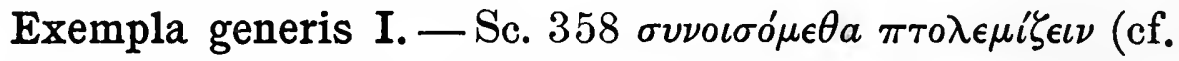

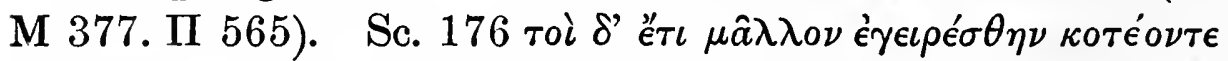

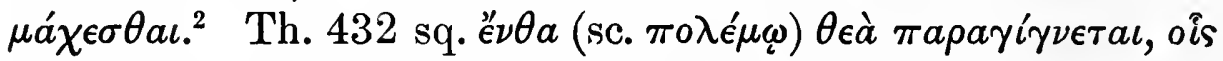

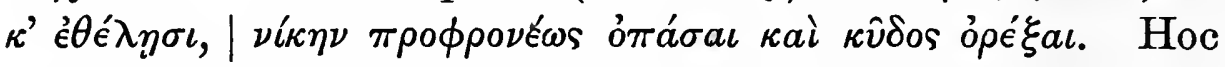
loco Rzachius, omissa distinctione in fine versus 432 , cum editoribus plerisque faciens infinitivos ex é $\theta e ́ t \eta \eta \iota \iota$ pendere indicat, quæ est Steinacheri quoque sententia. ${ }^{3}$ At ois $\kappa^{\prime} \epsilon^{\prime} \theta \hat{c}^{\prime} \lambda \eta \emptyset \iota$ in fine versus positum insequentibus vix coniungi potest, præsertim si conferas vv. 429.430 .439 , ubi non est dubium quin ééé $\lambda \omega$ in enuntiatis eiusdem generis absolute dictum sit.

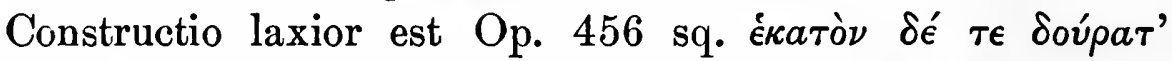

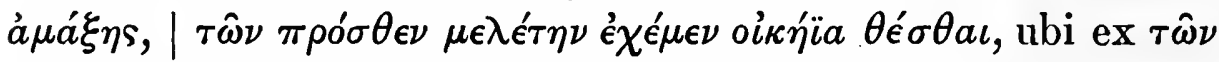
genetivo тá cum $\theta \dot{\epsilon} \sigma \theta a \iota$ audiendum est, $\mathrm{cf} . \Omega 2 \mathrm{sq}$. Plura autem

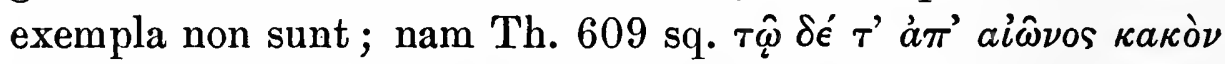
$\dot{\epsilon} \sigma \theta \lambda \hat{\omega} \dot{a} \nu \tau \iota \phi \epsilon \rho i \zeta \epsilon \iota \mid$ é $\mu \mu \epsilon \nu a \iota$ (sic codd.), etiamsi mendosum non esset, alienum videretur, cum infinitivus penderet e verbo certandi, cf. $\Pi 765$ sq. o 321 sq. $\sigma 38$ sq. Sed multo melior est

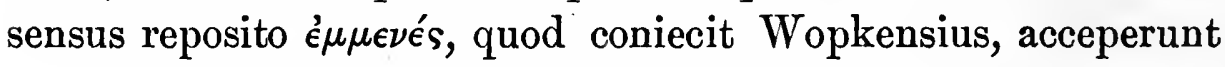

${ }^{1}$ Carmina Hesiodea laudata sunt ex editione maiore Rzachii, Hesiodi Carmina, Lips., 1902. (Th. = Theogonia ; Op. =Opera et Dies ; Sc. = Scutum). De hac quæstione disputaverunt Steinacher, J., Die Syntax des Hesiodeischen Infinitivs, etc., Landskron, 1885, pp. 14 sqq.; Seip, O., De participii et infinitivi apud Hesiodum usu, Diss. Gissæ, 1886, pp. 54-70.

${ }^{2}$ Infinitivus e verbo pendet, non ex participio, ut videtur existimare Rzach, qui post $\epsilon^{\prime} \epsilon_{\epsilon} \epsilon \epsilon \sigma \eta \eta \nu$ distinguit, et Seip, op. cit., p. 59. Similis est sententia

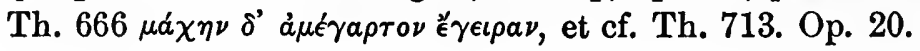

${ }^{3}$ Op. cit., p. 25. 
in editionibus Flachius, Schoemannius, Rzachius. Locus qui est

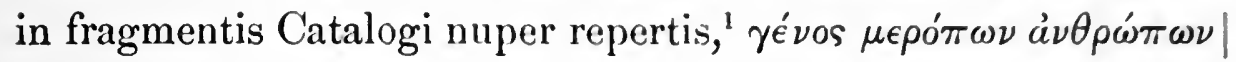

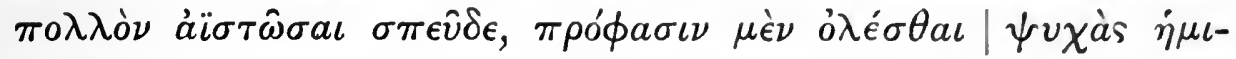
$\theta \dot{\epsilon} \omega \nu . .$, , constructionis consecutive videtur insigne exemplum ; sed vocabula $\sigma \pi \epsilon \hat{\delta} \delta \epsilon \rho o ́ \phi a \sigma \iota \nu$ propter scripturam incertam aliter legi possunt.

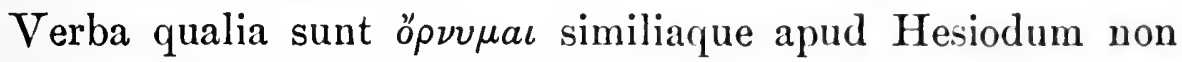
adsciscunt infinitivos qui finales esse videantur; nam in omnibus exemplis, velut Sc. 40. 196, infinitivum explere sententiam iudicandum est.

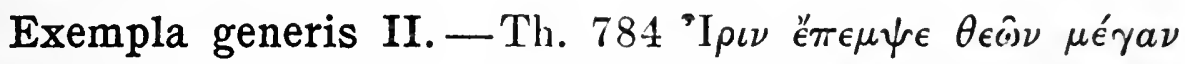

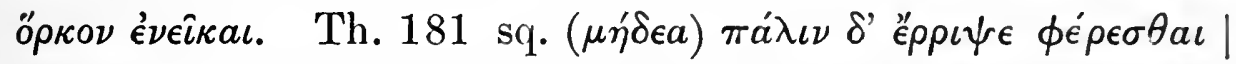
$\hat{\epsilon} \xi \circ \pi i \sigma \omega$. Cum nomine prædicato coniunctus est infinitivus Th.

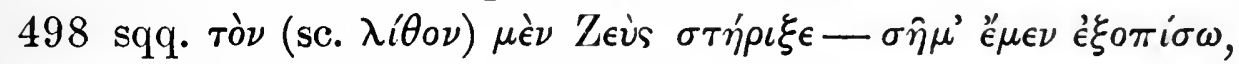

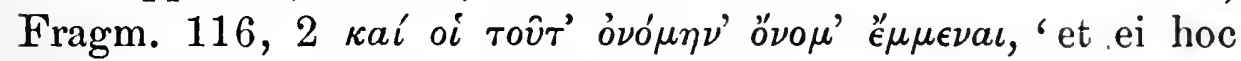

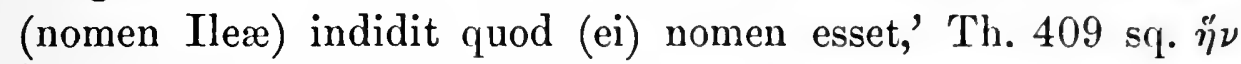

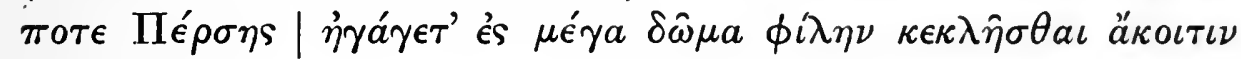
(cf. $\Xi 268$ ).

Exempla generis IIIa.-Th. $819 \delta \hat{\omega} \kappa \epsilon ~ \delta \grave{\epsilon} \mathrm{K} v \mu o \pi o^{\prime} \lambda \iota \iota \nu$

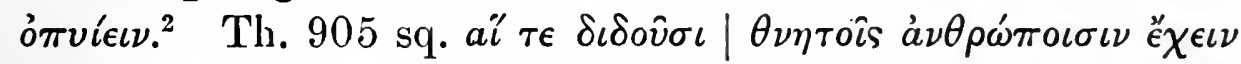

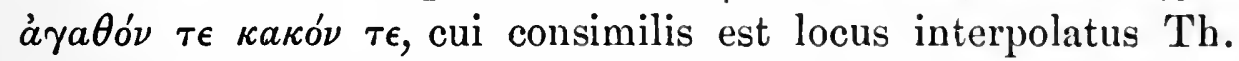

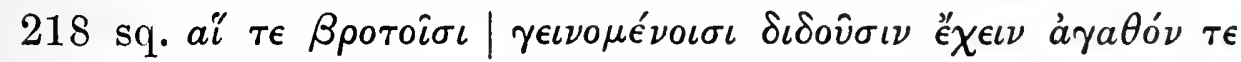

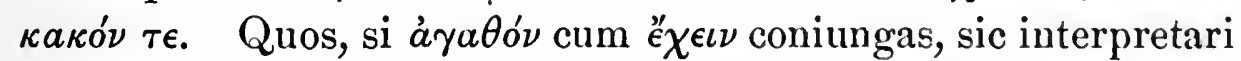
possis: 'quæ mortalibus (hoc) dant, ut habeant bonumque malumque'; sed præstat constructio finalis : ' . . . dant bonaque

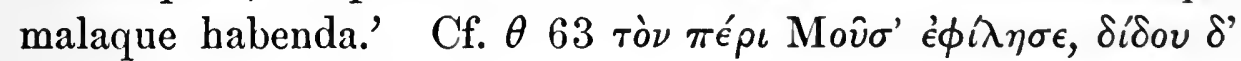

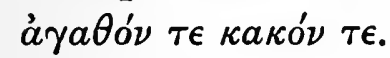

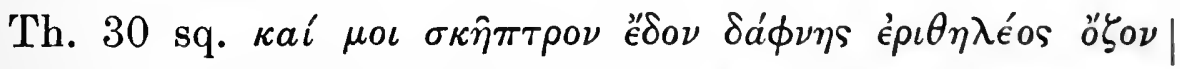
$\delta \rho \varepsilon ́ \psi \mid a \sigma \theta a \iota \theta \eta \eta{ }^{\prime} \nu$ (sic codices melioris classis $\Omega$ ), editores recen-

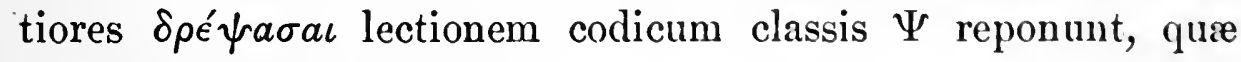
aptiorem efficit sententiam.

${ }^{1}$ Berliner Klassikertexte, V, 1 (Epische und elegische Fragmente bearbeitet von W. Schubart und U. von Wilamowitz-Moellendorf), Berlin, 1907, p. $34, \mathrm{v}$. 60 sqq.

${ }^{2}$ Locum totum seclusit Rzach. 
Cum aliis verbis ac $\delta i \delta \omega \mu \iota$ infinitivus est coniunctus Th. 303

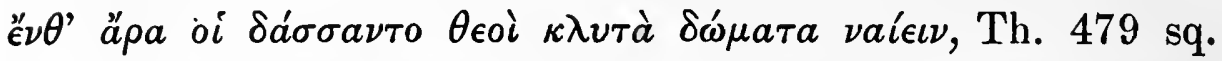

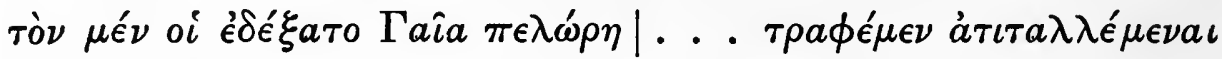
$\tau \epsilon$ (cf. O 190).

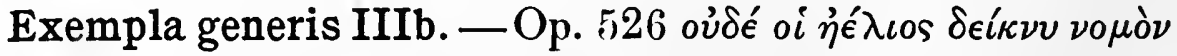

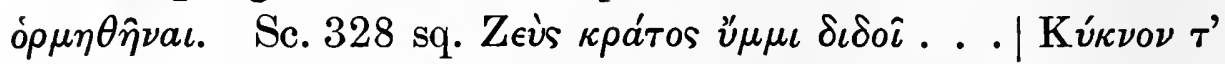

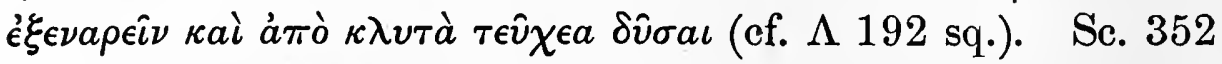

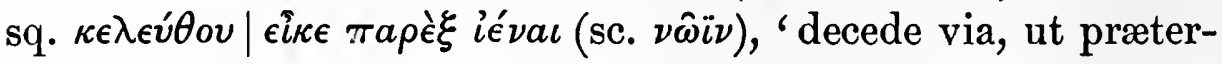
eamus,' (cf. $\Omega$ 716).

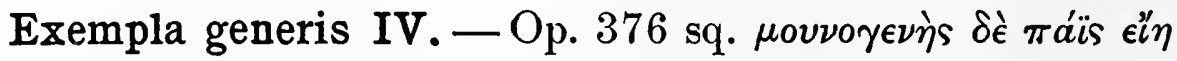

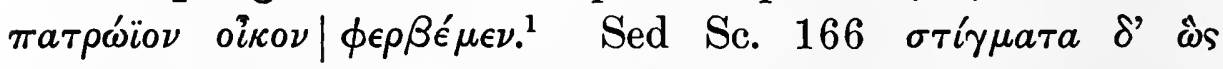

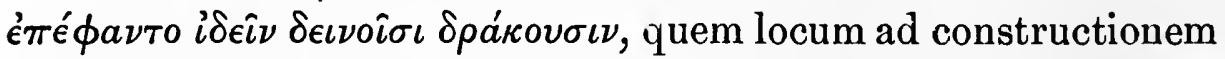
consecutivam refert Steinacherius, ${ }^{2}$ infinitivus ad definiendum inservit; nam sic verti potest: 'apparebant in diris draconibus tamquam maculæ aspectu.' Similem constructionem invenias Th. 700 sq., et cf. Seipium, op. cit., p. 63.

De syntaxi generali horum infinitivorum nihil fere est quod adnotem. Infinitivus cuius significatio sit re vera passiva non

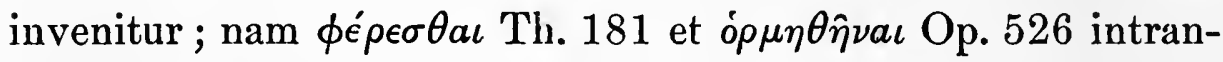
sitive dicti, neque $\kappa \epsilon \kappa \lambda \hat{\eta} \sigma \theta a \iota$ Th. 410, quod unum est perfecti temporis exemplum, multum ab eîvaı differt. Nomina prædicata aut ad nominativum, Sc. 176, aut ad accusativum, Th. 409 sq. 498 sqq. Fragm. 116, 2, relata sunt. In enuntiatum principale non est inclusus infinitivus, excepto Th. 905 sq. locoque consimili Th. 218 sq., ubi verbo antecedit.

Summa horum infinitivorum est circiter XVIII, ${ }^{3}$ quo e numero $\mathrm{X}$ sunt in Theogonia, III in Operibus, IV in Scuto, I in Fragmentis. Sic autem in genera dispertiti sunt : primi sunt IV, alterius $\mathrm{V}$, tertii VIII, quarti $\mathrm{I}$.

${ }^{1}$ Multi codices pro $\epsilon i ́ \eta$ habent $\sigma \dot{\omega} \zeta o \iota$ ( $\left.\sigma \omega \dot{\zeta} \xi \iota\right)$, quod receperunt Schoemann et alii, v. 377 reiecto.

${ }^{2}$ Op. cit., p. 15.

${ }^{3} \mathrm{Hæc}$ exempla ambigua vel dubia pratermissa sunt: Th. 609 sq. (p. 46); exemplum in fragmentis nuper repertis (p. 47 et n. 1); Th. 30 sq. (p. 47); Sc. 166 (p. 48). 
De aliis constructionibus.-Participium futuri pro infinitivo generis I est Sc. $91 \ddot{\omega} \chi \epsilon \tau o, \tau \iota \mu \eta^{\prime} \sigma \omega \nu \dot{a} \lambda \iota \tau \eta^{\prime} \mu \epsilon \nu o \nu$ Ẻं $\rho v \sigma \theta \hat{\eta} a,{ }^{1}$ Berliner Klassikertexte V, 1, p. 33 , vv. 45 sq. ó $\mu \eta \theta \hat{\eta} \nu a \iota \mid \pi o \iota \nu \dot{\eta} \nu$

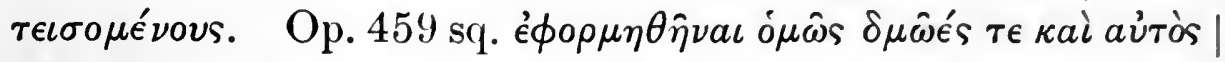

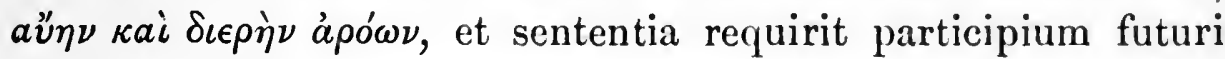
neque obstat forma; nam quamquam non est aliud exemplum huius verbi in futuro positi apud scriptores qui fuerunt ante Alexandrum, nec vero exstat ullum futurum asigmaticum a verbis in ó $\omega$ desinentibus ductum, tamen formæ futuri quales

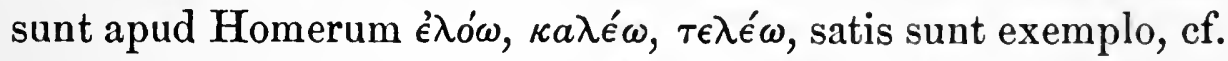
Kühner-Blass, Gramm. § 228. Monro, Hom. Gramm., § 63.

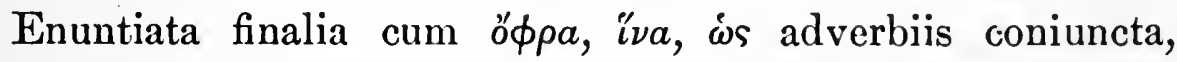
quorum numerus est apud Hesiodum XXVIII, ${ }^{2}$ cum infinitivo vix comparari possunt. Proxime autem accedunt hæc: Op.

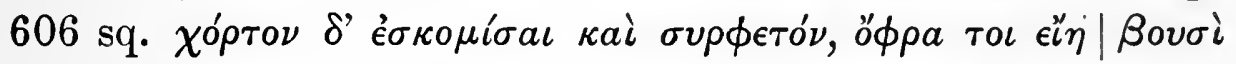

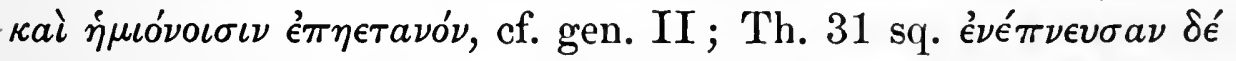

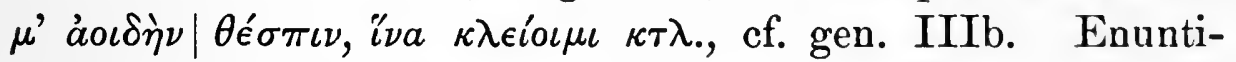

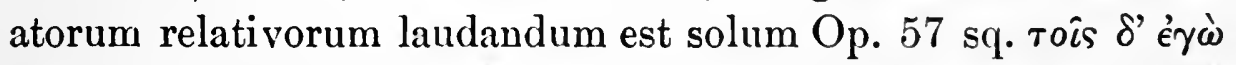

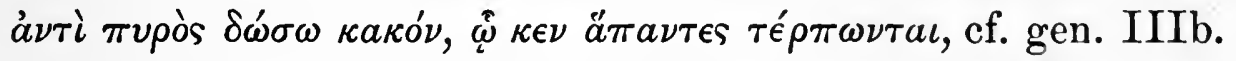

Quantum e numero exiguo exemplorum concludere licet, constructio infinitivi finalis vel consecutivi eadem fere est apud Hesiodum quæ apud Homerum. Deest certe formula $\beta \hat{\eta} \delta^{\prime} \iota^{\prime} \mu \epsilon \nu$ et quæ ei similes sunt; sed alia quædam verba vocesque apud Hesiodum primum adsciscunt infinitivum, qualia sunt

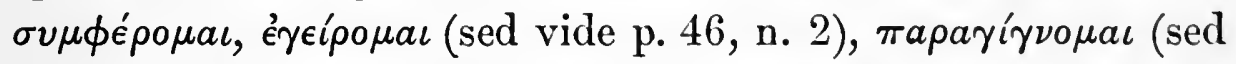

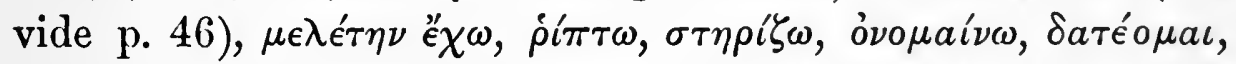
$\delta e^{\prime} \chi \mu a \iota, \delta \epsilon i \kappa \nu v \mu$. Quorum autem pleraque verbis Homericis similia significantibus respondent.

Hoc vero unum in usu Hesiodeo memorabile est, constructionem $\ddot{\omega} \sigma \tau \epsilon$ adverbii cum infinitivo coniuncti eo processisse ut

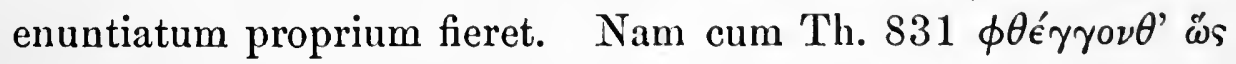

${ }^{1}$ Locus a Paleyio in editione sua suspectus, quod participium motum non significaret; qua de re disseruit etiam Journ. Phil., 8, pp. 79 sqq. Wecklein $\lambda a \tau \rho \epsilon u ́ \sigma \nu$ coniecit, Rhein. Mus., 41, p. 302.

${ }^{2}$ Weber, Absichtssïtze, I, pp. 65-67. 


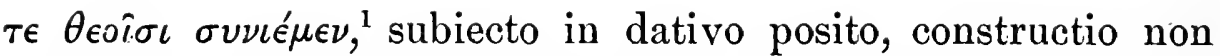
multum absit ab exemplis Homericis sine $\omega \sigma \tau \epsilon$ conformatis,

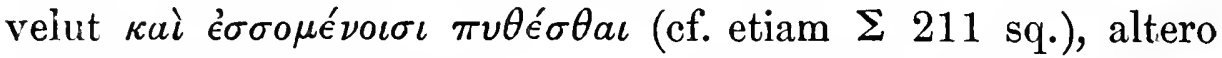
loco, Op. 43 sq. pं

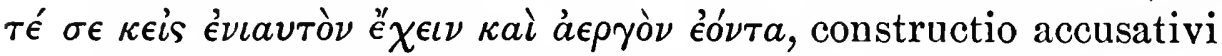
cum infinitivo coniuncti ad effectum notandum requirit. Sed ubi ea ex adverbio coniunctio facta est, enuntiatum consecutivum iam tale est constitutum quale postea frequentabatur.

\section{Caput II : Hymni Homericr. ${ }^{2}$}

Exempla generis I. - Aphr. $220 \beta \hat{\eta} \delta^{\prime} i^{\prime} \mu \epsilon \nu$, et Dem. 302.

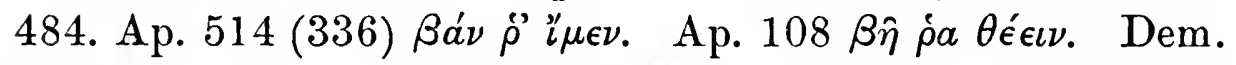

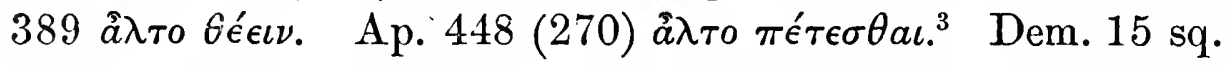

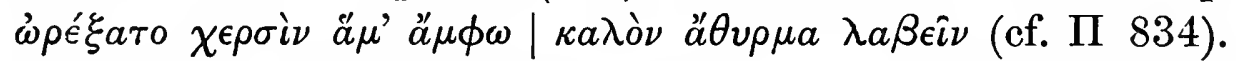

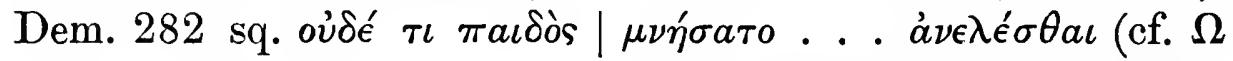

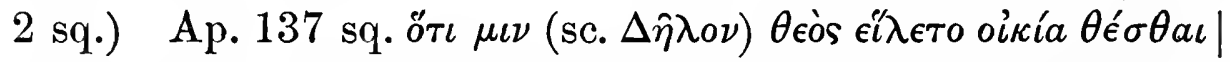

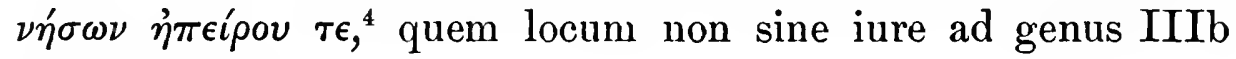
quoque referas.

Ut de locis dubiis pauca dicamus, in hymno ad Selenen (XXXII) 1 M finitivus nullam habet constructionem ac fortasse ex adiectivo ad M $\eta^{\prime} \nu \nu$ relato, velut $\epsilon \dot{\varepsilon} \epsilon \iota \delta \hat{\eta},{ }^{5}$ per mendum ortus est. Inter-

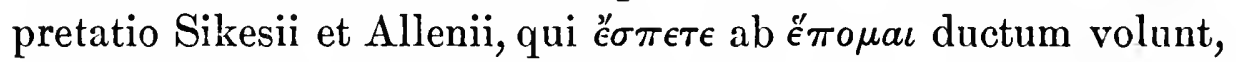
' canere pergite,' longius repetita est. Herm. 166 sq. aùtà $\rho$

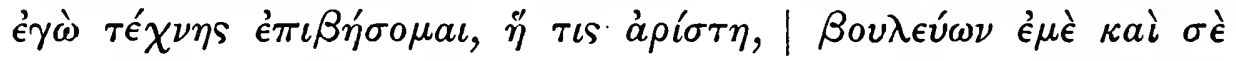

${ }^{1}$ In hoc loco interpretando alii alia temptaverunt, vide Goettling-Flach ad loc., et Steinacher, op. cit., pp. 16 sq.

${ }^{2}$ Hymni laudati sunt ex editione quam curaverunt Sikes et Allen, London, 1904. Quattuor hymni maiores singulis compendiis Dem., Ap., Herm., Aphr. designantur, minores autem et nominibus et numeris eius editionis.

${ }^{3} \hat{\omega} \rho \tau o$, quod coniecit Windisch, in textum recepit Gemoll ; sed nihil emendatione opus est.

${ }^{4} \mathrm{Vv} .136-138$, qui in solis codicibus classis ' $y$ ' inveniuntur, ad aliam textus formam et ipsam antiquam videntur pertinere. Vide Sikes et Allen ad loc. et in Introd., p. xxv.

${ }^{5}$ Sic Gemoll, Botheium secutus. 


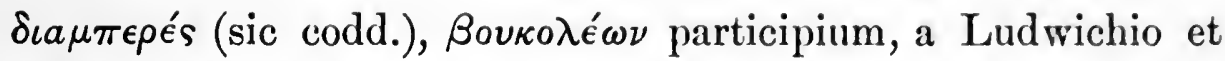

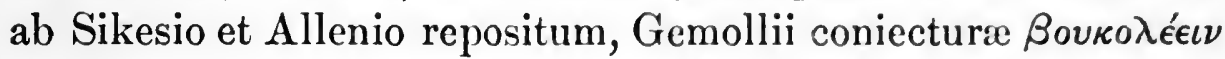

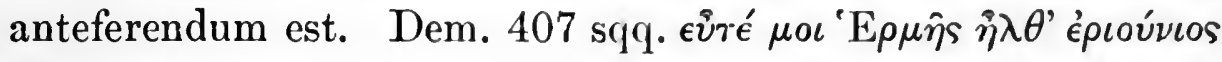

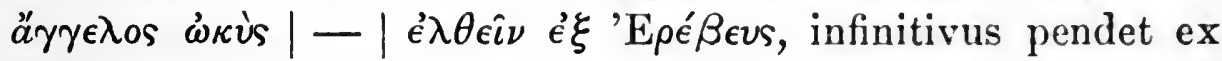
$\hat{\eta} \lambda \theta^{\prime}$ ă $\gamma \gamma \epsilon \lambda$ os, quod idem est atque $\eta^{\prime} \gamma \gamma \epsilon \iota \lambda \epsilon \nu$ (cf. $\Lambda 714 \mathrm{sq} . \Sigma$ 166 sq.), neque opus est Hermanni coniectura a Baumeisterio recepta à $\xi_{\epsilon}^{\prime} \mu \epsilon \nu$.

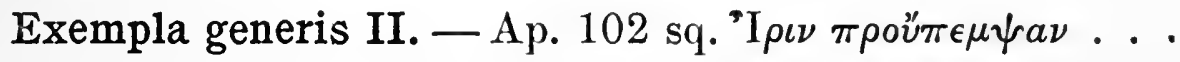

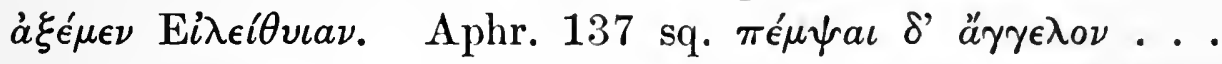

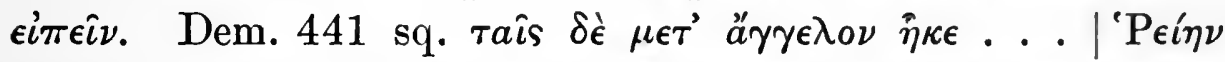

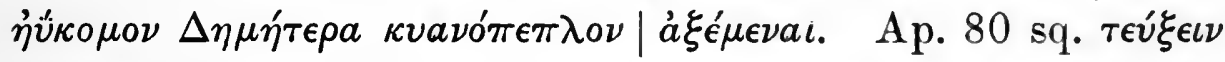

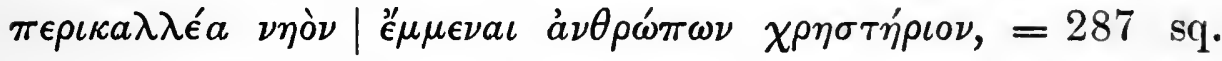

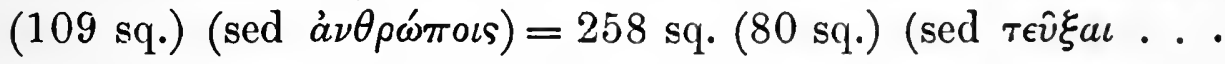

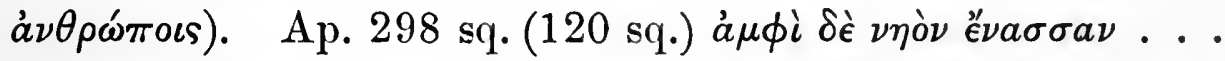

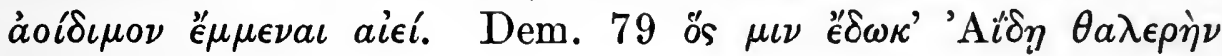

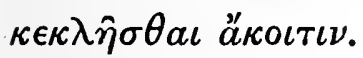

Pauci sunt infinitivi ambigua constructione: Dem. 321 sq.

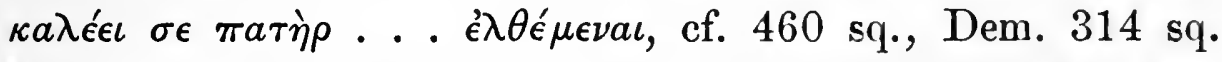

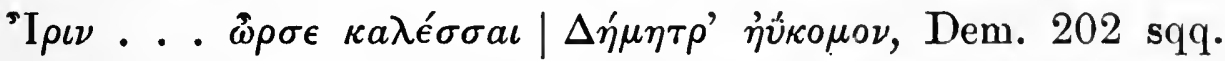

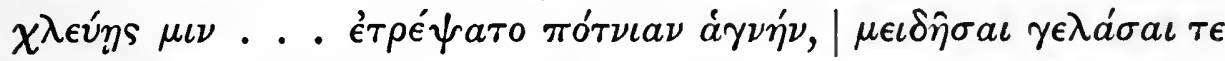

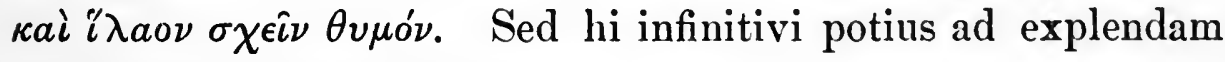
sententiam videntur inservire.

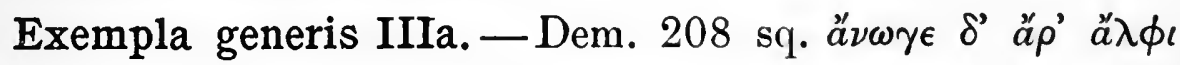

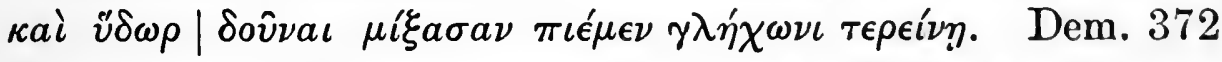

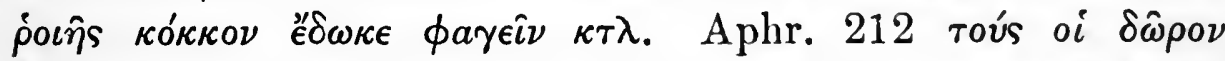
$\dddot{\epsilon} \delta \omega \kappa \epsilon \nu$ é $\chi \epsilon \iota \nu$. Locis autem ambiguis, hymno minore ad Aphr.

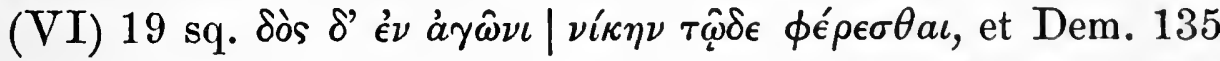

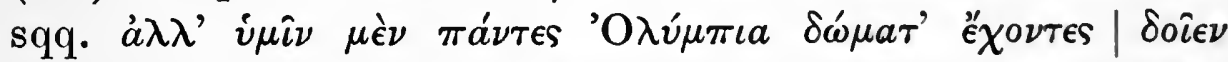

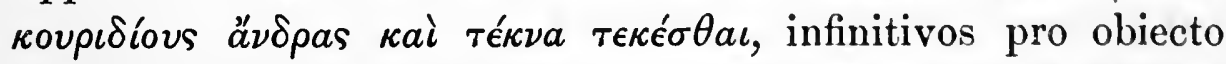

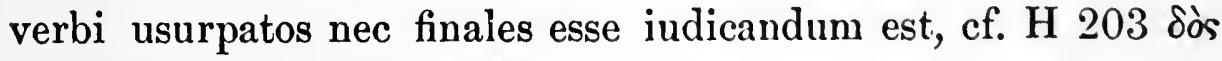

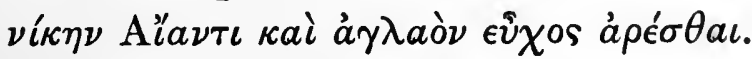

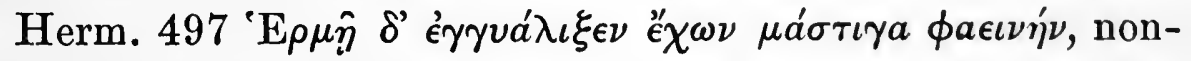
nulli ${ }^{1}{ }^{\prime} \chi \epsilon \iota \nu$ infinitivum reponunt, quæ coniectura, ut speciem

${ }^{1}$ Baumeister, Gemoll, Ludwich. 
veri habet, sic est facilior quam ut mendi causam declaret.

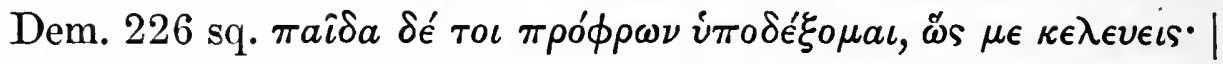

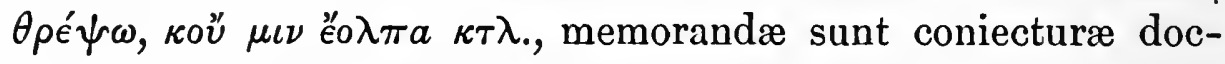

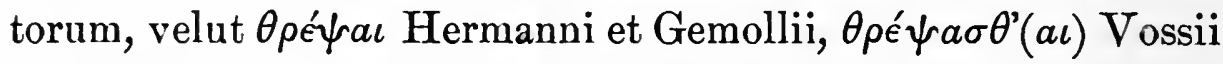
et Baumeisteri, in quibus infinitivus non solum cum $\kappa \epsilon \lambda \epsilon \dot{\epsilon} \epsilon \varsigma$ sed etiam cum $i \pi \delta^{\prime} \epsilon^{\prime} \xi \mu \mu \iota \iota$ coniungi potest, cf. Hes. Th. $479 \mathrm{sq}$. Sed nihil causæ est cur a codicum auctoritate hoc loco discedamus.

Exempla generum IIIb et IV. - Certa exempla horum generum non sunt inventa. Hymno ad Pana (XIX) 33 sq. $\theta a^{\prime} \lambda \epsilon$

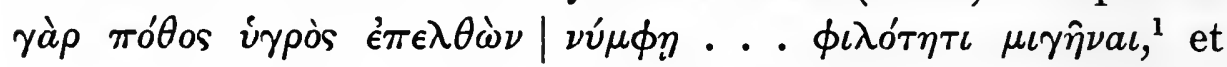

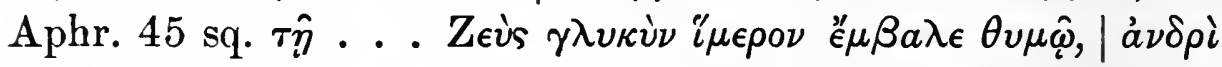
$\kappa a \tau a \theta \nu \eta \tau \hat{\omega} \mu \iota \chi \theta \dot{\eta} \mu \epsilon \nu a \iota$, infinitivi a vocibus cupiendi pendentes voluntatem potius quam effectum notant. Hymno ad Poseidona

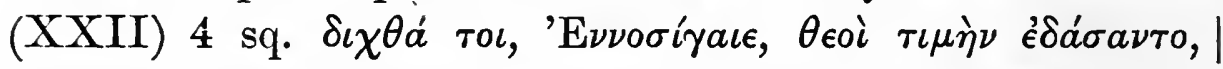

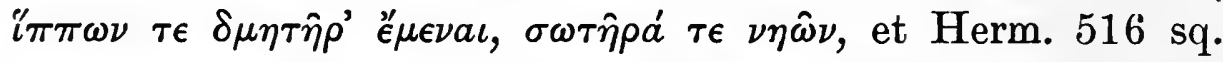

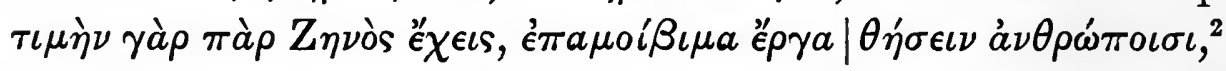
infinitivi notionem $\tau \iota \mu \grave{\eta} \nu$ vocis explicant. Infinitivi ad á $\nu \delta a ́ v \omega$

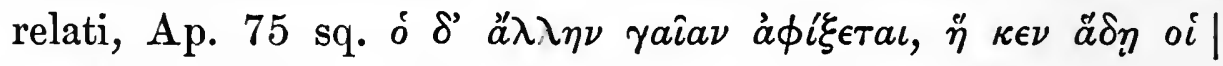

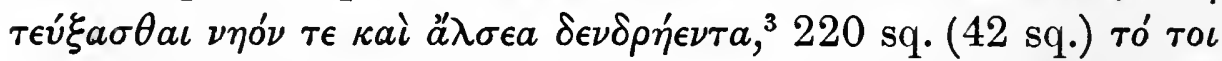

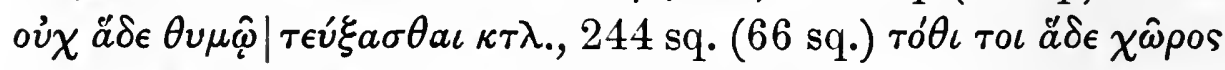
$\dot{a} \pi \eta^{\prime} \mu \omega \nu \mid \tau \epsilon \dot{\xi} \xi a \sigma \theta a \iota \kappa \tau \lambda$., respectum notant.

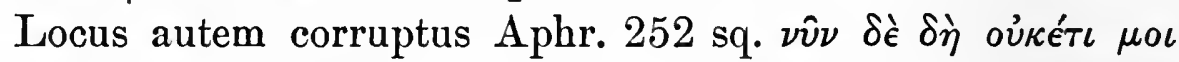

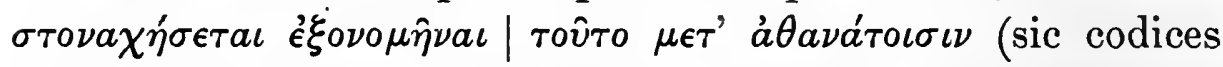

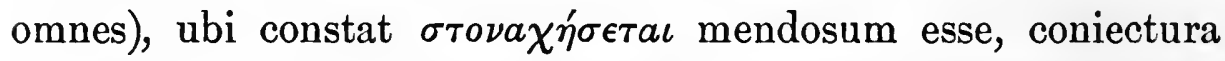
nondum est restitutus ut infinitivi syntaxin illustret; nam

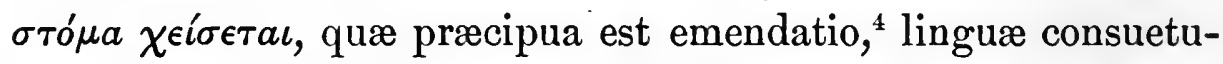
dine atque exemplis non satis confirmatur. Qui adlati sunt

${ }^{1}$ Ad $\theta a ́ \lambda \epsilon$ verbum multæ sunt coniecturæ (vide Sikes et Allen, adn. crit. ad loc. ), quarum optima videtur $\lambda a ́ \theta \epsilon$ Ruhnkenii.

${ }^{2}$ Infinitivus temporis futuri hoc loco dignus est memoratu, sed fortasse ex notione pollicendi, quæ inest enuntiato principali, pendet.

${ }^{3}$ Post of distinctionem faciunt Sikes et Allen, quasi vero infinitivus ad $\dot{a} \phi(\xi \in \tau a \iota$ pertineat; sed ceteris locis collatis perperam factam apparet.

${ }^{4}$ Hanc emendationem a Martinio prolatam probavit Tyrrell, Hermathena, IX, p. 33, receperunt Sikes et Allen. 


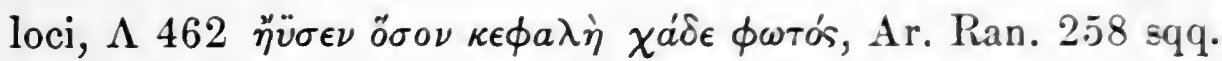

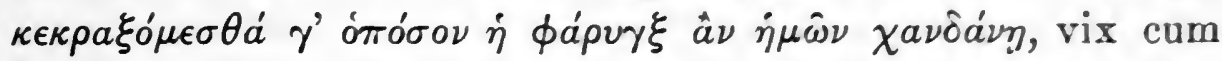

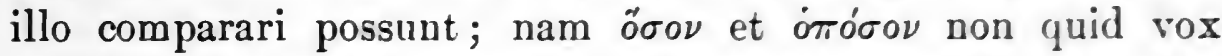
efficere queat sed quantum vocis emittatur significant. Nec magis placet $\sigma \tau o^{\prime} \mu$ ' à $\chi \eta^{\prime} \sigma \epsilon \tau a \iota$, quod coniecit Buttmannus, ${ }^{1}$ propter duram infinitivi constructionem.

Inter locos dubios ultimus adferatur Herm. $11 \mathrm{sq.} \tau \hat{\eta} \delta^{\prime} \eta \bar{\delta} \eta$

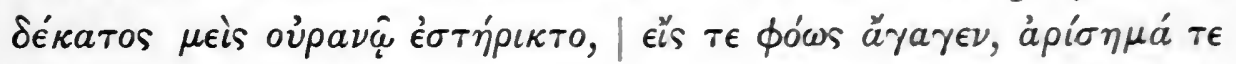

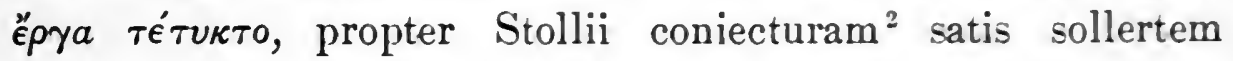

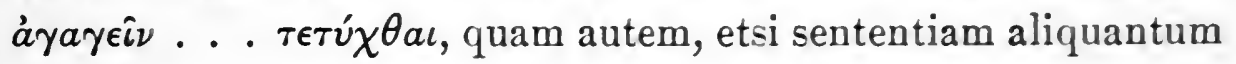
expedit, recipere non est necesse.

De syntaxi generali infinitivi.-Unus est infinitivus temporis perfecti et formæ passivæ, $\kappa \epsilon \kappa \lambda \hat{\eta} \sigma \theta a \iota$ Dem. 79, cf. $\Xi 268$ et Hes. Th. 410. Nomina prædicata ad accusativum relata sunt Ap. $80 \mathrm{sq} .=258 \mathrm{sq} \cdot(80 \mathrm{sq})=.287 \mathrm{sq} \cdot(109 \mathrm{sq}$.$) , Ap. 298$ sq. (120 sq.), Dem. 79. Infinitivus inter vocabula enuntiati principalis sed post verbum interiectus est non modo in formula $\beta \hat{\eta} \delta^{\prime}\left(\beta a ́ \nu ~ \dot{\rho}^{\prime}\right) \iota^{\prime} \mu \epsilon \nu$, sed etiam Ap. 137 sq. (p. 50), Dem. 208 sq. 372 (p. 51).

Summa infinitivorum finalium vel consecutivorum, omissis locis ambiguis corruptisve, ${ }^{3}$ est XXI, quo e numero IX sunt in Dem., IX in Ap., ${ }^{4}$ III in Aphr. Generis autem primi sunt $\mathrm{X}$, alterius VIII, tertii (a) III.

De aliis constructionibus. - Participium futuri pro infinitivo generis I est sexies: Aphr. 220 (cum voce $\beta \bar{\eta} \delta ’ ~ ‘ \mu \mu \nu$ coniunctum); Herm. 178 ( $\epsilon i \mu \iota)$; hymno ad Artemin (XXVII) 13

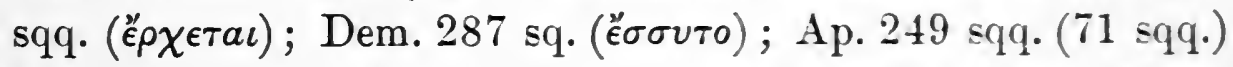

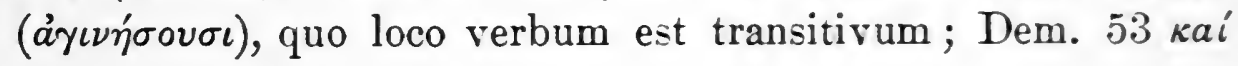

${ }^{1}$ Lexil. II, \& 84, 4.

2 Neue Jahrb., 79, p. 319.

${ }^{3} \mathrm{Hi}$ sunt Sel. (XXXII) 1. Herm. 166 sq. (p. 50); Dem. 407 sqq. 202 sqq. 314 sq. 321 sq. 460 sq. Aphr. (VI) 19 sq. Dem. 135 sqq. Herm. 497 (p. 51) ; quique pp. 52-53 tractati sunt.

4 Ex his IV in parte Deliaca, V in Pythica inreniuntur. 


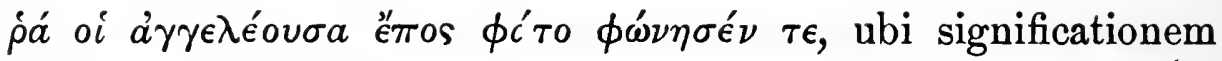
eundi non habet. ${ }^{1}$

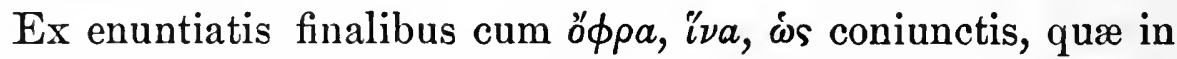
Hymnis sunt numero XVII, ${ }^{2}$ tria sola videntur cum infinitivo

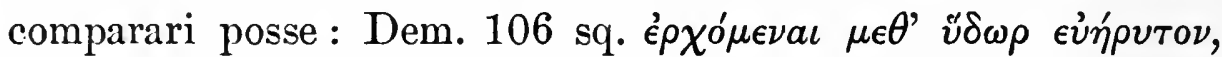

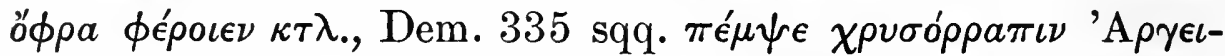

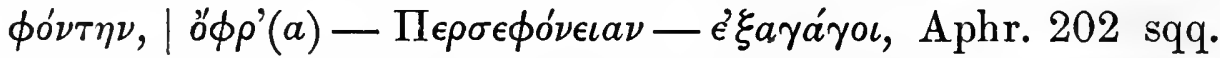

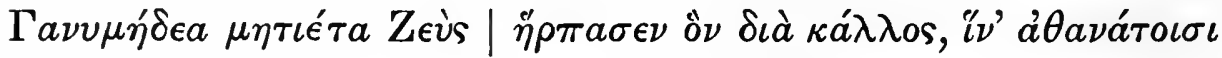

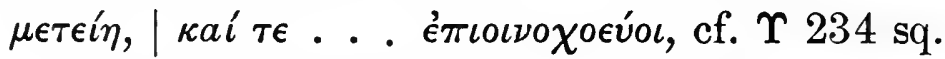

Unum est enuntiatum relativum in quo finis tempore futuro

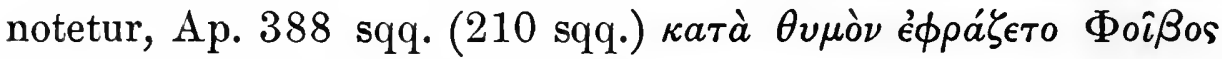

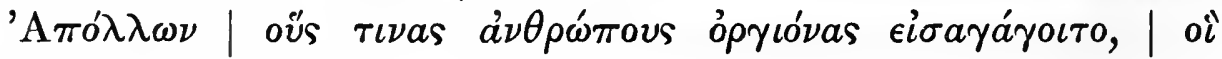
$\theta \epsilon \rho a \pi \epsilon \dot{v} \sigma o \nu \tau a \iota \kappa \tau \lambda$.

Cum infinitivo $\tilde{\omega} \sigma \tau \epsilon$ particula est coniuncta Ap. 529 sq.

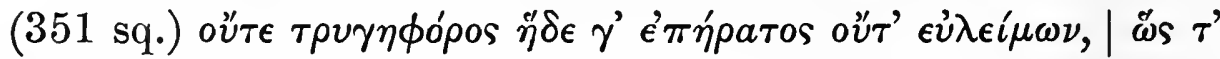

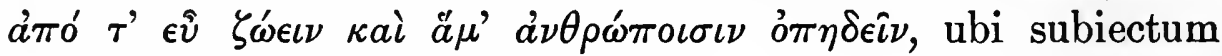
infinitivorum audiendum est.

Apparet igitur Hymnos Homericos in huius constructionis usu minus etiam quam carmina Hesiodea ab Iliade Odysseaque dissentire. Novæ quidem sunt conformationes infinitivi coniuncti cum verbis ä $\lambda \lambda o \mu a \iota, \nu a i ́ \omega$ (ædifico), $\mu \iota \mu \nu \eta ̋ \sigma \kappa o \mu a \iota$, aipéo $\mu a \iota$ (cum infinitivo gen. I vel IIIb); sed omnes in formam constructionis Homericæ facile redigi possunt.

\section{Caput III: Reliqui Poetæ Prisci}

A. Poetce Epici ${ }^{3}$ et Batrachomyomachia ${ }^{4}$

Exempla huius capitis tam pauca sunt ut potius ad ordinem scriptorum quam ad genera constructionis spectemus.

${ }^{1}$ Participium præsentis voluit Gemoll, Ruhnkenium secutus, sed cf. T 120,

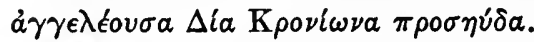

2 Weber, Absichtssätze, I, pp. 67 sq.

${ }^{3}$ Ed. Kinkel, Epicorum Græcorum Fragmenta, Lips., 1877.

4 Ed. Monro, Homeri Opera et Reliquiæ, Oxon., 1896. Vide etiam editionem Ludwichii, Die Homerische Batrachomachia, Leipzig, 1896. 


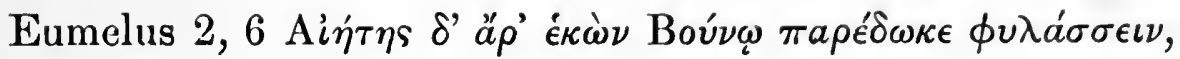
(sc. $\chi \omega ́ \rho \eta \nu)$, gen. IIIa.

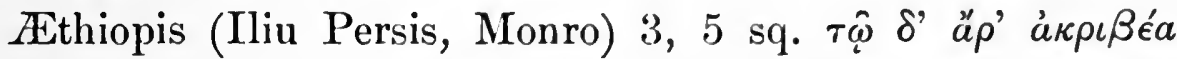

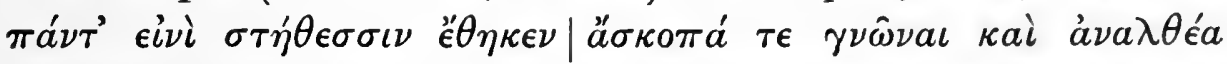

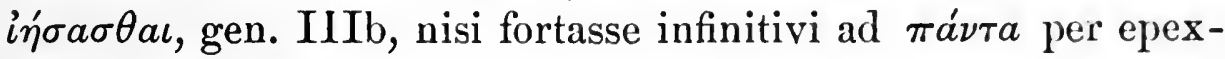
egesin relati sunt.

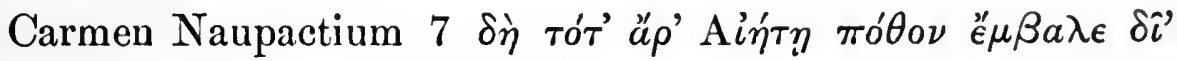

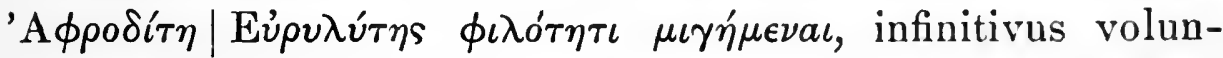
tatem ac non effectum videtur notare, cf. hymnum ad Aphroditen 45 sq. (p. 52).

Batrachomyomachia 139 sq. $\mu \dot{v} \epsilon s ~ \ddot{v} \mu \mu \iota \nu$ à $\pi \epsilon \iota \lambda \dot{\eta} \sigma a \nu \tau \epsilon$ é $\pi \epsilon \mu \psi a \nu$

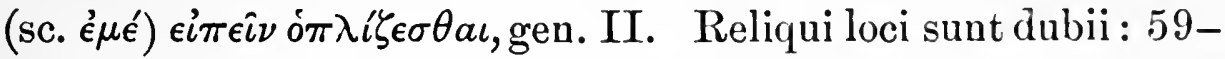

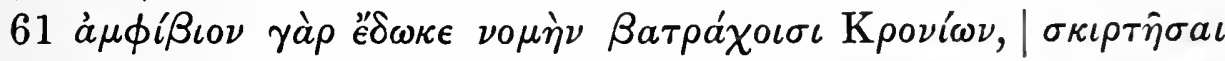

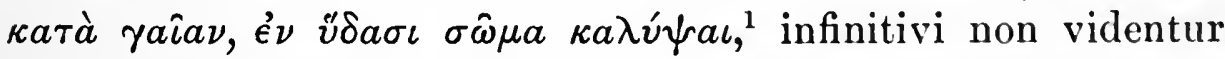
esse generis IIIb sed epexegetici ; et 30 sq., ubi est prope in

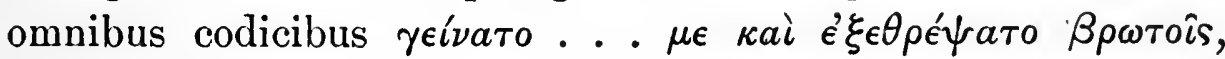

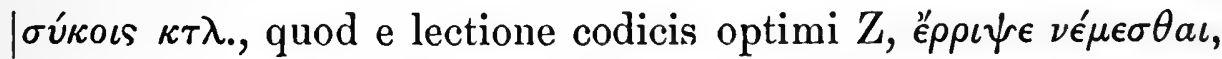

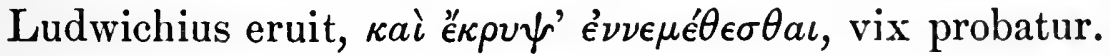

De aliis constructionibus. - Participinm futuri est Batr. 174

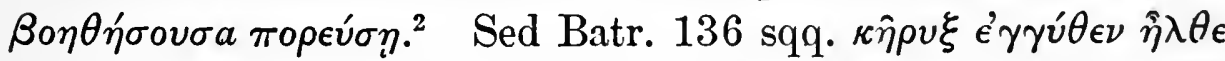

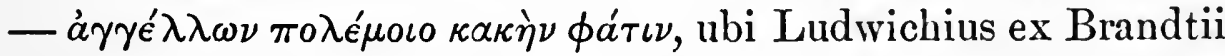
coniectura á $\gamma \gamma \epsilon \lambda \epsilon^{\prime} \omega \nu$ scribit, participium præsentis, collatis $\nu 94$. $\pi$ 459, defendi potest. Comparandum est etiam enuntiatum

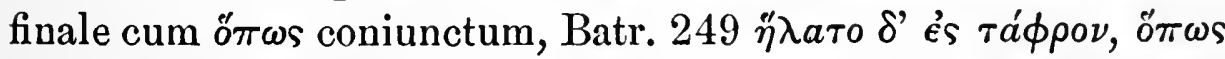

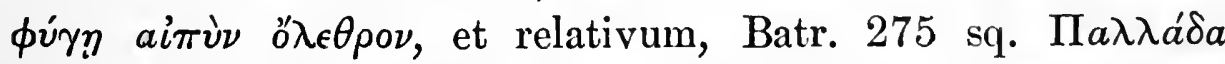

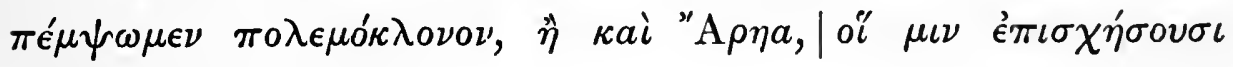

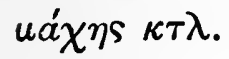

\section{Epigrammata Homerica}

Ne quæ pars ' corporis Homerici' in hac disputatione pretermittatur, Epigrammata (ed. Monro, Homeri Opera et Reliquiae, Oxon., 1896) hic excutiemus. Quorum fructus est profecto

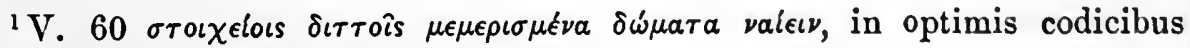
omissum secluserunt Monro et Ludwich.

${ }^{2} \xi \pi a \lambda \epsilon \xi \dot{\eta} \sigma o v \sigma a$ cum aliquot codicibus Ludwich. 
exiguus ; nam unum certum est exemplum, 4, 1 oĭ $\mu^{\prime}$ ă $\sigma \eta \emptyset \hat{\eta} \kappa \epsilon$

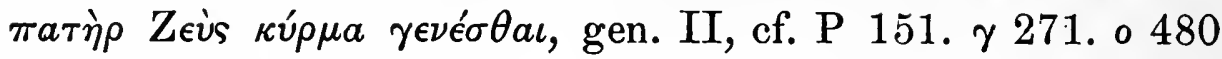
sq. Alio loco, 14, 2 sqq.

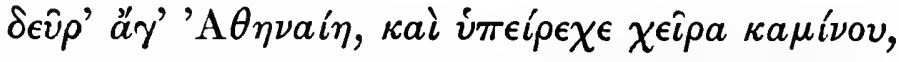

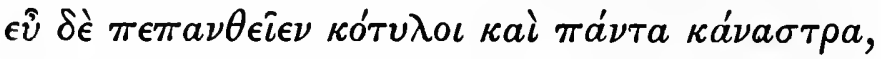

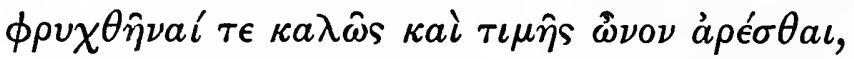

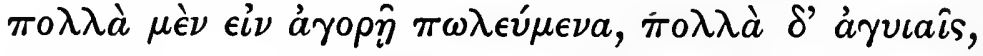

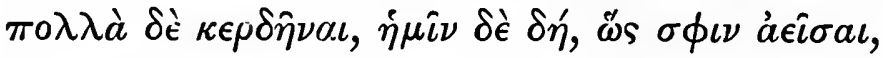
exemplum insigne constructionis laxæ in versu 4 esse apparet, (nam de versu 6 misere corrupto non liquet); sed forsitan infinitivi ex $\pi \epsilon \pi a \nu \theta \epsilon i \epsilon \nu$ non pendeant positique sint in precatione pro optativo.

\section{B. Poetae Elegiaci et Iambici ${ }^{1}$}

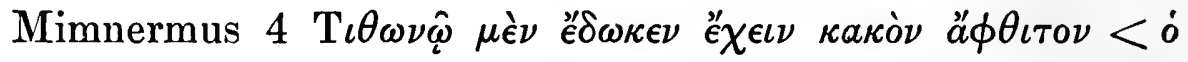
Zèेs $>\mid \gamma \hat{\eta} \rho a s$, gen. IIIa, nisi quidem infinitivus accusativi loco est.

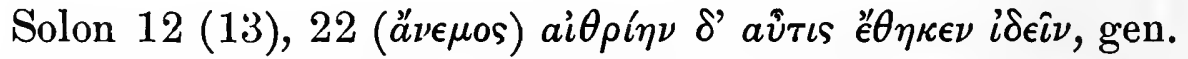

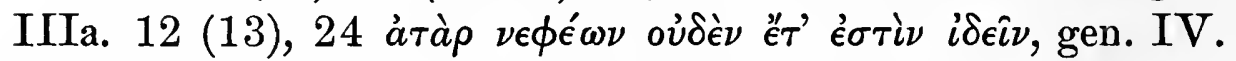

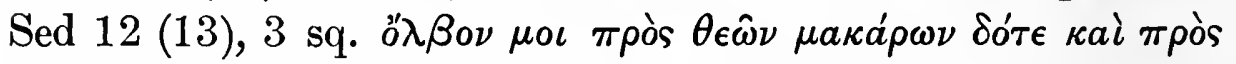

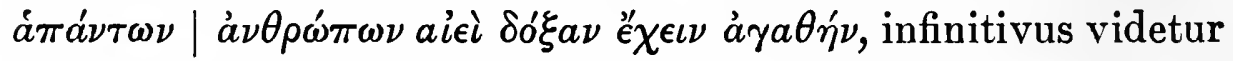
pro obiecto esse usurpatus.

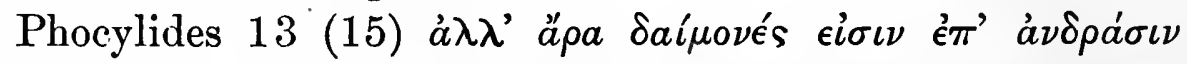

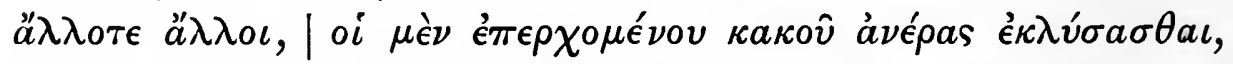
in fragmento manifesto non absoluto, constructionem generis $I V$, quæ quidem singulari sit conformatione, vix licet indagare.

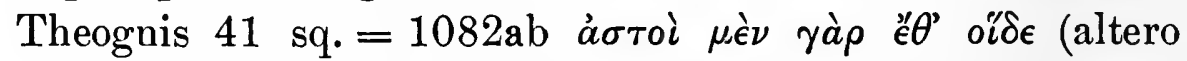

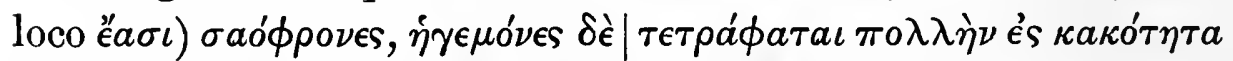
$\pi \epsilon \sigma \epsilon \hat{\imath} \nu$, 'sed duces conversi sunt ut in malitiam multam incidant,'

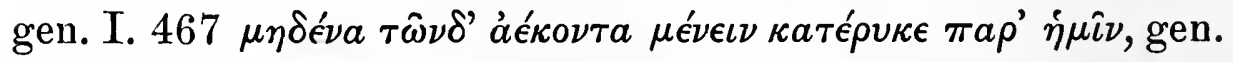

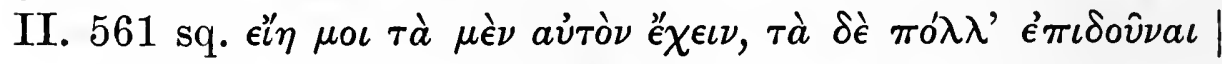

${ }^{1}$ Numeri sunt Anthologiæ Lyricæ (Hiller-Crusius), Lips., 1904, quibus adiecti sunt numeri discrepantes Bergkiani, Puetæ Lyrici Græci, ed. 4, vol. 2, Lips., 1882. 


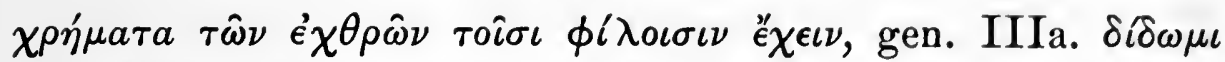
cum é $\chi \epsilon \iota \nu$ infinitivo coniunctum est etiam 445 sq. $=1162 \mathrm{ef}$. 1057 sq. 1386 sq., quæ exempla, cum de donis deorum agatur,

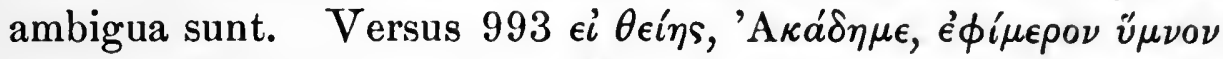
á $\epsilon i \delta \epsilon \iota \nu$, si recte se habet, significat 'si proposueris hymnum ad canendum,' attribuendusque est generi IIIa ; sed insolenter dictum hoc videtur pro eo quod sit 'si canendi certamen institueris,' quare arridet Turnebi coniectura $\epsilon^{\prime \prime} \theta^{\prime} \epsilon^{\prime \prime} \eta \sigma^{\prime} \kappa \tau \lambda$. Cf. $\sigma$ 366 sqq., quo ex loco hic fortasse ductus est. Non sunt omnino

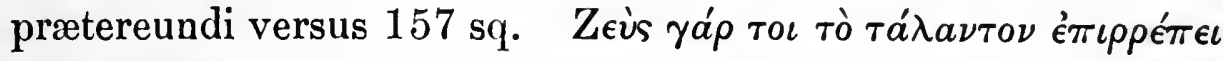

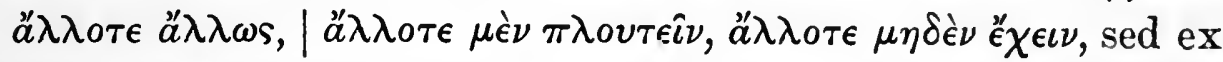

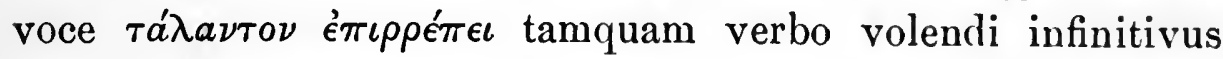

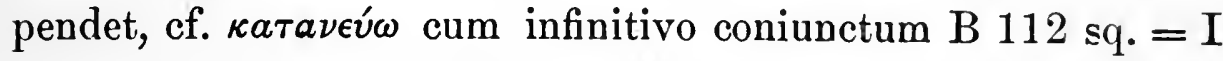

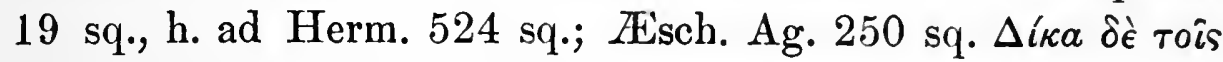

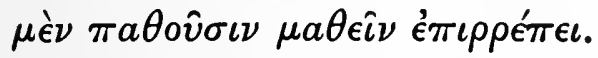

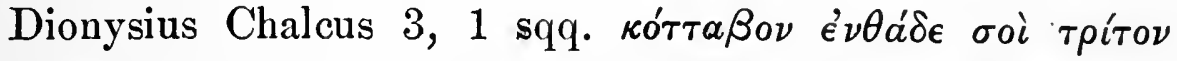

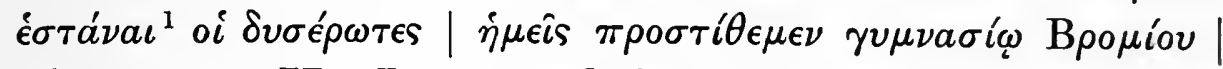

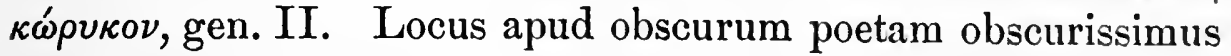
hæc videtur significare: 'cottabum hic tibi statuimus ut stet (tamquam) tertius (ludus), follis in gymnasio Bromii.'

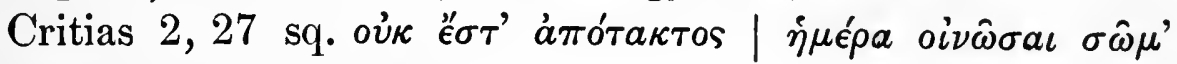

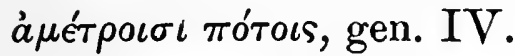

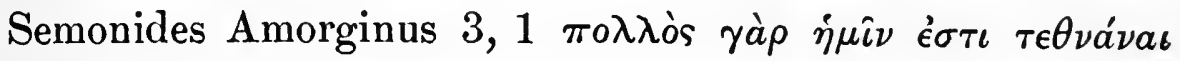
xpóvos, gen. IV.

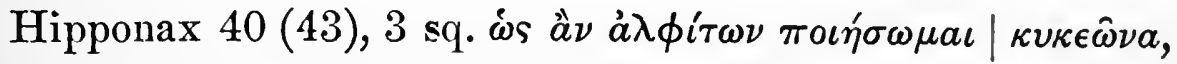

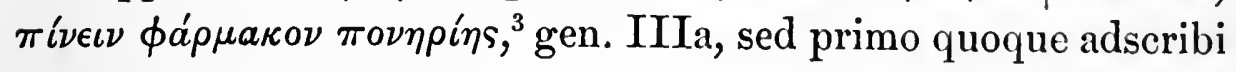
potest.

De aliis constructionibus. - Participium futuri cum verbis eundi coniunctum est Solon 1, 7 sq. (2, 5 sq. Bgk.); 2 (4), 16 ; Dionysius Chalcus 2, 1; [Plato] 1, $2 \hat{\eta} \lambda \theta \epsilon$ yà $\dot{\eta} \tau \lambda \dot{\eta} \mu \omega \nu$

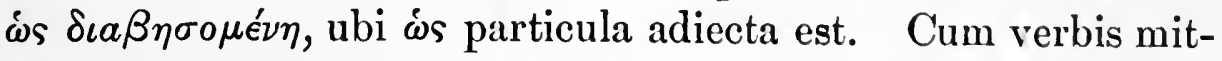

\footnotetext{
${ }^{1}$ Sic Athenæi codices, quos secuti sunt Hiller-Crusius ; i $\sigma \tau a ́ v a \iota$ Bergk, cum Casaubono.

${ }^{2}$ Vide Buecheler, Neue Jahrb., 111, p. 125.

${ }^{3}$ Lectionem traditam $\pi i \nu \omega \nu$ servavit Bergk.
} 
tendi coniunctum relatumque ad accusativum est Solon 12 (13), 75 sq.; Hipponax 43 (46). De loco corrupto Theogn. 337 sq. et fragmento Archilochi 79 (82), ubi deest enuntiatum principale, nihil dici potest.

Enuntiata finalia adverbiis coniuncta sunt numero $\mathrm{V}$ apud Theognin, IV apud ceteros, ${ }^{1}$ sed vix ullum exemplum cum infinitivo comparari potest.

Iam cum hæ constructiones nihil novi adferant, eo memorabilior est usus $\omega \sigma \tau \epsilon$ particulæ, quæ invenitur nón modo ubi infinitivus ad aliquod vocabulum enuntiati principalis tamquam subiectum suum est relatus, Theogn. 413 sq. 502 sq. 917 sqq. 1388 sq. Cleobulina 2 ( 1 Bgk.), sed etiam ubi exstat subiectum proprium vel audiri potest, Theogn. 521 sq. 559 sq. $^{2} 1363$ sq. (559 sq. 917 sqq. 1363 sq. accedit $\mu \eta^{\prime}$ particula, 521 sq. oủ), Critias 2, 15 sq. Unde apparet hanc constructionem iam fere æque ac nudum infinitivum frequentari.

\section{Poetce Philosophi: Xenophanes, Parmenides, Empedocles ${ }^{3}$}

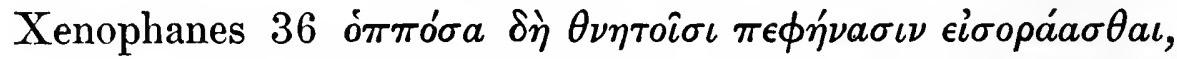
gen. IV. Sed huius versus, quem adfert Herodianus $\pi \epsilon \rho \grave{\imath}$

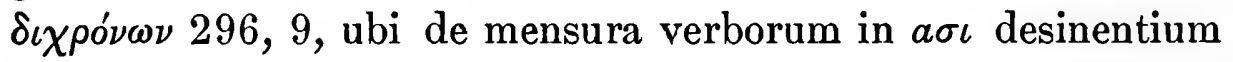
disserit, sententia fortasse non est perfecta, atque infinitivus ex aliquo vocabulo versus insequentis pendere potuit.

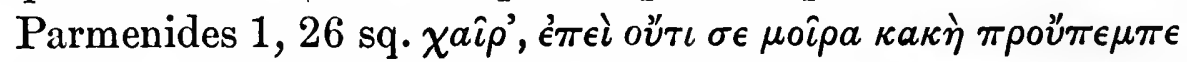

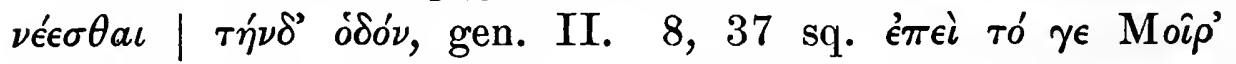

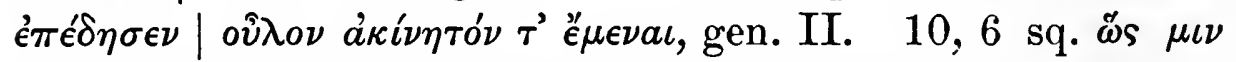

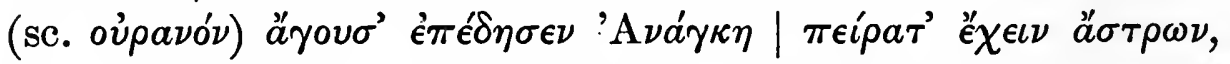

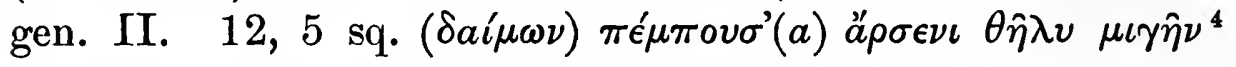

${ }^{1}$ Weber, Absichtssätze, I, p. 76.

$2 \lambda \hat{\varphi} \sigma \tau \alpha$ pro $\ddot{\omega} \sigma \tau \epsilon$ Bergk, ex Geelii coniectura.

${ }^{3} \mathrm{Hæc}$ fragmenta laudata sunt ex editione Dielsii, Poetarum Philosophorum Fragmenta, Berol., 1901 ; sed cf. etiam eiusdem 'Fragmente der Vorsokratiker,' ed. 2, vol. 1, Berl., 1906.

${ }^{4}$ Sic Diels, Steinium secutus ; codd. $\mu \iota \gamma \dot{\nu} \nu$. 


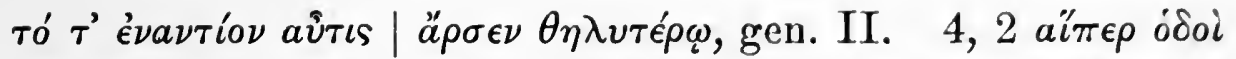

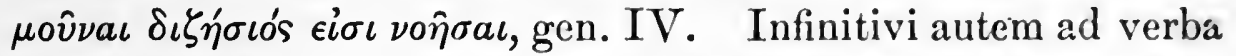

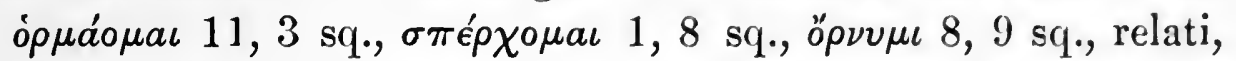
ad explendam sententiam videntur inservire.

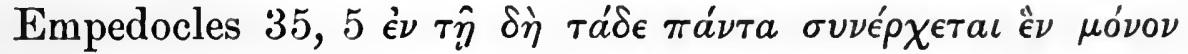

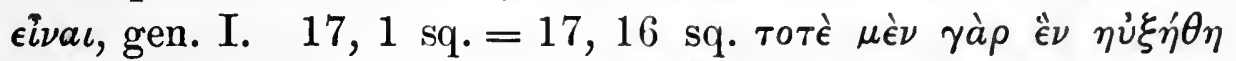

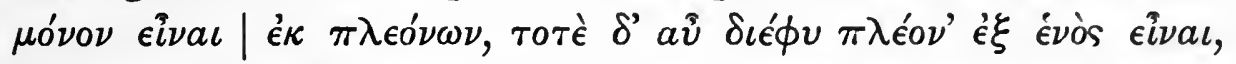

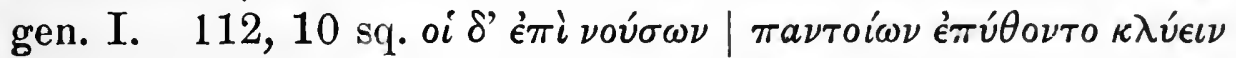

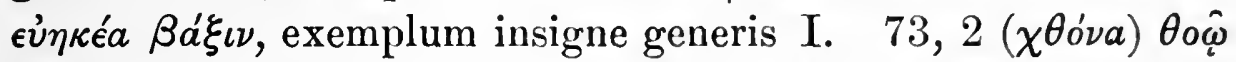

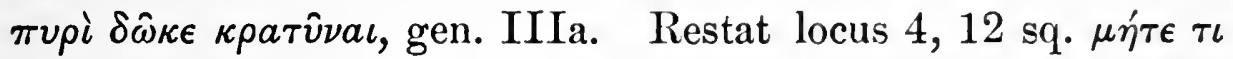

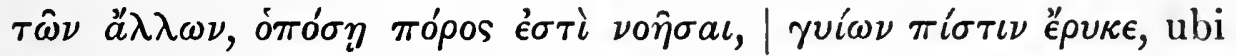

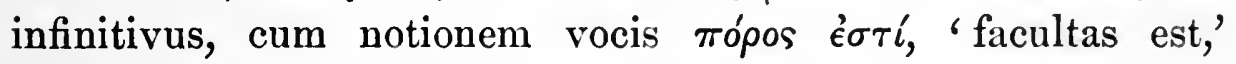
expleat, non est generi IV adscribendus.

De aliis constructionibus. - In his fragmentis nec participia futuri neque enuntiata finalia sunt quæ cum infinitivo comparari possint ; sed duo enuntiata relativa similitudinem habent generis

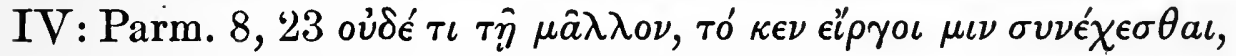

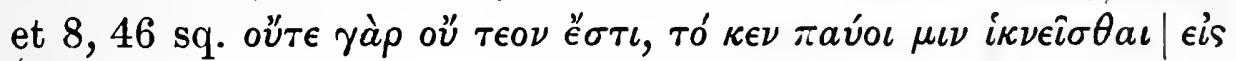
ó $\mu o ́ \nu$.

Cum infinitivo $\check{\sigma} \sigma \epsilon$ particula est coniuncta Emped. 100, 4 sq., ubi alteri infinitivo est subiectum in accusativo positum, et Parm. 8, 17 sq., ubi post $\epsilon_{a} a ́ \omega$ verbum particula abundat. Atque exemplum simplicis $\dot{\omega}$ addendum sit, si Xenoph. 15, 1 sq., $\epsilon i$

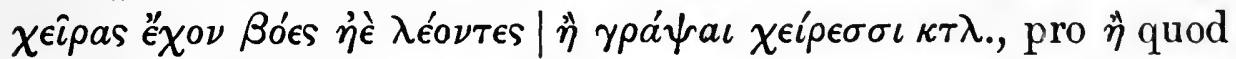
est in codicibus, Hilleri coniecturam $\dot{\omega} s$ recipiamus; sed vide Dielsium ad loc. in Poet. Phil. Fragmentis. Denique vox '̇ $\phi^{\prime} \dot{\phi}$ $\tau \epsilon$ cum infinitivo primum coniuncta est Emped. 4, 6 sqq. $\mu \eta \delta \epsilon^{\prime}$

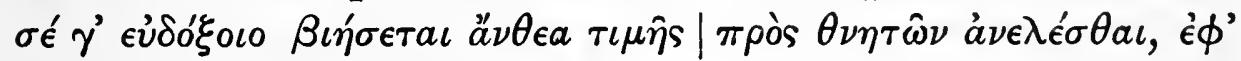

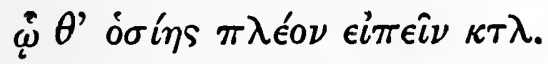

D. De syntaxi generali infinitivorum huius capitis

His in fragmentis dispersis nec raro corruptis non multa adnotari possunt. Infinitivus significationis re vera passivæe est loco dubio Hom. Epigr. 14, 4 ( $\phi \rho v \chi \theta \hat{\eta} \nu a \iota)$, temporis perfecti 


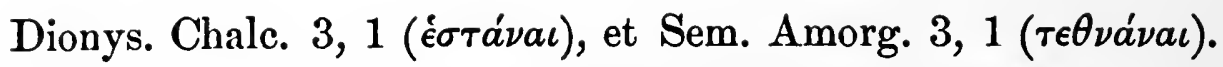
Nomina prædicata ad nominativum relata sunt Emped. 35, 5 et 17, 1 sq. = 17, 16 sq., ad accusativum Hom. Epigr. 4, 1, Dionys. Chalc. 3, 1 sqq., Parm. 8, 37 sq. Infinitivus inter vocabula enuntiati principalis est interiectus Mimn. 4, Theogn. 1057 sq. (loco ambiguo), Sem. Amorg. 3, 1; atque adeo verbo antecedit Theogn. 467, Dionys. Chalc. 3, 1 sqq.

Quod autem ad usum universæ constructionis attinet, tantum abest ut in his carminibus maximam quidem partem deperditis imminuius videatur ut novæ quædam conformationes infinitivi inducantur, e quibus præcipue commemorandæ sunt hæ : Theogn. 41 sq. 467 (p. 56) ; Crit. 2, 27 sq., Sem. Amorg. 3, 1 (p. 57) ; Parm. 4, 2, Emped. 35, 5. 17, 1 sq. = 17, 16 sq. 112, 10 sq. (p. 59); atque Hom. Epigr. 14, 2 sqq. (p. 56), si locus fide dignus est. Sed non minoris est alia res momenti, quod huiusmodi infinitivo $\omega \sigma \tau \epsilon$ particula sæpius adiungere se cœpit, cuius sunt in fragmentis elegiacorum exempla IX, in philosophorum II. 


\section{INDEX LIBRORUM}

\section{QUIBUS PRACIPUE SUBSIDIIS USUS SUM}

I. Editiones scriptorum Græcorum.

A. Homeri.

Clarke, S., et Ernesti, J. A. Homeri Opera Omnia. Glasguæ, 1814. Doeđerlein, D. L. Homeri Ilias. Lipsiæ, 1863-1864.

Düntzer, H. Homers Odyssee. Erklärende Schulausgabe. Paderborn, 1863.

- Homers Ilias. Erklärende Schulausgabe. Paderborn, 1866.

La Roche, J. Homeri Odyssea. Lipsiæ, 1867-1868.

Homers Ilias, für den Schulgebrauch erklärt. Berlin, 18701871.

Homeri Ilias. Lipsiæ, 1873-1876.

Hayman, H. The Odyssey of Homer. Vol. III. Books XIII to XXIV. London, 1882.

Pierron, A. L'Iliade d'Homère. . . . Deuxième édition. Paris, 1883-1884.

L'Odyssée d'Homère. . . . Deuxième édition. Paris, 18871888.

Merry, w. w., et Riddell, J. Homer's Odyssey. Second edition. Vol. I. Books I-XII. Oxford, 1886.

Cauer, P. Homeri Odyssea. . . . Lipsiæ, 1886-1887.

Homeri Ilias. . . Editio maior. Vindobonæ, 1890-1891.

Ameis, K. F., et Hentze, C. Homers Ilias, für den Schulgebrauch erklärt. Leipzig, 1894-1906.

Homers Odyssee, für den Schulgebrauch erklärt. Leipzig, 1895-1901.

van Leeuwen, J., et Mendes da Costa, M. B. Homeri Iliadis Carmina. Editio altera. Lugduni Batavorum, 1895-1896.

Homeri Odysseæ Carmina. Editio altera. Lugduni Batavorum, 1897-1898.

Monro, D. B. Homeri Opera et Reliquiæ. Oxonii, 1896. 
Homer, Iliad, Books I-XII. Fifth edition. Oxford, 1899. Books XIII-XXIV. Fourth edition. Oxford, 1897.

Homer's Odyssey. Books XIII-XXIV. Oxford, 1901.

Merry, w. W. Homer, Odyssey, Books I-XII. Oxford, 1899. Books XIII-XXIV. Oxford, 1896.

Leaf, w. The Iliad. Second edition. London, 1900-1902.

Monro, D. B., et Allen, T. W. Homeri Opera. Tomi I et II (Ilias). Oxonii, 1902.

Ludwich, A. Homeri Ilias. Lipsiæ, 1902-1907.

B. Hesiodi.

Schoemann, G. F. Hesiodi quæ feruntur Carminum Reliquiæ. Berolini, 1869.

Goettling, C., et Flach, J. Hesiodi Carmina. Editio tertia. Lipsiæ, 1878.

Paley, F. A. The Epics of Hesiod. Second edition. London, 1883.

Flach, J. Hesiodi quæ feruntur Carmina. Lipsiæ, 1885.

Rzach, A. Hesiodi Carmina. . . . (Editio maior). Lipsiæ, 1902.

Berliner Klassikertexte. . . . V, 1. Epische und elegische Fragmente bearbeitet von W. Schubart und U. von Wilamowitz-Moellendorf. Berlin, 1907.

C. Hymnorum Homericorum.

Baumeister, A. Hymni Homerici. Lipsiæ, 1860.

Hymni Homerici accedentibus epigrammatis et batrachomyomachia. Lipsiæ, 1882.

Gemoll, A. Die homerischen Hymnen. Leipzig, 1886.

Ludwich, A. Hymnus Homericus in Mercurium. . . Progr. Regimontii, 1890.

Sikes, E. E., et Allen, T. W. The Homeric Hymns. London, 1904.

D. Reliquorum poetarum priscorum.

Kinkel, G. Epicorum Græcorum Fragmenta. Vol. I. Lipsiæ, 1877.

Ludwich, A. Die homerische Batrachomachia. . . . Leipzig, 1896.

Bergk, T. Poetæ Lyrici Græci. Editionis quartæ vol. II, poetas elegiacos et iambographos continens. Lipsiæ, 1882.

Hiller, E., et Crusius, 0. Anthologia Lyrica. . . . Lipsiæ, 1904.

Diels, H. Poetarum Philosophorum Fragmenta. . . . Berolini, 1901. 
Die Fragmente der Vorsokratiker. Griechisch und Deutsch Zweite Auflage. Erster Band. Berlin, 1906.

\section{Scripta critica et philologica.}

Albrecht, C. De accusativi cum infinitivo coniuncti origine et usu Homerico. (Studien zur griechischen und lateinischen Grammatik, herausg. von G. Curtius, IV. 1-58.)

Ameis, K. F., et Hentze, C. Anhang zu Homers Ilias. Leipzig, 18821900.

Anhang zu Homers Odyssee. Leipzig, 1889-1900.

Berdolt, W. Zur Entwickelungsgeschichte der Konstruktionen mit $\ddot{\omega} \sigma \tau \epsilon$. . . . Progr. Eichstätt, 1894.

Bolling, G. M. The Participle in Hesiod. Diss. Washington, 1897.

Brugmann, K. Griechische Grammatik. Dritte Auflage. München, 1900.

Kurze vergleichende Grammatik der indogermanischen Sprachen. Strassburg, 1902-1904.

Capelle, C. Die neueren arbeiten auf dem gebiete der homerischen syntax. (Philologus, 37. 89-129.)

Classen, J. Beobachtungen über den Homerischen Sprachgebrauch. Neue Ausgabe. Frankfurt a. M., 1879.

Delbrück, B. Syntaktische Forschungen. Vol. I (Der Gebrauch des Conjunctivs und Optativs im Sanskrit und Griechischen). Halle, 1871. Vol. IV (Die Grundlagen der griechischen Syntax). Halle, 1879. Vol. V (Altindische Syntax). Halle, 1888.

Ueber den indogermanischen, speciell den vedischen dativ. (Zeitschrift für vergleichende Sprachforschung, . . . herausg. von A. Kuhn, . . . 18. 81-106.)

Vergleichende Syntax der indogermanischen Sprachen. (Grundriss der vergleichenden Grammatik der indogermanischen Sprachen, III-V. Strassburg, 1893-1897.)

Draeger, A. Historische Syntax der lateinischen Sprache. Zweite Auflage. Leipzig, 1878-1881.

Ebeling, H. Lexicon Homericum . . . edidit H. Ebeling. Lipsiae, 1880-1885.

Gildersleeve, B. L., et Miller, C. W. E. Syntax of Classical Greek. . . . First Part. . . New York, 1900. 
Goodwin, w. W. Syntax of the Moods and Tenses of the Greek Verb. Boston, 1900.

Hentze, C. Aktionsart und Zeitstufe der Infinitive in den homerischen Gedichten. (Indogermanische Forschungen, 22. 267-289.)

— Zur Entwickelungsgeschichte der Finalsätze auf Grund der homerischen Epen. (Philologus, 65. 161-192.)

Humphreys, M. W. The Problems of Greek. (Congress of Arts and Science, Universal Exposition, St. Louis, 1904, Vol. III. 162172.)

Jolly, J. Geschichte des Infinitivs im Indogermanischen. München, 1873.

Keil, A. De particularum finalium Græcarum vi principali et usu Homerico. Diss. Halis Saxonum, 1880.

Koch, K. Zum Gebrauch des Infinitivs in der homerischen Sprache. Progr. Braunschweig, 1871.

Kühner, R., et Blass, F. A Ausführliche Grammatik der griechischen Sprache. Erster Teil : Elementar- und Formenlehre. Dritte Auflage. . . Hannover, 1890-1892.

- et Gerth, B. Ausführliche Grammatik der griechischen Sprache. Zweiter Teil : Satzlehre. Dritte Auflage.... Hannover, 1898-1904.

La Roche, J. Der Infinitiv bei Homer. (Homerische Untersuchungen, zweiter Teil, pp. 1-78, Leipzig, 1893.)

Lehrs, K. De Aristarchi Studiis Homericis. Editio tertia. Lipsiæ, 1882.

Meierheim, C. De infinitivo Homerico capita III. Specimen I. Diss. Gottingæ, 1875.

Meyer, L. Der Infinitiv der homerischen Sprache. Diss. Göttingen, 1856.

- Handbuch der griechischen Etymologie. Leipzig, 1901-1902.

Monro, D. B. A Grammar of the Homeric Dialect. Second edition. Oxford, 1891.

Paley, F. A. On some Peculiarities in the use of Future Participles of Greek Verbs. (Journal of Philology, 8. 79-82.)

Prellwitz, W. Etymologisches Wörterbuch der griechischen Sprache. Zweite Auflage. Göttingen, 1905.

Seip, 0. De participii et infinitivi apud Hesiodum usu. Diss. Gissæ, 1886. 
Seume, H. De sententiis consecutivis Græcis. Diss. Gottingæ, 188:.

Stahl, J. M. Kritisch-historische Syntax des griechischen Verbums der klassischen Zeit. Heidelberg, 1907.

Steinacher, J. Die Syntax des Hesiodeischen Infinitivs mit stetem vergleichenden Rückblick auf Homer. Landskron, 1885.

van Leeuwen, J. Enchiridium Dictionis Epicæ. Lugduni Batavorum, 1892-1894.

Weber, P. Entwickelungsgeschichte der Absichtssätze. Erste Abtheilung: von Homer bis zur attischen Prosa. (Beiträge zur historischen Syntax der griechischen Sprache, herausg. von M. Schanz. Heft 4. Würzburg, 1884.)

Weigel, F. Quæstiones de vetustiorum poetarum elegiacorum græcorum sermone. . . . (Dissertationes Philologæ Vindobonenses, III. 109-238.)

Wilhelm, E. De infinitivi linguarum Sanscritæ Bactricæ Persicæ Græcæ Oscæ Umbræ Latinæ Goticæ forma et usu. Isenaci, 1873. 


\section{VITA}

Natus sum Charles Jones Ogden anno MDCCCLXXX Brooklynii in civitate Neo-Eboracensi. Ibi postquam litterarum elementis in Academia Polytechnica eruditus sum, in Collegium Columbiae sum admissus, cursuque studiorum rite perfunctus, cum per triennium iuri legibusque et scientiæ rerum politicarum operam dedissem, ad gradus baccalaurei in legibus et magistri in artibus ab eadem universitate provectus sum anno MDCCCCIII. Sed quod in negotiis iudiciisque ægre carebam studiis doctrinæ, ad litteras humaniores olim dilectas neque umquam penitus omissas rursus me contuli. Quam in disciplinam benigne me acceperunt viri eruditi qui scholas in Universitate Columbiae habebant de lingua litterisque Graecis Perry, Wheeler, Young, de Latinis Peck, McCrea, Knapp, de Indicis Jackson; ac primum scholaris, deinde socius Drislerianus, postremo adiutor in docendo factus sum. Iis viris omnibus gratiam et decet referre et iuvat, sed præcipue viro doctissimo comissimoque Edward Delavan Perry, cuius sine consilio hoc opusculum neque susceptum neque absolutum esset. 




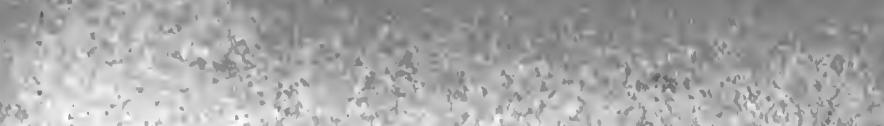

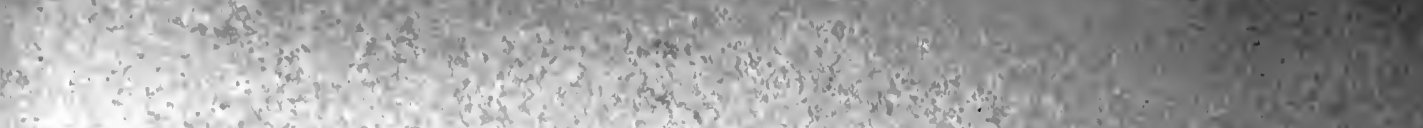

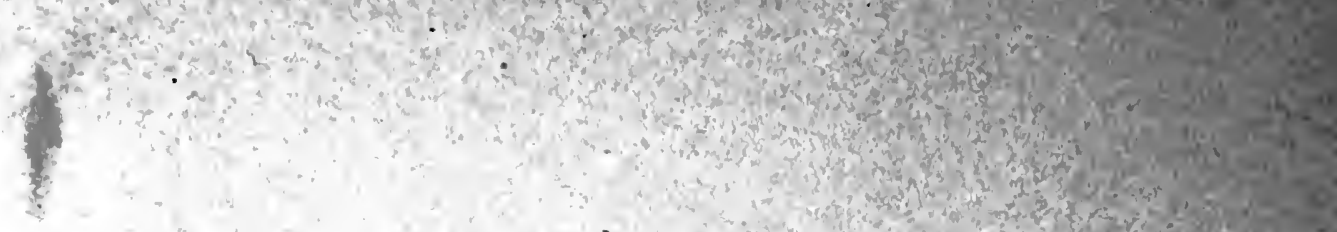

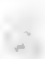
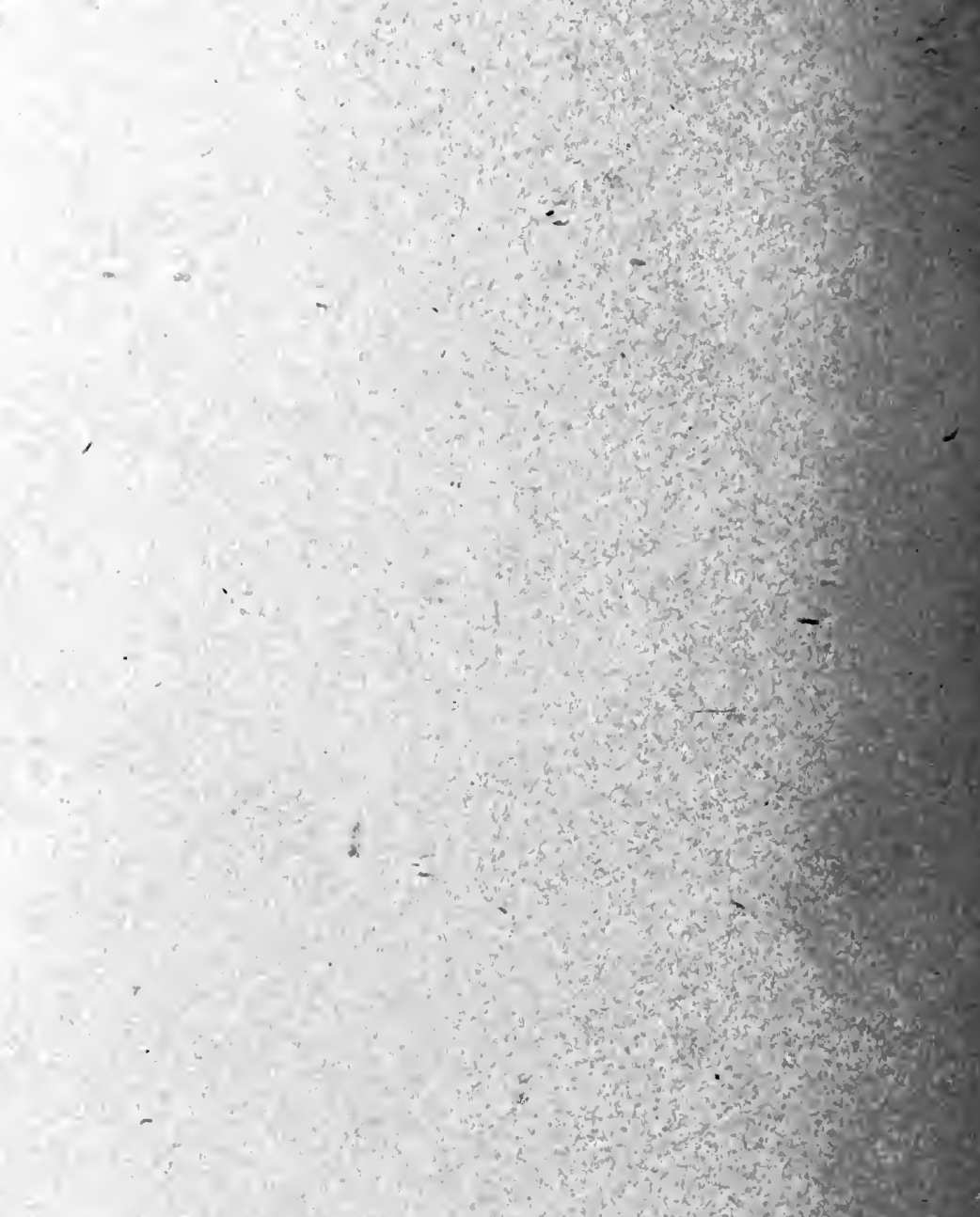

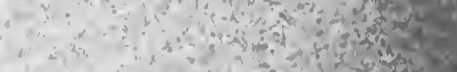
(1)

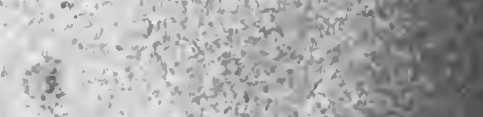

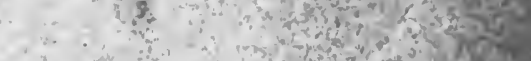

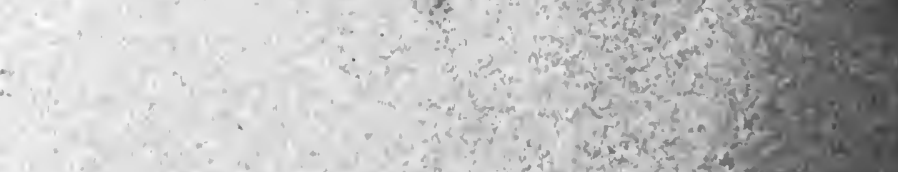

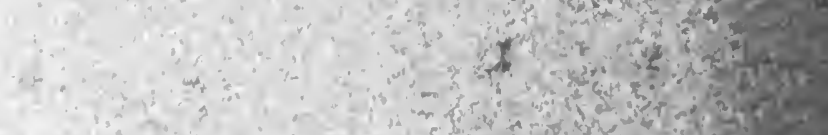

13.2.

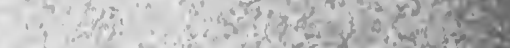

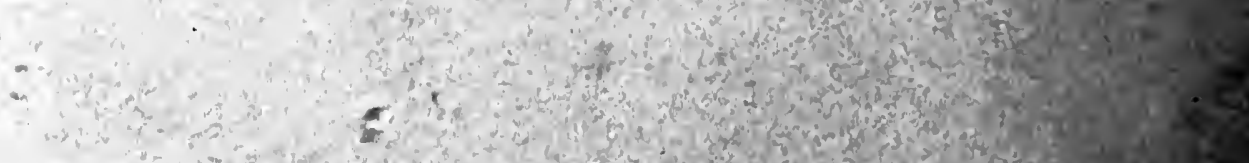

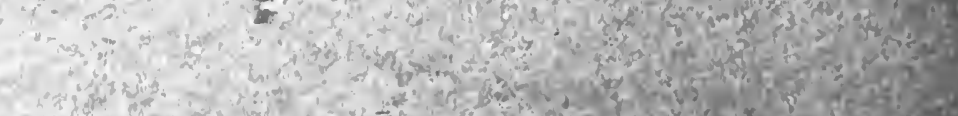

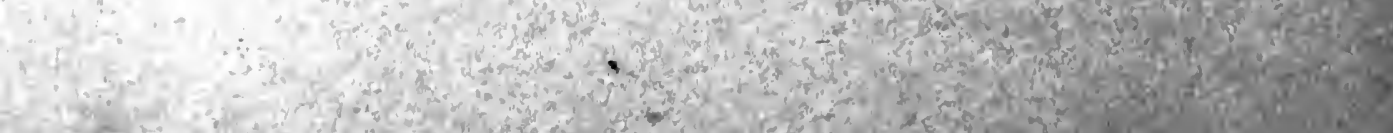

